\title{
NOTES ON THE FAMILY AMPHIURIDAE (OPHIUROIDEA)
}

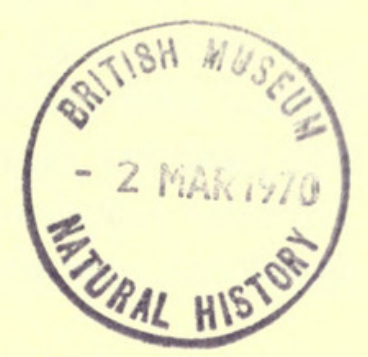

BY

AILSA M. CLARK

$P p$. I-8I; II text-figures

BULLETIN OF

THE BRITISH MUSEUM (NATURAL HISTORY) ZOOLOGY Vol. I9 No. I

LONDON : 1970 
the Bulletin of The BRitish MUSEum (NATURAL HISTORY), instituted in I949, is issued in five series corresponding to the Departments of the Museum, and an Historical series.

Parts will appear at irregular intervals as they become ready. Volumes will contain about three or four hundred pages, and will not necessarily be completed within one calendar year.

In I965 a separate supplementary series of longer papers was instituted, numbered serially for each Department.

This paper is Vol. I9, No. I of the Zoological series. The abbreviated titles of periodicals cited follow those of the World List of Scientific Periodicals.

World List abbreviation

Bull. Br. Mus. nat. Hist. (Zool.).

(C) Trustees of the British Museum (Natural History), I970 


\title{
NOTES ON THE FAMILY AMPHIURIDAE (OPHIUROIDEA)
}

\author{
By AILSA M. CLARK
}

THIs paper deals primarily with the family Amphiuridae in Mortensen's sense, that is excluding Ophiactis and its allies, although it was necessary to include Amphiactis, mainly because of a nomenclatorial problem. The relationship between the Amphiuridae and the Amphilepididae is reviewed with the result that the Amphilepididae is reduced to the rank of a subfamily. The taxonomic weight of various characters which have been used in grouping the species of amphiurids is assessed and a modified formula for expressing oral armament concisely is introduced.

My thanks are extended to the International Federation of University Women for a grant which enabled me to study important collections of amphiurids in the United States, providing much of the background to the present work.

The family Amphiuridae now consists of over four hundred nominal species of ophiuroids, most of them living on or burrowing in more or less muddy sand or gravel and some of them very delicate, easily losing the disc, so that a few species are known only from incomplete specimens. The family has recently (I962) been the subject of a revision by Fell, who has divided the larger genera Amphiura, Amphiodia, Amphipholis and Amphioplus into groups of more manageable size which are unfortunately rather artificial in my opinion.

The family was established in $\mathrm{I} 867$ by Ljungman, though with the now extraneous subfamilies Ophiacanthinae and Ophionereidinae included (since raised to family rank), while his subfamily Amphiurinae comprised five divisions, of which the present Ophiactidae made two (Hemipholis being separated from Ophiactis and Ophiopholis), Amphilepis a third and the amphiurids proper the other two : Amphipholis, Ophiophragmus and Ophiostigma in one and Ophiocnida, Amphiura, Ophiopeltis and Ophiocentrus in the other.

Lyman (I882) in his "Challenger" report merged Amphipholis and Ophiopeltis with Amphiura but recognized Ophiocnida, Ophiophragmus, Ophiostigma and Ophiocentrus, as well as Ophionema and Ophionephthys, the last two having been set up by Lütken (I869).

In I899 Verrill subdivided Amphiura on the basis of differences in the number and arrangement of the oral papillae, reviving Amphipholis Ljungman and establishing two new genera, Amphiodia with three (rarely four) oral papillae on each side of each jaw, all of them arising from the dental and oral plates, with no papilla on the adoral shield and Amphioplus with four or five oral papillae, the outermost one at least arising from the adoral shield. 
Although he recognized the distalmost oral papilla (sometimes also the third one) as representing the scale or scales of the distal or second oral tentacle, Verrill makes no special mention in his keys to the occurrence of the first oral tentacle scale in his two new genera. When present, this scale arises at a higher level in the mouth slit above the oral papillae. ${ }^{1}$
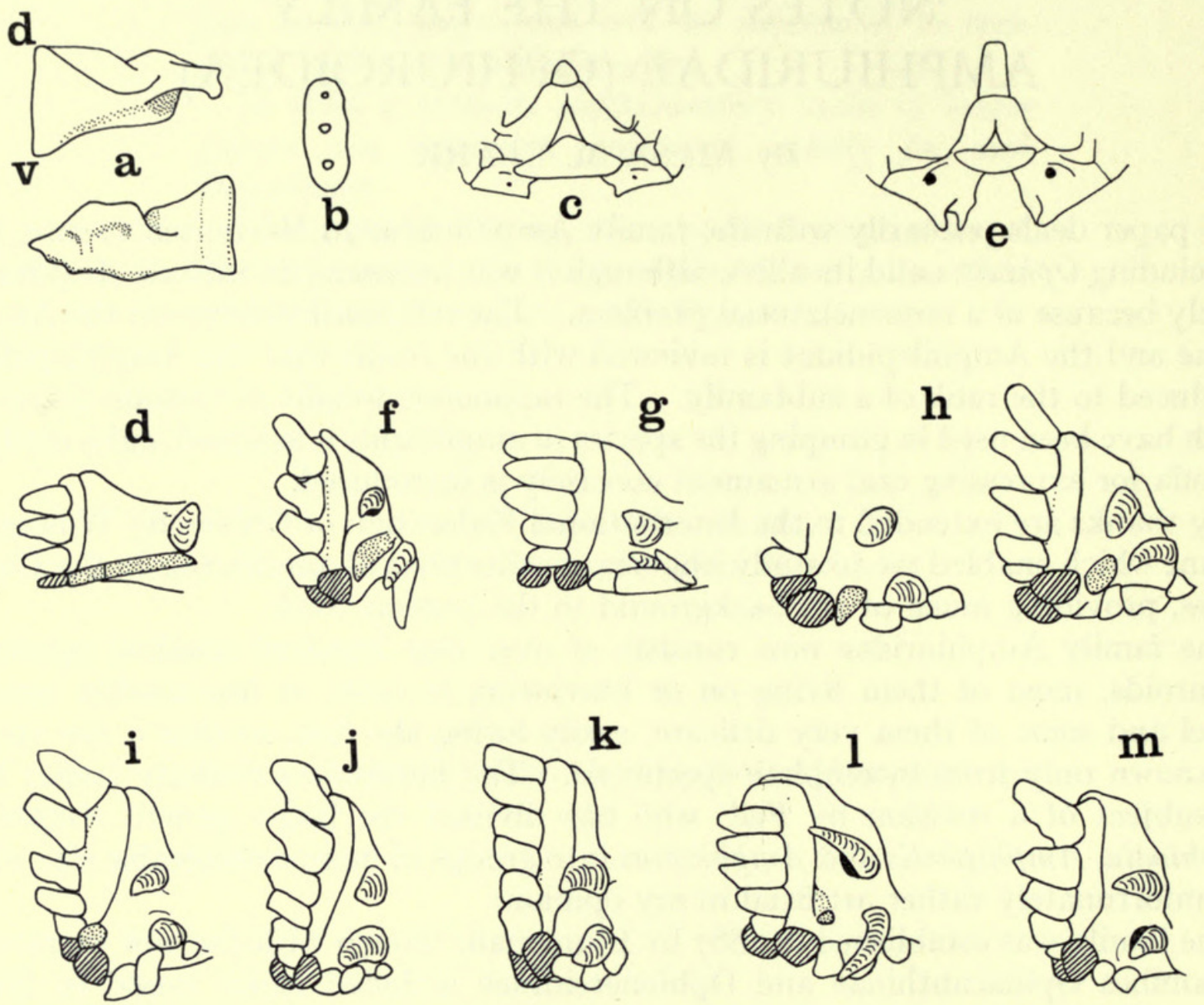

$\mathbf{m}$

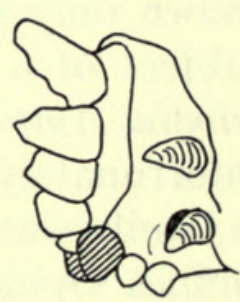

FIG.I, a-d. Amphilepis norvegica (Ljungman), B.M. reg. no. 98.5.3.688, Trondhjem Fjord, Norway ; a. Oral plate in adradial view (above) and abradial view (below), b. dental plate, c. dorsal (internal) view of a whole jaw and d. adradial view of projecting part of intact jaw (compare with usual ventral view, fig. 8f). e. Amphiura chiajei Forbes, 98.5.3.700, same locality, dorsal view of jaw for comparison with c. f-m. Adradial views of projecting part of intact jaws of : f. Amphiura filiformis (O. F. Müller), 72.2.3.I56, Vigo Bay, Ireland ; g. Amphipholis squamata (Delle Chiaje), I937.I2.3I.I, Beachy Head, Sussex ; h. Amphioplus abditus (Verrill), 90.8.23.43, Martha's Vineyard, two jaws of same specimen (see fig. gf for ventral view); i. A. archeri A.M.C., 1956.5.23.I, paratype, Ghana, two jaws of same specimen, the left-hand one with the only oral tentacle scale ; k. A. depressus (Ljungman), 82.12.23.375, Fiji ; 1. A. integer (Ljungman), Morrumbene Estuary, Mozambique ; m. Amphiodia occidentalis (Lyman), 98.r r.28.ro, Queen Charlotte Is., B.C. [The oral tentacle scale(s), where present, is stippled and the infradental papillae cross-hatched.]

1 This scale or papilla has been given a variety of names by ophiuroid specialists and even by the same person at different times. The following people have called it the " first oral tentacle scale (or papilla) " : Lyman, Verrill, Koehler in I905, H. L. Clark, Mortensen and Thomas. Others, including Matsumoto, 
Subsequently other specialists, including Matsumoto (I9I5 and I9I7), Djakonov (I954) and Fell (I960) in their keys to the genera of Amphiurids, have included the presence of the first oral tentacle scale as characteristic of Amphioplus as opposed to its absence in Amphiodia. In fact a number of species which do not comply with this requirement have been referred to these genera, particularly as regards Amphioplus, which is subdivided accordingly further on in this paper.

After Verrill's the next important contribution to the study of the family was that of Matsumoto (I9I7) who devised a formula to express the occurrence of the oral papillae on each side of a jaw. In his scheme the roman number " $I$ " represents the infradental papilla (the pairing of which at each apex is characteristic of the family), "II " is the superficial papilla or papillae on the side of the oral plate and " III " the papilla or papillae on the adoral shield. By this formula the oral papillae of Amphioplus are +I+II+III and those of Amphiodia +I+II-III. However, Matsumoto made the proviso that "when a papilla arises partly from the oral plate and partly from the adoral shield it is referred to the second group" (i.e. II). Since such a dual origin is shown by many of the species of Amphiura, particularly those with the distal papilla spiniform unlike that of $A$. chiajei the type-species, then Matsumoto's designation of Amphiura as +I-II+III is not always correct, although it does express the discontinuity of the series of oral papillae so characteristic of the genus. It seems to me that the proviso should be ignored and group III expanded to include species with the distal papilla arising from the distal end of the oral plate. However, a more elaborate formula is really needed to help pinpoint the position and occurrence of the individual oral papillae more precisely, as well as to cover the oral tentacle scale. Unfortunately Matsumoto's formula does not lend itself to subdivision and qualification. Accordingly I put forward the following alternative devised by Dr. J. P. Harding, Keeper of Zoology. The examples given after each paragraph show the evolution of the formula stage by stage.

I. The individual papillae are represented by the letter m, so that most Amphiura species can be expressed as mm and Amphioplus as mmmm (see figs. 2, 3 and 9).

2. The three main areas involved, corresponding to Matsumoto's I, II and III, namely the apex of the jaw below the dental plate, the side of the oral plate and the edge of the adoral shield, are delimited from each other by two commas, thus most species of Amphiura become m,,m and Amphioplus can be m,mm,m.

3. When a papilla arises jointly from two adjacent loci, for instance at the junction of oral plate and adoral shield, then the $\mathrm{m}$ is split up into two ns with the comma between and for emphasis a linking bar above, thus $\mathrm{m}, \mathrm{n}, \mathrm{n}$ for certain species of Amphiura which cannot be shown as $\mathrm{m}, \mathrm{m}$ and $\mathrm{m}, \mathrm{mn}, \mathrm{nm}$ for most species of Amphioplus. (There are also a few species of Amphioplus in which the fourth and

Djakonov, Chang and Fell, have used " internal", "lateral ", " additional" or " supplementary papilla", while Koehler in I9I4 used "intermediate" "but in I922 (possibly altered in translation?) called it the "second" papilla. I propose to use the term " oral tentacle scale" even though it is normally more papilliform than squamiform. It seems unnecessary to specify that it is the first such scale since the one or two corresponding scales of the second oral tentacle on the edge of the adoral shield and/or at its junction with the oral plate are universally regarded as oral papillae. However, it should be pointed out that in a few species of Amphioplus it becomes more or less superficial in position, in some individuals fitting in to the series of oral papillae so as to become almost indistinguishable from them in ventral view. 
distalmost oral papilla is partly based on the first ventral arm plate ; for these it is necessary to add a third comma and to split the last $m$ as well, thus $m, m n, n n, n$ but the great majority of species can be dealt with without this refinement.)

4. If there is a significant gap in the series of papillae this is indicated by the insertion of an o, so that for Amphiura the formula becomes m,o,mo (or m,on,no).

5. The presence or absence of the oral tentacle scale can be shown by + or $-t$, which can be added at the end of the formula, thus for Amphioplus it is usually $\mathrm{m}, \mathrm{mn}, \mathrm{nm}+\mathrm{t}$ and for Amphiodia m,mm,o - t. Since the oral tentacle scale is rarely in sequence with the oral papillae but normally arises at a higher level it seems better to separate it from the main formula in this way. However, there are a few species, notably of Amphioplus, and the type-species of Ophionephthys, in which some individuals have a more or less superficial second papilla lateral to the infradental and clearly homologous with the oral tentacle scale, since on some jaws it is set at a higher level. This is indicated by equating $t$ with the first $m$ in group II, which can be linked within brackets ; thus in Amphioplus abditus (figs. I h and $9 \mathrm{f}-\mathrm{i}$ ) the formula may be $\mathrm{m},(\mathrm{m}=\mathrm{t}) \mathrm{m}$, on, $\mathrm{n}$ for some series but $\mathrm{m}, \mathrm{om}, \mathrm{on}, \mathrm{n}+\mathrm{t}$ or $\mathrm{m}, \mathrm{mm}$, on, $\mathrm{n}+\mathrm{t}$ for others.

6. Finally, if one papilla is enlarged, this can be shown by the use of capital letters, thus m,o,M $+\mathrm{t}$ for Amphiura chiajei or mediterranea or $\mathrm{m}, \mathrm{mN}, \mathrm{Nm}+$ or $-\mathrm{t}$ for Amphioplus hastatus (see figs. 2j and 9p,q).

As a parallel to this formula, it may be of use in discussing the genera of Amphiurids if the four main arrangements of oral papillae, those of Amphiura, Amphiodia, Amphipholis and Amphioplus, are designated as A to D respectively, as follows:

A Amphiura (usual formula $\mathrm{m}, \mathrm{o}, \mathrm{mo}+\mathrm{t}$ )

B Amphiodia (usual formula $\mathrm{m}, \mathrm{mn}, \mathrm{n}-\mathrm{t}$ )

C Amphipholis (usual formula $\mathrm{m}, \mathrm{mN}, \mathrm{N}-\mathrm{t}$ )

D Amphioplus (usual formula m,mn,nm $+\mathrm{t}$ )

Most of the genera of the family can then be simply qualified by one letter or the other, for instance Amphiacantha (D), having Amphioplus-type oral armament, although a few such as Ophionephthys cannot be fitted into any one category.

Although this particular sequence of genera with two, three and four oral papillae is the logical one to adopt, it must be emphasized that Amphiura and Amphioplus are probably more closely related to each other than either is to Amphiodia or Amphipholis. This is discussed further under the heading of Amphioplus.

Until I 962 the most important characters used for separating many amphiurid genera were those furnished by modifications of the disc. For instance Ophiocentrus (A), Ophiocnida (B), Ophiostigma (C) and Amphiacantha (D) have spinelets on some of the disc scales, while Acrocnida (A), Amphichondrius (C) and Paracrocnida (D) have the ventral disc scales either thickened and themselves almost granuliform (Acrocnida and Paracrocnida) or else covered with superficial granules (Amphichondrius). However, Thomas (I962) has cast some doubt on the taxonomic value of some disc modifications, notably the development of the marginal "fence" of papillae in Ophiophragmus (B), since he has observed some West Indian individuals in which this is completely lacking, so that they are superficially indistinguishable 
from Amphiodia. Since the West Indian species concerned are very liable to lose and regenerate their discs, like a number of other Amphiurids, I think it important that a proper study be made of the resultant disc modifications. Almost certainly the primary rosette with enlarged central and five radial plates is lost in regeneration and the proportions of the radial shields may be altered, though possibly the latter is only transitory; just how much any armament is affected remains to be seen.

In his revision of the four largest genera of the family, Fell (I962a) attempted to subdivide them firstly on the basis of another character provided by the disc-namely the extent of the disc scaling, which in some species is reduced so that the skin is naked, semitransparent and appears dark in preserved specimens-and secondly by the number of tentacle scales.

More or less extensive lack of scaling on the disc is not an entirely new character for distinguishing genera in this family, extreme reduction of the scaling having been used as the main distinction of Ophionema and Ophionephthys by Lütken (I869) as well as of Ophiopeltis Düben and Koren (I845), though the last-named was for eighty years regarded as a synonym of Amphiura until revived by Fell.

It seems to me best to consider first the use of these two characters as they bear on the subdivision of Amphiura and then to go on to deal with the other nominal genera in the light of this study.

\section{AMPHIURA Forbes}

Amphiura Forbes, I843 : I49-I50 ; Lütken, I859a : 54-55 ; Ljungman, I867 : 318 ; Lyman, I882 : I22-I26 ; Verrill, I899a : 24, 25-26 ; I899b : 306-308 ; Matsumoto, I9I7 : I94 ; Fell, I962a : 4-5, II-I2 ; I962b : 8I. Type-species : A. chiajei Forbes, I843, designated by Verrill, I899, Lyman's earlier (I865) designation of $A$. filiformis (O. F. Müller) being invalid, this not being among the three species included by Forbes, namely Amphiura florifera Forbes (a synonym of $A$. chiajei according to Lütken (I869: 75) followed by Ljungman), $A$. neglecta (a synonym of Amphipholis squamata according to Lütken) and A. chiajei itself.

Fell's subdivision of Amphiura on the basis of the extent of disc scaling and the number of tentacle scales can be represented in a grid as shown below.

Disc $\left\{\begin{array}{llll}\text { fully scaled } & \overbrace{\mathrm{o}_{\text {O }}}^{\text {Tullamphiura }} & \text { Monamphiura } & \text { Amphiura } \\ \text { partly scaled } & \text { Icalia } & \text { Pandelia } & \text { Hemilepis } \\ \text { more than half naked } & \text { Ophiopeltis }{ }^{1} & \multicolumn{2}{c}{\text { Amphinephthys }}\end{array}\right.$

Apart from Amphiura itself, all these names were new except for Ophiopeltis and Hemilepis. Ophiopeltis was described with the rank of a genus by Düben and Koren (I845) but Hemilepis was a name first used by Ljungman (I87I) together with Ophiopeltis (spelled Ophiopelte) for two groups of Atlantic species of Amphiura with partial or almost complete lack of disc scaling respectively; these names might

1 Ophionema Lütken was not taken into consideration by Fell but falls into the same section of the grid as Ophiopeltis. 


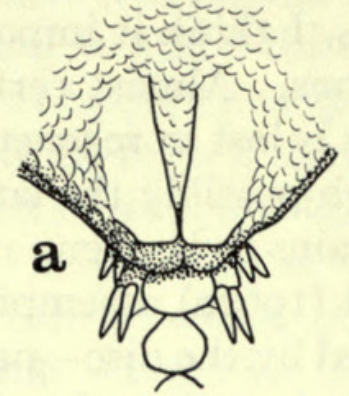

b
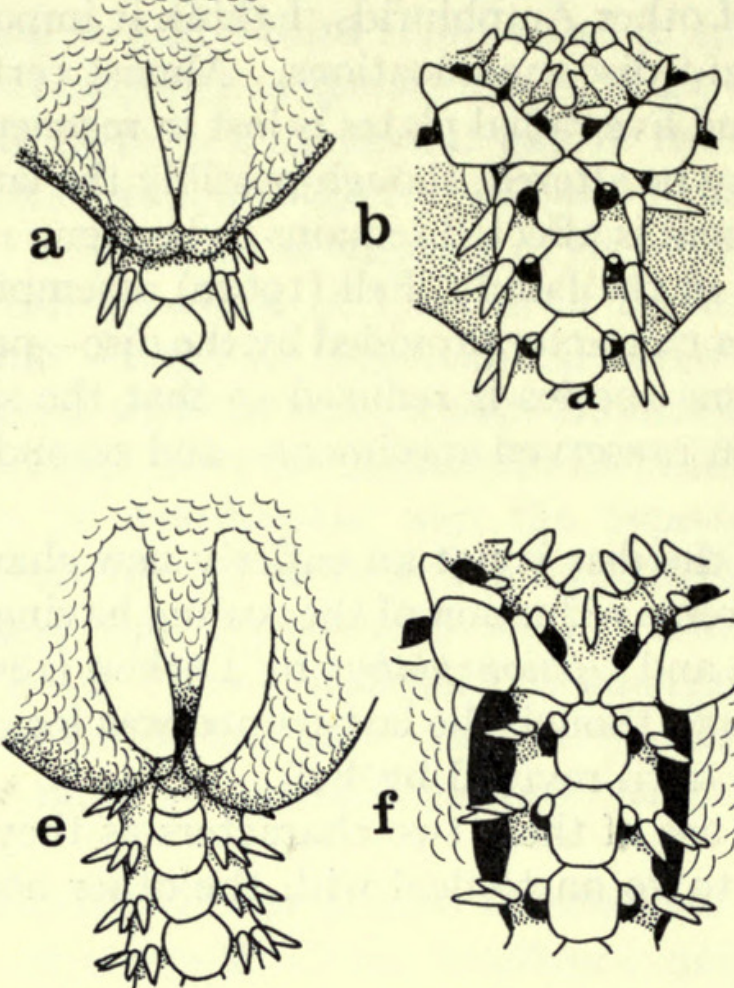

$\mathbf{f}$

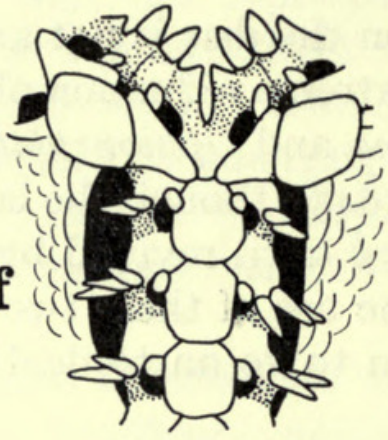

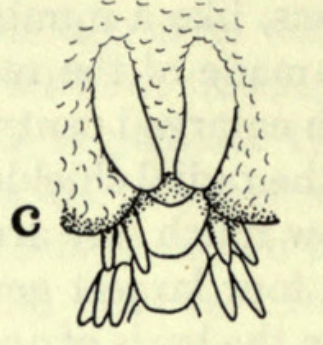

d
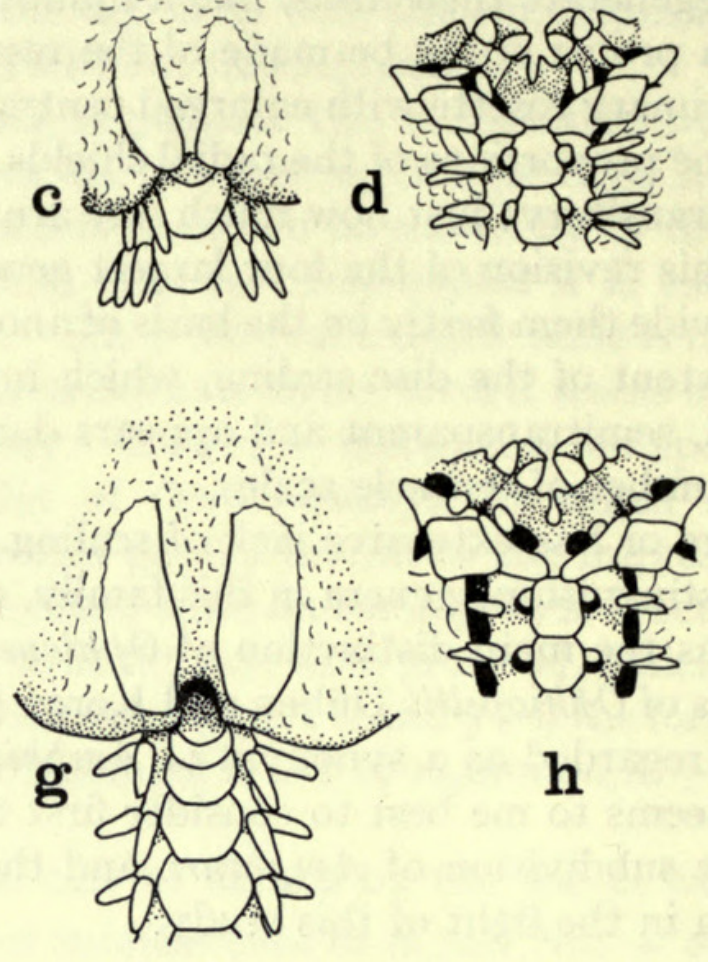

h
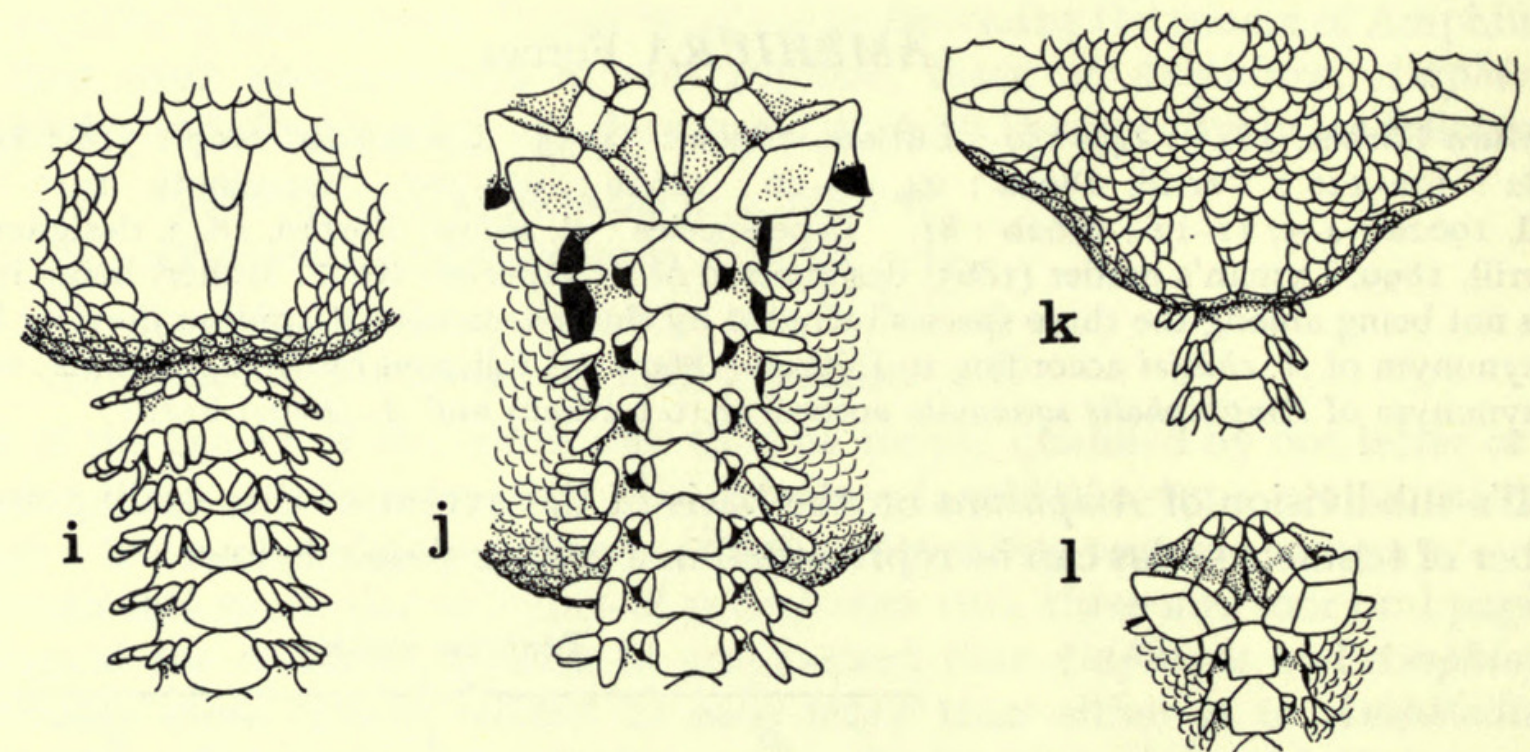

Fig. 2. Dorsal and ventral views of parts of Amphiura spp. a and b. A. semiermis Lyman, M.C.Z. no. I343, "Blake" st. 44, West Indies ; c and d. A. brachyactis H.L.C., M.C.Z. 4933, holotype, Broome, NW Australia; e and f. A. abbreviata Koehler, Copenhagen Museum collection, Amboina; g and h. A. microsoma H.L.C., M.C.Z. 3736, holotype, Torres Strait area (there are exceedingly tenuous disc scales in the stippled area, which are impossible to outline without over-emphasizing their distinctness, as well as those shown around the radial shields) ; i and j. A. mediterranea Lyman, M.C.Z. I330, syntype, Nice, S. France ; k and 1. A. stepanovi Djakonov, M.C.Z. I346 (labelled as syntype of A. stepanovii Tscherniawsky, a nom. nud; d.d. only $3 \mathrm{~mm}$.), Sevastopol, Black Sea. [In e and $g$ the separation of the radial shields is probably unnatural and due to shrinkage in preservation.] 
therefore be interpreted as of subgeneric rank as used by Ljungman. Lyman (I882) ignored them when dealing with Amphiura in his "Challenger" report but Verrill (I899 a and b) included both names to cover small groups of species of Amphiura (again without precisely designating them as subgenera); also Koehler (I9I4) mentioned Hemilepis only as a "group" name, while Matsumoto (I9I7) inferred that it is synonymous with Amphiura, together with Ophiopeltis and Ophionephthys.

Because of the great number of species of Amphiura, the usual practise when describing new ones has been to restrict comparisons to other species with the same combination of tentacle scale number and disc covering, some specialists having gone so far as to call these similarly-endowed species a " group ". In keys also these two characters have been used for convenience to split up the large number of species involved. However, from the time of Lyman's "Challenger" monograph (I882) until Fell's paper of I962, no-one has regarded the groups so formed as sufficiently distinct to warrant even a subgeneric distinction.

The taxa of Fell's with reduced disc scaling may be considered first.

Of the four species included in Hemilepis by Ljungman, Fell designated Amphiura semiermis Lyman, I869 (fig. 2a, b) as type-species and referred twenty other species to the genus. A. semiermis has rather indistinct scales on the dorsal side of the disc and although in some specimens these cover the whole dorsal side stopping at the margin, in others they are lacking interradially and reduced centrally too. Koehler's photograph (I9I4, pl. iv, fig. 6) shows that the holotype of Amphiura latispina Ljungman, I867b (Hemilepis according to Fell) also has the dorsal scaling reduced, the interradii being bare (but for a few isolated scales) and the central scales also inconspicuous so that the scaling appears to be limited to the five radial areas around the pairs of radial shields. This condition of the disc scaling is at variance with Fell's diagnosis of Hemilepis as having the disc " scaled above but wholly or partly naked below " but approaches his Amphinephthys in which the disc is " naked above and below save for the radial shields and a narrow zone of scales bordering the shields".

Amphinephthys itself is inconsistent among Fell's other nominal genera, as he himself admits, since it spans two spaces in the grid, including species such as the type, Amphiura crossota Murakami, I943, with two tentacle scales and also $A$. microsoma H. L. Clark, I9I5 (fig. 2g, h) with only one scale. Amphinephthys is otherwise distinguished by having the disc covered with skin except for scales around the radial shields. I have not seen any material of $A$. crossota but have been able to examine the holotype of Amphiura microsoma, which does have scales in the skin of the disc, though these are so fine and nearly transparent that when dried the skin turns dark and appears to lack calcification. Also H. L. Clark (I938) has referred small specimens with fully-scaled disc to the species. The type specimen of the closely related (if not conspecific) nominal species Amphiura brachyactis H. L. Clark, I938 (also from Australia) (fig. 2c, d) has slightly more opaque disc scales, though they are still obscured in the skin. Amphiura diacritica H. L. Clark, I938, which has two tentacle scales like $A$. crossota, was also referred to Amphinephthys by Fell, although the type specimen was described as having obscured scales in the ventral skin of the disc, though not in the dorsal side. 
Another species which Fell referred to Amphinephthys (though doubtfully) was Amphiura polyacantha Lütken and Mortensen, I899, from the East Pacific off Panama, his doubt being aroused by the reversal of the names polyacantha and gymnogastra on the caption to Lütken and Mortensen's plate ix, though the correct figures $3-5$ are quoted both in their text and on the plate itself. These figures show that $A$. polyacantha does have the scale reduction characteristic of Amphinephthys and also that it is very similar to the type specimen of Amphiura arcystata H. L. Clark, I9II from California, though in that the disc scaling is even more limited in extent. As I noted in I965, $A$. arcystata was referred not to Amphinephthys but to Hemilepis by Fell, apparently as a compromise measure between the three specimens figured by H. L. Clark, only one of which could be described as having the disc scaled above only, a condition supposed to be diagnostic of Hemilepis. One of the other

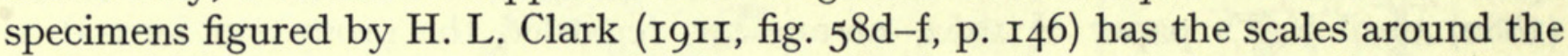
radial shields more extensive on the dorsal side than those of the type but still not quite continuous interradially or centrally and not extending on to the ventral side

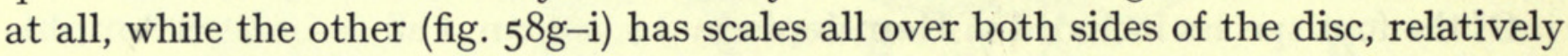
shorter radial shields and fewer and sharper arm spines (judging from the figure). It might seem hard to believe that these two specimens are conspecific with the type or possibly even with each other) since their proximal dorsal arm plates are quite a different shape, markedly rhombic and only narrowly contiguous as opposed to rounded with only the slightest lateral angles in the type. However, the Japanese specimens which I studied in I 965 do have more nearly ovate plates. Matsumoto (I9I7) recorded some additional Japanese specimens as arcystata, noting that the larger ones have discs of the "Ophionephthys-type" (i.e. with scales only around the radial shields) ; presumably the smaller ones have more extensive scaling. Djakonov (I954) also found that some small specimens from the north-west Pacific have fine granuliform scaling on both sides of the disc in contrast to the usual condition.

Further records of $A$. arcystata from the eastern Pacific have been made by May (I924), Nielsen (I932) and Ziesenhenne (I937). May noted that specimens from Monterey Bay usually have the disc naked at the centre and interradially but sometimes the upper side is completely scaled. Nielsen found that all his nine specimens from La Jolla had the discs naked except around the radial shields and the same was probably true of Ziesenhenne's seven lower Californian ones since he noted that on the dried specimens the discs were brown but the radial shields white. The only specimens of $A$. arcystata in the British Museum collections, for which I am indebted to Captain Ziesenhenne, are three from Santa Cruz Island, southern California, all of which have the discs mainly covered with dark brown skin in which there is not a trace of imbedded scales. The shape of the dorsal arm plates in all of them is rounded, not at all rhombic.

It remains to be seen from direct comparison of abundant material from both sides of the North Pacific whether Japanese specimens can be distinguished in any way from Californian ones. The extent of the disc scaling does not appear sufficiently constant to warrant a specific distinction (let alone a generic one). A comparison between Amphiura arcystata and the type-species of Amphinephthys, Amphiura crossota Murakami, from the Caroline Islands is also called for. 
Yet another name which should be considered in dealing with Amphiura arcystata, polyacantha and gastracantha is Amphiura verticillata Ljungman, I867, known only from a damaged specimen from the Galapagos Islands. This was described by Ljungman as having minute scales covering the disc and accordingly Fell retained it in Amphiura but Koehler's photographs (I927a, pl. ii) show scales apparently only remaining in oval areas around the radial shields, as if the interradial and central scales were much less substantial and so were easily lost or obscured. The distal oral papilla of $A$. verticillata arises from the oral plate as in the Californian type of arcystata, not from the edge of the adoral shield as in H. L. Clark's figures of the other (Japanese) specimens which he named arcystata. The shapes of the radial shields, oral and adoral shields and of the ventral arm plates in verticillata are not unlike those of the type of arcystata and of polyacantha but the almost rectangular dorsal arm plates, thick distal oral papilla and somewhat square-tipped arm spines of verticillata may provide significant differences.

Thus we have three closely related species, Amphiura arcystata, polyacantha and verticillata referred to three different nominal genera, Hemilepis, Amphinephthys and Amphiura, by Fell's system.

There are several examples of differences in the extent of the disc scaling in individuals which have been attributed to separate species as well as others such as those of arcystata already cited which are considered conspecific. For instance, H. L. Clark (I938) described Amphiura brachyactis, which Fell placed in Pandelia on account of its single tentacle scale and the occurrence of fine scales (by implication in the description) on the upper side of the disc only. Clark commented that brachyactis is very closely related to A. microsoma (see above p. 9) which he had described in I9I5 and which Fell refers to Amphinephthys since the type was described as having the disc almost naked above as well as below. However, in I938 H. L. Clark also recorded some specimens which he attributed to microsoma even though their discs were distinctly covered with scales on both sides. I have examined the holotypes of both nominal species and find that even in microsoma there is an almost continuous coat of scales although these are so fine and transparent as to be almost obscured by the skin, which appears more or less dark in colour except around the radial shields where the scaling is more nearly opaque. The two species appear to be distinguished by the relative arm length but they are certainly congeneric. Among the species with no tentacle scales, Amphiura syntaracha H. L. Clark, I9I5, which Fell refers to Icalia, has the disc scaled except in the proximal parts of the ventral interradii but is otherwise very similar to four other Japanese nominal species with much more reduced scaling, namely $A$. ecnomiotata $\mathrm{H}$. L. Clark, I9II, aestuarii Matsumoto, I9I5, vadicola Matsumoto, I9I5 and sinicola Matsumoto, I94I, all of which Fell places in Ophiopeltis. Further, Djakonov (I954) has described two forms, incompleta and profundi of Amphiura psilopora H. L. Clark, IgII (lacking tentacle scales so that Fell refers it to Nullamphiura), these forms being distinguished from the fully-scaled form psilopora by having the disc skin-covered ventrally with either coarse or fine soft skin. Mortensen (I936) has noted specimens of Amphiura deficiens Koehler, I922b (Icalia according to Fell) in which the disc is almost completely scaled ventrally, unlike the condition in the type-material. 
Another species of Djakonov's, Amphiura inepta (1954) is referred by Fell to Monamphiura (with one tentacle scale and the disc fully-scaled), presumably on the basis of Djakonov's figures. However, the description notes that the disc appears bare ventrally in specimens preserved in spirit although dried specimens show very small, thin, rounded scales arranged loosely in the ventral interradii.

Until much more work has been done on individual and seasonal variation in the disc scaling of these burrowing amphiurids it is difficult to decide to what extent it can be used in taxonomic distinctions, even at specific level, unless supported by other characters.

With regard to the use of the number of tentacle scales as a generic character, there are several species of Amphiura which have been shown to be variable in this respect. An extreme example is Amphiura belgicae Koehler, I900, which Mortensen (I936) notes may have the tentacle scales numbering two, one or none, some specimens having one number throughout while in others it varies even on different pores of the same arm. Other species may also have mixed scale counts, the proximal or at least the basal pores having a different number to the distal ones, or odd numbers may occur at random, one number may predominate in certain individuals or immature specimens may have fewer scales than adults of the same species. Examples of all these conditions include Amphiura angularis Lyman, I879, anomala Lyman, I875, aster Farquhar, I90I, concolor Lyman, I879, dacunhae Mortensen, I936, fibulata Koehler, I9I3, rosea Farquhar, I893, simonsi A. M. Clark, I952, stimpsoni Lütken, I859, sundevalli (Müller \& Troschel, I842) and verticillata Ljungman, I867. Accordingly I very much doubt the wisdom of giving generic weight to the number of tentacle scales in this family.

As a result of these observations, I consider that the following should be referred to the synonymy of Amphiura Forbes, I843 :

Ophiopeltis Düben \& Koren, I845 (type-species 0 . securigera Düben \& Koren, I845) [but see below].

Hemilepis Ljungman, I87I (type-species Amphiura semiermis Lyman, I869). Amphinephthys Fell, I962 (type-species Amphiura crossota Murakami, I943).

Icalia Fell, I962 (type-species Amphiura denticulata Koehler, I896, a synonym of $A$. fragilis Verrill, I885).

Pandelia Fell, I962 (type-species Amphiura hinemoae Mortensen, I924).

Nullamphiura Fell, I962 (type-species Amphiura psilopora H. L. Clark, IgII). Monamphiura Fell, I962 (type-species Amphiura alba Mortensen, I924).

The range of form within the assemblage of species so reunited is extensive and some natural groups distinguished by combinations of characters may prove to be recognizable but I very much doubt whether these should be ranked higher than subgenera.

Of these seven names, there is only one which I think merits recognition as a subgenus of Amphiura, this is Ophiopeltis as noted by me in I 966 when describing a new Australian species.

Among the many amphiurids with no disc armament and reduced tentacle scales coupled with Amphiura (A)-type mouth parts, the most obviously different from the type-species of the genus, $A$. chiajei, are those which have no tentacle scales at all 
combined with extremely reduced disc scaling. Some of these have been referred in the recent past to the genus Ophionephthys but, as Fell has pointed out, are clearly not congeneric with the type-species, $O$. limicola Lütken, I869, from the West Indies, since that species has two (rarely three) small oral papillae distal to the infradental one, besides an oral tentacle scale, all arising from the oral plate (its formula being normally $\mathrm{m}, \mathrm{omm}, \mathrm{o}+\mathrm{t}$ ), one small tentacle scale on most of the arm pores, a conspicuous row of scales around the periphery of the disc dorsally and the adoral shields meeting widely at their proximal (interradial) ends. In Fell's revision a generic distinction is rightly made between $O$. limicola and these other species, namely O. ecnomiotata (H. L. Clark, I9II), O. africana Balinsky, I957, O. decacantha H. L. Clark, I938, O. heptacantha Mortensen, I940 and O. octacantha H. L. Clark, I9I5, all of which he regards as congeneric with Ophiopeltis securigera Düben and Koren. Ophiopeltis was a monotypic genus as originally proposed, including only Ophiopeltis securigera, characterized by its very long arms, I2-I 5 times the disc diameter, completely naked disc, absence of tentacle scales and modification of the middle of the three arm spines with an axe-headed tip (fig. $3 \mathrm{~b}, \mathrm{~d}$ ).

In I86I Michael Sars redescribed $O$. securigera and noted that drying renders visible some microscopical imbricating scales in the skin covering the disc. No mention of this had been made by Düben and Koren, who described the skin of the disc as so very thin and soft that it often ruptures in preserved specimens over the arm bases, as it has done in the single (dried) specimen from the Shetland Islands in the British Museum collections, which is the only example of securigera available to me and which shows no trace of the microscopic scales noticed by Sars. ${ }^{1}$

It was presumably on the strength of this observation by Sars that Lütken (I869) rediagnosed Ophiopeltis as having extremely minute scales in the skin of the disc and accordingly separated off a new genus Ophionema characterized by complete absence of any such scales. However, as a supporting character he cited the unspecialized arm spines of the type-species, Ophionema intricata.

Two years later in I87I, G. O. Sars described a new species of Ophiopeltis, $O$. borealis, but Ljungman treated Ophiopeltis (spelled Ophiopelte) as a subgenus of Amphiura and expanded it to include filiformis (O. F. Müller, I776), atlantica Ljungman, I867 and sarsi Ljungman, I87I, as well as securigera and borealis.

However, Lyman in his "Challenger " report (I882) and subsequent authors until I962 have considered Ophiopeltis as a synonym of Amphiura, not even a subgenus, because of the existence of intermediate species like Amphiura borealis (G. O. Sars) with shorter arms and partially-scaled discs but other characters approximating to those of Ophiopeltis securigera. The wisdom of this is supported by Mortensen's figure of these two species side by side (I927, fig. I22), showing that they are very similar, differing only in the presence of disc scales over most of the dorsal side coupled with inward divergence of the radial shields and by the lesser modification

1 This specimen of securigera also shows two interesting anomalies. Firstly it has a small poorlycalcified tentacle scale on most of the arm pores, which is quite distinct in the dried condition (though could well be inconspicuous in spirit ones). Secondly there are two distal oral papillae on each side of all the jaws, the inner of the two arising from the outer part of the oral plate so that the formula is $\mathrm{m}, \mathrm{om}, \mathrm{m}+\mathrm{t}$. (Fell (I962a) has also observed this phenomenon.) On two of the jaws there is a small median apical papilla between the infradental pair, as may also occur in a number of amphiurids, including Amphiura borealis. 
of the second arm spines in borealis. Other species are known in which the disc scaling is intermediate in extent between the complete or almost complete absence of scales in securigera and the partial covering in borealis but the issue has been clouded by the fact that, with the exception of some Japanese species, these others have been referred to Ophionephthys, which Matsumoto (I9I5 and I9I7) maintained in Amphiura, being unfamiliar with the type-species, O. limicola, the mouth parts of which had not then been figured. The Japanese species described by Matsumoto are Amphiura aestuarii, $A$. vadicola and, in I94I, $A$. sinicola, which are more or less intermediate, particularly in the rather wider dorsal and ventral arm plates, between other Japanese species such as $A$. syntaracha $\mathrm{H}$. L. Clark, I9I5, which has scales all over the disc except on the proximal parts of the ventral side, and A. ecnomiotata H. L. Clark, I9II, subsequently referred to Ophionephthys by H. L. Clark in I9I5 since it has scaling around the radial shields. Following Matsumoto, Koehler (I922a) also considered Ophionephthys as a synonym of Amphiura. However, Mortensen in I924 and I936 had a different conception of the nature of Ophionephthys (identical with that adopted by Fell in I962); he referred to the genus two species (stewartensis and magellanica) with tentacle scales present and Amphioplus (D)-type oral papillae, of which the discs were assumed to be deficient in scaling just because they were missing in the specimens collected. The fallacy in this has been revealed by the recent discovery of Castillo (I968) that intact magellanica has a scale-covered disc and is clearly referable to Amphioplus ; probably the same will prove to be true of Ophionephthys stewartensis, which should be referred to Amphioplus meantime. By I940 Mortensen had changed his mind and was again describing species of Ophionephthys (namely heptacantha and iranica) with Amphiura (A)-type oral papillae, as H. L. Clark had been doing since I9I5.

The species that Fell has referred to Ophiopeltis from Ophionephthys are Amphiura aestuarii Matsumoto, I9I5, Ophionephthys africana Balinsky, I957, O. decacantha H. L. Clark, I938, Amphiura ecnomiotata H. L. Clark, I9II, Ophionephthys heptacantha Mortensen, I940, O. iranica Mortensen, I940, O. octacantha H. L. Clark, I9I5 and Amphiura vadicola Matsumoto, I9I5 (A. sinicola Matsumoto, I94I, which clearly belongs to the same group having been overlooked by Fell). In addition there are three other species which Fell has included in Ophionema but which, in my opinion, are close to some of these listed above, namely Ophionephthys phalerata Lyman, I874, O. temuis H. L. Clark, I938 and Ophionema hexactis Mortensen, I940. Both phalerata and hexactis have the second from lowest of the arm spines strongly spinose at the tip, while tenuis has the corresponding spine on the more distal arm segments modified into an axe-headed shape (a feature not mentioned by H. L. Clark in his description but observable on a paratype in the British Museum collections and also noted by Mortensen in I940 on one sent to him for comparison with Ophionephthys iranica, which species he emphasized is closely related to tenuis). On the contrary, the two American species of Ophionema, O. intricata Lütken, I869 and $O$. hexacantha Nielsen, I932, have the arm spines relatively unspecialized, tapering in shape and only slightly blunted and rugose at the tips. In addition these two evidently lack even the narrow area of disc scales round the proximal end of each radial shield which is visible in hexactis, iranica and tenuis. In securigera also there 
is little or no scaling here. I have seen no examples of Ophionema myself and can rely only on Nielsen's remarks and figures and Lütken's earlier description (in Danish) of $O$. intricata. Fell did not include the genus in the key given in his main revision, nor did he diagnose it, though this was done in his Australian amphiurid paper, with particular reference to Ophionephthys tenuis which he was referring to Ophionema (while simultaneously placing the related iranica in Ophiopeltis).

The type-species of Ophiopeltis, O. securigera, has only four arm spines proximally and three for most of the length of the arm, of which the middle one is strongly modified into a flattened, axe-headed shape (Fig. 3c, d) ; the dorsal arm plates are fanshaped, wider than long and the disc scaling is more or less completely absent so that the bar-like radial shields are parallel. An additional species from southern Australia, Amphiura (Ophiopeltis) parviscutata, was described by me in I966 and is very closely related to securigera, which it resembles in these characters.

The twelve other affiliated species mentioned above fall into two fairly natural groups on the basis of arm structure. In the first come those having not more than five arm spines and only the second from lowest one more or less strongly modified at the tip, with at the same time the arm plates not particularly narrowed so that the dorsal ones are all wider than long. In this group come aestuarii, iranica, tenuis, phalerata and hexactis. Owing to Lyman's very poor figures of phalerata it is difficult to make a proper comparison of it and his statement that its adoral shields are " curved and united at their ends so as to form a continuous ring "supported by the diagrammatic figure-is completely at variance with the condition found in any of the other species under consideration, all of which have the adorals spaced interradially with a pit between their ends. Only the holotype of hexactis is known and this has six arms and three madreporites ; it remains to be seen whether other specimens from the Persian Gulf share this irregularity. The arm spines number four and the second from lowest has a very spinose tip. The four other species all have five arm spines proximally. In this group of five species some have the disc scaling less reduced than others, so that in aestuarii and phalerata the radial shields are separated proximally on the surface by a wedge of scales, whereas in iranica, tenuis and hexactis the shields are parallel with scales only at their proximal and abradial ends.

The second group of species, comprising africana, decacantha, ecnomiotata, heptacantha, octacantha, sinicola and vadicola, is marked by the possession of seven to ten arm spines proximally and several of these, not just the second one, are flattened and markedly square-tipped or spinose at the ends ; also the arm plates are more or less narrowed so that, at least at the base of the arm, the dorsal ones are longer than wide. All these species (with the possible exception of africana, the photograph of which does not show the condition clearly) have the radial shields inwardly divergent.

It follows from this that Ophiopeltis securigera is more closely related to the first group than to the second and indeed it seems to me that if Ophionema is to be maintained as separate from Ophiopeltis, then this second group should also be distinguished with the same taxonomic rank.

The question is, what should this rank be? Fell would make it a generic one on a par with his other taxa but I cannot bring myself to do this because the different 


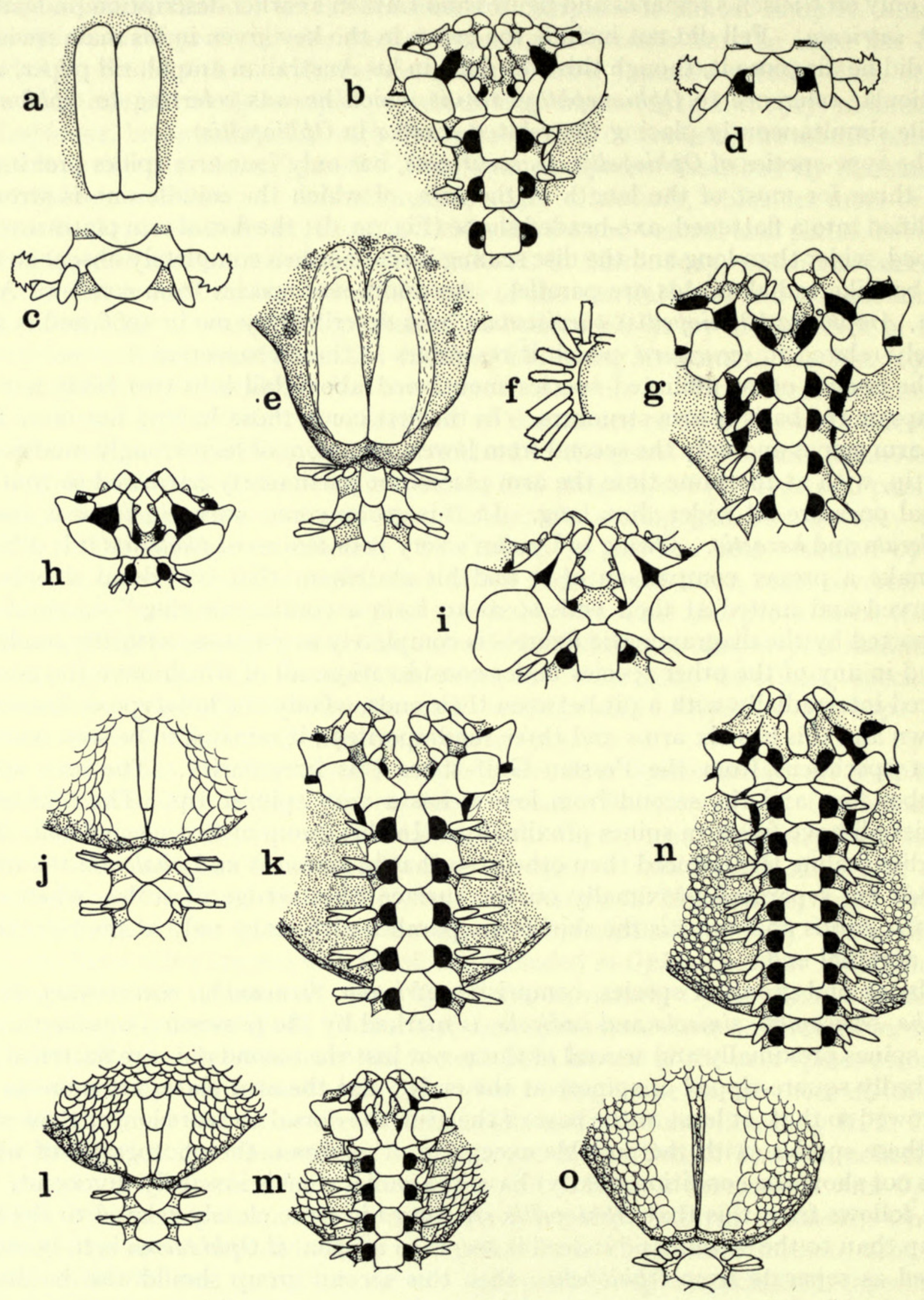


groups of species involved are not sharply defined. For instance in European waters Amphiura borealis (as already quoted) links Amphiura with the type-species of Ophiopeltis, while in Japan there is a series of species from A. syntaracha H. L. Clark (Fig. 3m, n), still with no tentacle scales but with the disc completely (though loosely) scaled except in the proximal parts of the ventral interradii and with arms at least ten times the disc diameter, through aestuarii with more restricted disc scaling but still only five arm spines and relatively wide dorsal arm plates, then to sinicola, vadicola and finally ecnomiotata, with seven to ten spines, progressively narrower arm plates and longer arms. Accordingly I propose to regard these three taxa as subgenera of Amphiura. Unfortunately since one of them is split off from Ophiopeltis sensu Fell it is necessary to add yet another name to the literature.

\section{AMPHIURA subgenus OPHIOPELTIS Düben \& Koren, I845, restricted}

Ophiopeltis Düben and Koren, I845 : 437 ; I846 : 236-238, pl. vi, figs. 3-6 ; M. Sars, I86I : I4 ;

Ljungman, I867b : 32I ; Lütken, I869: 94 (75); G. O. Sars, I87I : I5-I7 ; Fell, I962a :

$8-9$; 1962b : 82. Type-species : Ophiopeltis securigera Düben and Koren, I845. Amphiura (Ophiopelte) : Ljungman, 1871 : 643.

Amphiura (part), Lyman, I882 and following authors until I962.

DiAgnosis. A subgenus of Amphiura in which the disc scaling is absent or reduced to a small area proximal to each of the bar-like parallel radial shields or to a slightly larger patch with a wedge between the proximal ends of the radial shields, which consequently appear divergent ; the arms are extremely long, more than ten times the disc diameter ; the oral shields have only a slight proximal lobe, if any, and the adorals are widely separated interradially (? in phalerata) ; the distal oral papilla is never very large and sometimes (hexactis) rudimentary ; the dorsal arm plates are wider than long; the arm spines proximally number four or five, the second from lowest one becoming more or less modified with an axe-headed or very spinose tip, especially on the outer part of the arm, tentacle scales are normally lacking though a poorly-calcified small scale may occur on some pores of certain individuals.

INCLUDED SPECIES. Ophiopeltis securigera Düben \& Koren, I845, from northern Europe, Ophionephthys phalerata Lyman, I874, from the Philippines, O. tenuis H. L. Clark, I938, from north-west Australia, Amphiura (Ophiopeltis) parviscutata A. M.

FIg. 3. Dorsal and ventral views of parts of Amphiura spp. (except for i). a-d. A. (Ophiopeltis) securigera Düben and Koren, I953.4.8.138, Shetland ; a. radial shields and a small area of surrounding skin (stippled), b. two jaws (the madreporite on the right) showing the abnormal occurrence of two distal oral papillae each side and incipient single tentacle scales, c. fiftieth arm segment from above and d. from below ; e-g. A. (Fellaria) octacantha (H.L.C.), M.C.Z. 3744, holotype, Torres Strait area (in $f$ the fifteenth free arm segment is shown and the spines are slightly foreshortened; in g one distal oral papilla is displaced and another, extreme left, lost); h. A. (Ophionema) intricata (Lütken) (after Nielsen, I932) ; i. Ophionephthys limicola Lütken (modified from Nielsen and from Thomas, I962) ; j and k. A. fragilis Verrill, U.S.N.M. 3260I, holotype, "Albatross" st. 2025, E coast of U.S.A. ; 1 and m. A. sarsi Ljungman, M.C.Z. I342, syntype, Azores ; n and o. A. syntaracha H.L.C., M.C.Z. I36r, holotype, Bay of Yeddo, Japan. 
Clark, I966, from Victoria, Australia, Ophionephthys iranica and Ophionema hexactis Mortensen, I940 from the Persian Gulf (the former also taken recently in the vicinity of Karachi, West Pakistan) and Amphiura aestuarii Matsumoto, I9I5, from Japan. Geographically therefore these are a mixed lot ; A. (Ophiopeltis) parviscutata is the one most closely related to the similarly temperate $A$. (Ophiopeltis) securigera, while the rest are from the tropical Indo-West Pacific and are morphologically intermediate to some extent with the species of the following subgenus from the same region.

\section{AMPHIURA subgenus FELLARIA nov.}

Amphiura (part) H. L. Clark, I9II : I48-I49; Matsumoto, I9I5 : 7I ; I9I7 : 2II-2I3 ; I94I : 339-342.

Ophionephthys (part) H. L. Clark, I9I5 : 239-240 ; 1938 : 240-24I ; Mortensen, I940 : 79-8I ; Balinsky, I957 : 7-9. [Non Ophionephthys Lütken, I869].

Ophiopeltis (part) Fell, r962a : 8 .

Diagnosis. A subgenus of Amphiura in which the disc scaling is reduced to a small area lateral and proximal to each pair of radial shields ; the arms are extremely long, usually fifteen to twenty times the disc diameter but sometimes even longer ; the oral shields have only a slight proximal lobe, if any, and the adorals are widely separated with a pit between their interradial ends ; the distal oral papilla is not rudimentary but may be large and clavate ; the dorsal arm plates are narrow, the basal ones at least, if not all of them, longer than wide ; the arm spines number seven to ten proximally and all or most of them are flattened with their tips rugose and squared-off or slightly flared ; tentacle scales are lacking.

TYPE-SPECIES. Ophionephthys octacantha H. L. Clark, I9I5, from northern Australia.

INCLUDED SPECIES. Ophionephthys africana Balinsky, I957, from Mozambique, Amphiura ecnomiotata H. L. Clark, I9II, from Japan and Ophionephthys heptacantha Mortensen, I940, from the Persian Gulf ; also Amphiura vadicola Matsumoto, I9I5 and A. sinicola Matsumoto, I94I, from Japan, which are to some extent intermediate with Amphiura sensu stricto. Ophionephthys decacantha H. L. Clark, I938, I consider is a synonym of $A$. (Fellaria) octacantha, having studied the holotypes of both. Despite the name decacantha, I could not find more than eight arm spines on any part of the arms of the former and the only apparent morphological difference consists of the barely contiguous proximal dorsal arm plates in the holotype of decacantha, those of octacantha tending to overlap slightly for most of their width, at least on the proximal segments. D.d. in both is about $5 \mathrm{~mm}$. but the disc of the holotype of octacantha is more drastically shrunken and I think that the original size was greater than in the other specimen, which might account for the small difference in arm structure. The type-localities are Friday Island, Torres Strait (octacantha) and Broome, north-west Australia (decacantha).

It may be noted here that H. L. Clark's figure of the holotype of Amphiura ecnomiotata is incorrect in showing the distal oral papillae as long and narrow ; in fact they are very thick and not particularly elongated; also the oral shields are 
in reality as wide as long or a little wider. In addition, in the skin of the disc between the radial shields interradially are scattered some very fine scales, not mentioned by Dr. Clark.

\section{AMPHIURA subgenus OPHIONEMA Lütken, I869, restricted}

Ophionema Lütken, I869 : 27-28 (9-I0), 94 (76), 98 (80) ; Lyman, I882 : I5I-I52 ; I883 : 253 ; H. L. Clark, I9I 8 : 282-284, pl. 2, figs. I-3 ; Nielsen, I932 : 265-267; Thomas, I964 : I59-I6o. [Non Ophionema : Mortensen, I940: 79-8I (O. hexactis, now referred to Ophiopeltis)]. Type-species : Ophionema intricata Lütken, I869.

Diagnosis. A subgenus of Amphiura in which the disc scaling is absent and the radial shields are bar-like and parallel ; the arms are extremely long, fifteen to twenty times the disc diameter ; the oral shields have no proximal lobe and the adorals are widely separated interradially ; the distal oral papilla is small and often more or less rudimentary ; the dorsal arm plates are fairly narrow, about as wide as long or a little longer ; the arm spines proximally number five or six and all taper to a rounded and only slightly rugose tip ; tentacle scales are lacking.

INCLUDED SPECIES. Ophionema intricata Lütken, I869, from the West Indies and O. hexacantha Nielsen, I932, from Panama. ${ }^{1}$

It seems advisable at this point to add references and a diagnosis to Ophionephthys for comparison with the superficially rather similar subgenera of Amphiura just dealt with.

\section{OPHIONEPHTHYS Lütken, I869}

Ophionephthys Lütken, I869 : 25-27 (7-9), 93 (75), 98 (80) ; H. L. Clark, I9I8 (part) : 278-282 ; Nielsen, I932 : 266, fig. 8 ; Fell, I962a (part) : 3-4, I5 ; Thomas, I962 : 680-68г. Typespecies: Ophionephthys limicola Lütken, I869. [The many references to species other than the type-species apply to Amphiura (Ophiopeltis), Amphiura (Fellaria), Amphioplus and (in the case of O? sesquipedalis Bell) to Amphiodia or Ophiophragmus.]

Diagnosis. A genus of the family Amphiuridae in which the disc scaling is reduced to a small patch of scales at the proximal end of each pair of radial shields and a line of scales near the edge of the disc extending across the interradii from the distal end of each radial shield ; the arms are extremely long, up to twenty times the disc diameter ; the oral papillae are normally limited to three in each series, the two distal ones on the side of the oral plate as well as the oral tentacle scale (occasionally odd series are found with a fourth papilla but this is nearly always situated also on the oral plate and rarely on the adoral shield) so that the oral formula is normally

1 Since completion of this MS, a paper by Domantay and Domantay (Studies on the classification and distribution of Philippine littoral Ophiuroidea (brittle stars). Philipp. J. Sci. 95: 1-77; r967) has come to my notice. This includes a description of a new species referred to Ophionema, O. philippinensis (p. 25), the affinities of which are difficult to assess from the information given. It is clear from the drawing of the upper side (fig. 4) that the disc has been lost, the central structure being the oral frame. The excessively high ratio of arm length to d.d. of 25-3o: I (d.d.-in fact the diameter of the oral frame-being given as only $2 \mathrm{~mm}$.) is almost certainly incorrect, the true ratio being probably much lower, rendering unlikely a close relationship with Ophionema intricata. 
$\mathrm{m}, \mathrm{mm}, \mathrm{o}+\mathrm{t}$ (occasionally $\mathrm{m}, \mathrm{mmm}, \mathrm{o}+\mathrm{t}$ and only rarely $\mathrm{m}, \mathrm{mm}, \mathrm{om}+\mathrm{t}$ ). In the type species the adoral shields meet widely interradially, the oral shields have a large rounded proximal lobe, the dorsal arm plates are as wide as or wider than long and there is a single tentacle scale.

REMARKs. Having started as a monotypic genus, I consider that Ophionephthys should revert to that condition. The treatment of some of the nominal species which have been referred to it since I869 is dealt with in the discussion leading up to the subgenera of Amphiura above but an extended account of the history is needed.

The species which have been referred to Ophionephthys since I869 fall into two categories. The first includes those with Amphiura (A)-type oral papillae, namely phalerata Lyman, ecnomiotata (H. L. Clark), octacantha H. L. Clark, aestuarii (Matsumoto), vadicola (Matsumoto), decacantha H. L. Clark, tenuis H. L. Clark, heptacantha Mortensen, iranica Mortensen and africana Balinsky. The second category consists of species with Amphioplus (D)-type oral papillae, namely stewartensis Mortensen, magellanica Mortensen, Amphioplus cyrtacanthus H. L. Clark, I9I5, A. lucidus Koehler, I922a, A. seminudus Mortensen, I940 and doubtfully A. luctator Koehler, I922a, the last four having been referred to it by Fell (I962a) (and not having been previously mentioned in this paper merit the fuller details). In I955 I myself named some discless West African specimens "?Ophionephthys sp.", noting, however, that although they are probably congeneric with O. magellanica and stewartensis, the same could not be said of their relationship with $O$. limicola.

Of the species in the first category, Fell removed all except phalerata and tenuis (which he included in Ophionema) to Ophiopeltis; I am now transferring those two also to Ophiopeltis but simultaneously abstracting to the new subgenus Fellaria six of the others-ecnomiotata, octacantha (with synonym decacantha), vadicola, heptacantha and africana.

In his revised diagnosis of Ophionephthys (I962a: I5), Fell gives the number of oral papillae as four or five (i.e. of the Amphioplus (D)-type) and used the genus as a repository for several species of Amphioplus the type-specimens of which were lacking the disc, arousing the supposition that their disc scaling was reduced. However, a number of amphiurids with fully-scaled discs also frequently shed or otherwise lose them. Anyway the figures of Nielsen (I932) and Thomas (Ig62) as well as some specimens kindly sent to me by Dr. Thomas show that Fell's description of the mouth parts is incorrect and that Ophionephthys limicola has oral papillae arranged unlike those of any of the major genera of Amphiurids. However, it would be remiss not to point out that occasional specimens, particularly some immature ones, of a few species of Amphioplus like A. strongyloplax (fig. 9b) and macraspis (both originally described as species of Amphiodia by H. L. Clark, IgII) may lack the fourth oral papilla from the adoral shield ; but then the third papilla, as often in Amphioplus, arises from the point of junction of the oral plate and the adoral shield, not from the oral plate alone as in $O$. limicola, the oral formula in these two species of Amphioplus being m,mn,nm $+\mathrm{t}$ or m,mn,no $+\mathrm{t}$. The presence of the oral tentacle scale of course distinguishes both Ophionephthys and Amphioplus from Amphiodia.

Of the second category of species, i.e. those referred to Ophionephthys by Fell, only 
the types of Amphioplus seminudus were in possession of their discs; these have scales present only around the proximal end of each pair of radial shields, the rest of the disc being naked. However, Castillo (I968) has recently discovered additional material of Ophionephthys magellanica from southern Chile, which he says show fully-scaled discs so that the species is undoubtedly referable to Amphioplus. It may be noted that Chang (I948) has figured a specimen with the disc fully-scaled above but naked below under the name of Amphioplus cyrtacanthus but this does not appear to have the arm spines hooked, unlike the holotype, and I think the identification needs confirmation. The three other species, lucidus, luctator and stewartensis also await the discovery of intact specimens ; meanwhile I am sure their affinities lie with Amphioplus.

There is, however, one species normally included in Amphioplus which appears to have some affinity with Ophionephthys limicola; this is Amphioplus coniortodes H. L. Clark, I9I8, also from the West Indian area. The holotype (fig gd, e) has the oral formula $\mathrm{m},(\mathrm{m}=\mathrm{t}) \mathrm{mm}, \mathrm{o}$ in most series, with three papillae on the side of the oral plate, the proximal-most of these being very slightly higher and clearly homologous with the oral tentacle scale of other species. The outermost papilla does not seem to me to make contact with the adoral shield although H. L. Clark describes it otherwise. In some series there is a very small papilla on the side of the first ventral arm plate in series with the rest giving a formula of $\mathrm{m},(\mathrm{m}=\mathrm{t}) \mathrm{mm}, \mathrm{m}$. This arrangement shows some difference from the specimen figured by Thomas (Ig62, fig. IOB) which has the more usual Amphioplus (D)-type formula m, $(\mathrm{m}=\mathrm{t}) \mathrm{mm}, \mathrm{m}$, while one of the four series drawn even has a second papilla on the edge of the adoral shield. The disc of $A$. coniortodes also tends to approximate to that of $O$. limicola, being covered with naked skin below while the dorsal scaling is extremely fine (so much so in the holotype as to be barely distinguishable). In addition there is an enlarged series of scales extending interradially from each radial shield, something like the line of scales in O. limicola. Finally, A. coniortodes also has extremely long arms, equal in length to about twenty times the d.d. Thomas has pointed out that the two species are commonly associated in the same soft mud in Florida, so some of the resemblances between them may be convergent. Fell (I962a) has referred $A$. coniortodes to his new nominal genus Ailsaria, together with several other species of Amphioplus with more or less reduced disc scaling. This is dealt with below under the heading of Amphioplus.

\title{
AMPHIURA (cont.)
}

\section{Amphiura correcta Koehler}

\author{
fig. $4 \mathrm{a}, \mathrm{b}$
}

Amphiura correcta Koehler, I907 : 300-30I, pl. I2, figs. 30, 31 .

Amphiura norae Benham, I909 : I04, figs. I-3 ; Fell, I958 : 26-27.

Amphiura abernethyi Fell, I95I : I-3, figs. I-4. 
Among the specimens studied by me at the Museum of Comparative Zoology, Harvard in I954 was a syntype of Amphiura correcta, the locality of which was unknown although the types were collected by Quoy and Gaimard on the voyage of Dumont d'Urville (on the "Astrolabe" primarily to Australia, New Zealand and

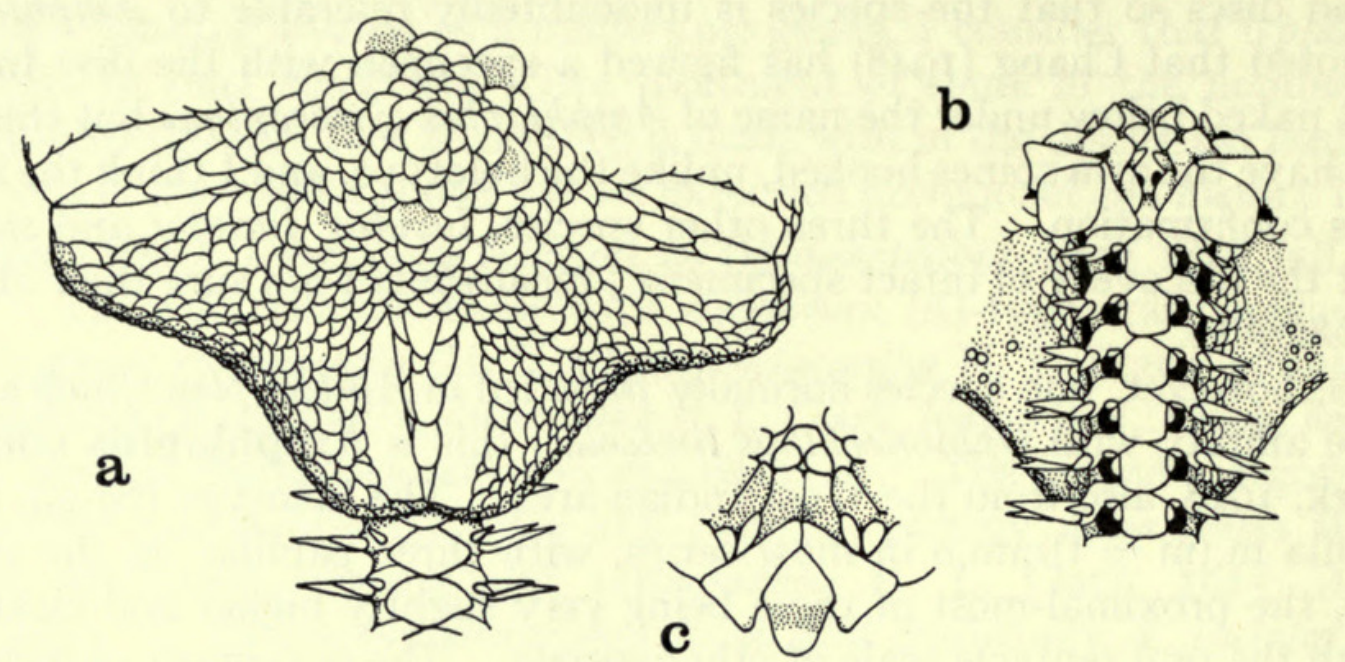

FIG. 4. a and b. Amphiura correcta Koehler, M.C.Z. I303, syntype, locality ? (presumably New Zealand); c. A. lorioli (Koehler), I948.5.26.69 (pt.), paratype of A. ceramis H.L.C., Zanzibar area, one jaw.

the South Seas). This specimen (fig. 4a, b) proved to be conspecific with Amphiura norae Benham from New Zealand. The same is true of a syntype of $A$. abernethyi sent to the British Museum by Dr. Fell in I952, which indicates that Fell's drawings over-exaggerated the peculiarities such as the shape of the radial shields and the scales between them ; the latter are simply rounded in the syntype sent to me; also there is a suture separating oral plates and adoral shields each side of the apex of the oral shield so that the two adorals are not contiguous, the oral shields themselves are more nearly hexagonal than rhombic, the distal oral papilla is broad rectangular or fan-shaped and the dorsal arm plates have the distal side with a median convex angle and are not simply curved. The fifth arm spine found in abernethyi compared with the four counted by Benham can be attributed to the much larger size of the types of the former. In a letter of November, I952, Dr. Fell agreed with me that norae and abernethyi could be "lumped together", having studied a further range of specimens which indicated to him that a single variable species is present. However, in his paper of $195^{8}$ he mentioned this synonymy as only a possibility.

\section{Amphiura lorioli (Koehler)}

fig. $4 \mathrm{C}$

Ophiactis lorioli Koehler, $1897: 328 ; 1899: 4$ 1-42, pl. 6, figs. $46,47$.

Amphioplus lorioli H. L. Clark, I915 : 258 ; 1918 : 295 ; Fell, 1962a : 17.

Amphiura ceramis H. L. Clark, I939: 58-6o, figs. I4, I5.

The holotypes of both Ophiactis lorioli and A. ceramis are in the British Museum collections. Comparison reveals no significant difference. Both have extremely 
large and few disc scales for an amphiurid and unusually small oral shields with the constricted though elongated distal lobe markedly depressed and a close pair of distal oral papillae each side. The oral formula is $\mathrm{m}, \mathrm{om}, \mathrm{m}+\mathrm{t}$ (or $\mathrm{m}, \mathrm{on}, \mathrm{n} n, \mathrm{n}+\mathrm{t}$ ), the distal papillae, though close together, hardly abutting at all on the edge of the adoral shield (as H. L. Clark's figure incorrectly shows them, though his description is better ; the teeth are also broader than his figure shows). There is some resemblance in the oral structure to Ophiomonas though the oral tentacle scale is rather deeper in the slit basally in A. lorioli. The paratypes of A. ceramis are remarkably variable in the number and arrangement of their oral papillae; one even has a formula of $\mathrm{m}, \mathrm{omm}, \mathrm{mn}, \mathrm{n}+\mathrm{t}$ in five series but $\mathrm{m}, \mathrm{omn}, \mathrm{n} n, \mathrm{n}+\mathrm{t}$ in the other five, thus illustrating the close relationship of Amphiura with Amphioplus.

\section{AMPHIODIA Verrill}

Amphiodia Verrill, I899a : 306, 3I3 ; I899b : 25 ; H. L. Clark, I9I5 : 245 ; Nielsen, I932 : 267 ; Djakonov, I954 : 6I ; Fell, I962a : 5, I5 ; Thomas, I962 : 640 ; I964 : I64-I65. Typespecies : Amphiura pulchella (Lyman, I869).

Amphiodia (Amphispina) Nielsen, 1932: 276.

[See also p. 25 for synonyms.]

The Amphiurid species with Amphiodia (B)-type jaw armament and unarmed discs exhibit a much narrower range of form with regard to other characters than those of the (A)-type. In none of the species so far described does the disc lack scales on the upper side, though they may be naked below, also tentacle scales are never lacking altogether and the number of arm spines rarely exceeds five. Accordingly Fell (I962a) could only split the genus into three using his criteria of disc scaling and tentacle scale number, dividing off Gymnodia with the disc skin-covered below from Amphiodia and Diamphiodia with fully-scaled discs and one or two tentacle scales respectively. (Evidently he suffered a change of mind about the new nomenclature involved, since the name Ailsaria appears in his key in the proper place for Gymnodia, judging from the diagnoses, while the nomen nudum Gymnoplus takes the place of Ailsaria.)

The type-species of Amphiodia, Amphiodia pulchella (Lyman, I869) has been fully described and figured by Thomas (I962) who points out that the ventral scales " may be difficult to see unless the specimen is dried". Accordingly Thomas refers Amphiura repens Lyman, I875 (included by Fell in Gymnodia), to the synonymy of A. pulchella. The type-species of Gymnodia, Amphiodia tabogae Nielsen, I932, is evidently very variable. The second specimen figured by Nielsen (I932, fig. Ioa and c, p. 273) appears very similar to Amphiodia pulchella and I fully agree with Thomas (I964) that there cannot be a generic distinction between them. Of the other two nominal species referred to Gymnodia, Amphiodia platyspina Nielsen, I932 is very similar to A. tabogae, differing mainly in the modification of some of the middle arm spines, while Amphiodia psilochora H. L. Clark, I9II (fig. 5g) has the oral tentacle scale present and so does not belong to the Amphiodia (B)-group at all ; it resembles an Amphioplus with the distalmost oral papilla suppressed as may occur in $A$. coniortodes already mentioned (p. 2I) ; I have also observed some scattered scales in the ventral interradii of the holotype of $A$. psilochora. Nielsen has also 

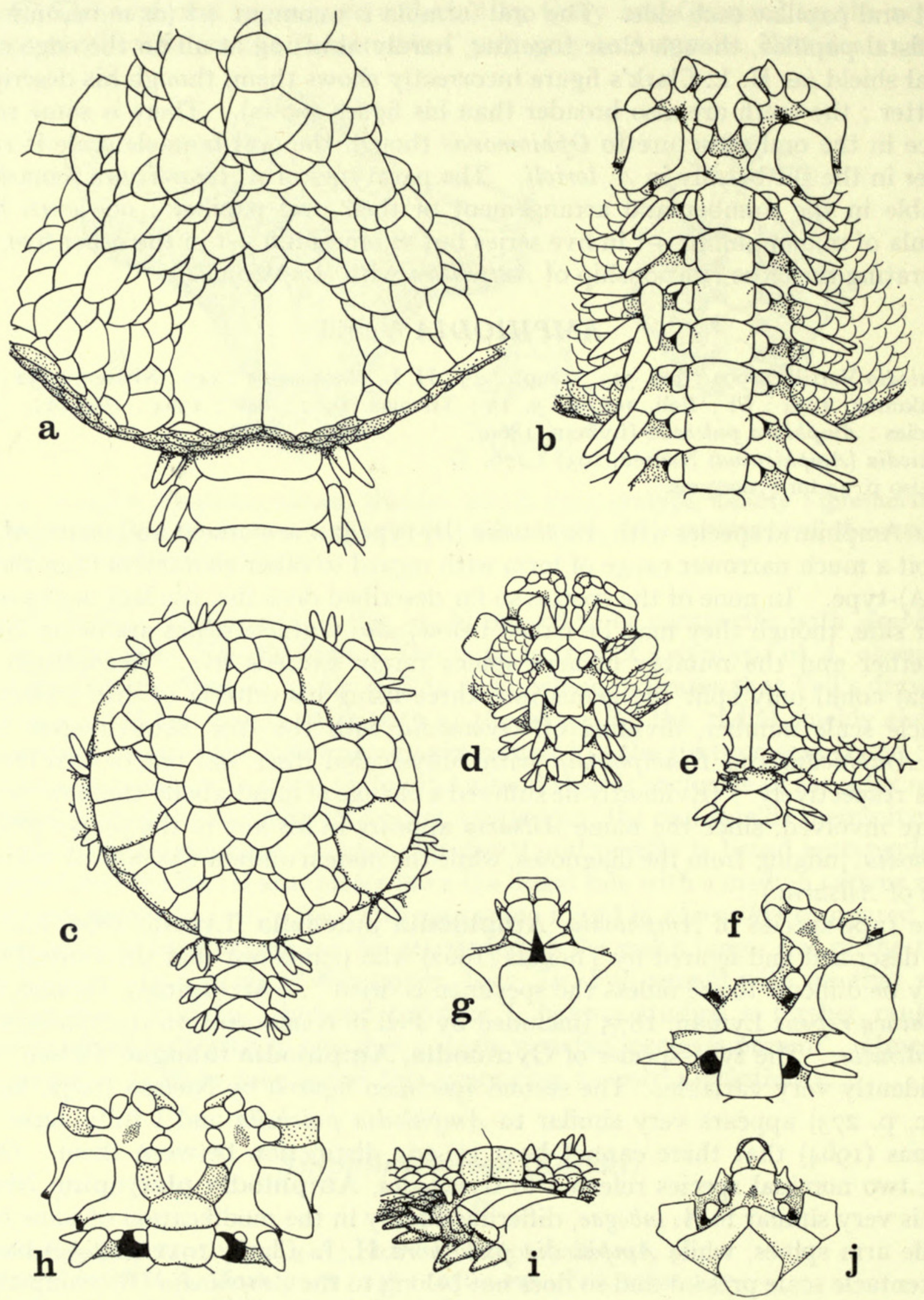
noted that in larger specimens (d.d. up to II mm. in his material) of Amphiodia occidentalis (Diamphiodia according to Fell) " the scales in the proximal part of the ventral interradii are resorbed, so that the skin of the disc is transparent on specimens in alcohol ". It should also be mentioned that Amphiodia obtecta Mortensen, I940, which Fell left in Amphiodia, has the ventral side of the disc naked ; Mortensen also commented that specimens in alcohol appear to be naked above as well but drying reveals the scales on the dorsal side. In face of these observations it seems impossible to accept variations in disc scaling as providing characters of generic or even subgeneric weight in this context.

As for tentacle scale number, supposed to characterize Diamphiodia, at least one species of Amphiodia, Amphiodia euryaspis H. L. Clark, IgII, has either one or two scales, as I found on studying the type-material in the Smithsonian Institution. Here again I cannot accept this as a generic character. Accordingly the following are here referred to the synonymy of Amphiodia Verrill, I899:

Gymnodia Fell, I962a (type-species Amphiodia tabogae Nielsen, I932).

Diamphiodia Fell, I962a (type-species Amphiura violacea Lütken, I856).

Nielsen's subgenus Amphispina (I932), for which no type-species was designated by Nielsen, is strictly speaking a nomen nudum on that account under Article I3b of the Code of Nomenclature. I cannot trace a subsequent type-designation and since I consider that Amphiodia (Amphispina) digitata Nielsen, I932, together with Ophiophragmus duplicatus Koehler, I930 and Amphiodia microplax Burfield, I924, form a natural group distinguished by the spiniform prolongations of the uppermost row of ventral disc scales, it is necessary to re-establish the name as follows:

\section{AMPHIODIA subgenus AMPHISPINA nov.}

Amphiodia (Amphispina) Nielsen 1932: 276-277.

Type-SPEcIEs. Amphiodia (Amphispina) digitata Nielsen, I932.

Diagnosis. A subgenus of Amphiodia distinguished by the modification of the uppermost row of ventral disc scales with the free edges prolonged into single or forked spines.

Fig. 5. a and b. Amphiodia psara H.L.C., M.C.Z. 965, holotype, Corona del Mar, California; c and d. Amphiodia crassa Koehler, U.S.N.M. 40953, "Albatross" st. 5282, Philippine Is. (d.d. only $2.5 \mathrm{~mm}$; in d the two giant arm spines of the first segment of the arm drawn are both lost but those of the adjacent arms are shown) ; e and f. Amphiodia (Amphispina) duplicata Koehler, I949.8.I5.24, paratype, Amboina, e showing spinose projections of marginal scales, $\mathrm{f}$ relatively more enlarged to show details of oral structure ; g. " Amphiodia" psilochora H.L.C., U.S.N.M. 25544, holotype, Sagami Bay, Japan, showing the oral tentacle scale in contrast with $\mathrm{f} ; \mathrm{h}$. Ophiophragmus wurdemanni Lyman, M.C.Z. III9, holotype, Charlotte Harbour, Florida; i. O. brachyactis H.L.C., M.C.Z. II20, holotype, off Sombrero Key, Florida, side view of base of arm showing marginal papillae fringing the distal edge of the large radial shields with a few additional papillae just above the arm base each side ; j. " Amphiodia" affinis (Studer), I936.12.30.769, South Georgia. 
I do not agree with Nielsen that Amphiodia urtica (Lyman, I860) should be referred to the subgenus Amphispina ; it has many or all of the ventral disc scales angular or with spinose more or less projecting points on the free edges and possibly merits a separate supraspecific distinction comparable with Acrocnida of the Amphiura-group. Fell (I962a) mistakenly refers it to Ophiophragmus although it lacks articulated marginal papillae.

\section{AMPHIODIA sensu extenso (cont.)}

Of the forty-seven nominal species included in Amphiodia, Diamphiodia and Gymnodia by Fell (I962a), a large number are from east or west America (excluding Alaska and Chile), namely Amphiodia atra (Stimpson, I852) (referred to Micropholis nov. by Thomas, I966 and with synonyms Ophiolepis limbata Grube, I857 and Amphiodia gyraspis H. L. Clark, I9I5, according to Thomas, I964), A. grisea (Ljungman, I867b), $A$. occidentalis (Lyman, I860), $A$. oerstedi (Lütken, I856), $A$. peloria Bush, I92I, $A$. periercta H. L. Clark, I9II, $A$. planispina von Martens, I867, A. platyspina Nielsen, I932, A. psara H. L. Clark, I935, A. pulchella (Lyman, I869) (with synonym Amphiura repens Lyman, I875, according to Thomas, I962), $A$. riisei (Lütken in Lyman, I860), A. sculptilis Ziesenhenne, I940, A. tabogae Nielsen, I932, A. trychna H. L. Clark, I9I8 (with synonym $A$. tymbara H. L. Clark, I9I8, according to Thomas, I962), $A$. vicina $\mathrm{H}$. L. Clark, I940 and $A$. violacea (Lütken, I856). To these can be added $A$. urtica (Lyman, I860) with synonym Amphiura barbarae Lyman, I875, according to Nielsen (I932).

More than half of these species, namely A. grisea, oerstedi, planispina, platyspina, psara (fig. 5a, b), riisei, sculptilis, tabogae, trychna, vicina and violacea, show a more or less marked tendency for broadening of the third oral papilla, which may approximate in proportions to the operculiform third papilla of Amphipholis sensu extenso, witness the uncertain position of Ophiolepis atra Stimpson, transferred to Amphipholis by Ljungman, I867, to Amphiodia by Verrill, I899 and back to a newly-formed division of Amphipholis by Thomas, I966. In addition, a number of the American species of Ophiophragmus, such as $O$. brachyactis H. L. Clark, I9I5, O. luetkeni (Ljungman, I87I), O. marginatus (Lütken, I859), O. paucispinus Nielsen, I932, and $O$. pulcher H. L. Clark, I9I8 (but not $O$. wurdemanni (Lyman, I860), the type-species), also share this tendency. Since Thomas (I962) has found the holotype of Amphiodia rhabdota H. L. Clark, IgI8 to be a specimen of Ophiophragmus pulcher deficient in the marginal papillae supposedly characteristic of the genus Ophiophragmus, I think that similar synonymies will also be discovered among some of the other nominal species, for instance Amphiodia violacea, A. psara (fig. 5a, b) and O. marginatus would bear comparison ind indeed the supra-specific limits between the species of Amphiodia and Ophiophragmus named above, together with most of the American species of Amphipholis sensu extenso, especially those which Thomas (I962) has referred to his new nominal genus Micropholis (namely Amphipholis atra (Stimpson, I852), gracillima (Stimpson, I852), subtilis Ljungman, I867b, platydisca Nielsen, I932, geminata (Le Conte, I85I) and puntarenae (Lütken, I856), are badly in need of revision. It is to be hoped that Thomas will go fully into this matter in his 
monograph of west Atlantic amphiurids (now in course of preparation), though it is unfortunate that the compass of this work apparently excludes the many closelyrelated species described from the western coasts of America.

The abstraction of the species of Amphiodia with the third papilla enlarged leaves only four American species with three approximately equal oral papillae on each half of the jaw, namely $A$. pulchella, $A$. occidentalis, $A$. periercta and A. peloria. Out of the 25 nominal species remaining which Fell referred to Gymnodia, Diamphiodia and Amphiodia, only eight more appear to me to be valid species of Amphiodia. These are $A$. craterodmeta H. L. Clark, I9II, $A$. crassa (Koehler, I904) (fig. 5c, d), $A$. dividua Mortensen, I933c, $A$. euryaspis H. L. Clark, I9II, A. fissa (Lütken, I869), A. frigida (Koehler, I897), A. minuta H. L. Clark, I939 and A. obtecta Mortensen, I940, to which may be added $A$. debita Koehler, I922a and acutispina Koehler, I9I4, of the three which Fell mentioned as incertae sedis. The remainder are disposed of as follows: Amphiodia psilochora H. L. Clark, I9II (fig. 5g) has an oral tentacle scale (as mentioned above, p. 23) and resembles an Amphioplus with the fourth (distalmost) oral papilla suppressed ; its oral formula is $\mathrm{m}, \mathrm{mm}, \mathrm{o}+\mathrm{t}$. It is here provisionally referred to Amphioplus and discussed further on p. 57. Amphiodia affinis (Studer, I885), ochroleuca (Brock, I888), grata (Koehler, I904), reposita (Koehler, I905) and servata (Koehler, I904) (see figs $5 \mathrm{j}$ and 8 (part)) also have the first oral tentacle scale present but usually have a slight diastema between the infradental and middle papillae (very small in the case of some specimens of ochroleuca-see fig. 8t) and the distalmost papilla is based at least partly on the edge of the adoral shield (except in affinis where both the distal papillae are usually inset somewhat on to the oral plates though there is a great deal of variation in their number and arrangement); the formula for most of these species can be expressed as $\mathrm{m}, \mathrm{om}, \mathrm{m}+\mathrm{t}$ and they are referred to subdivisions of Amphioplus as stated on pp. 48 and 49. Amphiodia assimilis (Lütken \& Mortensen, I899) and caulleryi (Koehler, I897), judging from the respective figures, resemble species of Amphiura with two distal oral papillae, having a large diastema at the side of the oral plate and the two distal papillae forming a symmetrical pair each side based on the adoral shield ; their formula may be given as m,o,mm $+\mathrm{t}$, possibly m,on,nm $+\mathrm{t}$, much as in Amphiura filiformis, with which I believe they are congeneric. (See also p. 43). Amphiodia digitula H. L. Clark, IgII is another such species and I agree with Djakonov (I954) in referring it to Amphiura. Amphiodia olivacea (Brock, I888) has short blunt marginal spines and should be referred to Ophiophragmus, while Amphiodia fuscoalba (Brock, I888) (the third of Fell's species incertae sedis) appears from the description to have Amphiura (A)-type oral papillae and granuliform scales on the underside of the disc ; it may therefore be referred to Acrocnida. Ctenamphiura sinensis A. H. Clark, I9I7, which Fell rather incomprehensibly placed in Diamphiodia despite its four oral papillae more like Amphioplus, I have recently (I967) referred to Paracrocnida. Similarly Amphioplus brachiostictus Tortonese, I949 has four oral papillae and cannot therefore be included in Amphiodia. However, Mortensen (I952) mentions it as being similar to Amphiodia chilensis (Müller and Troschel), which he maintains is better-placed in Amphiodia than in Ophiophragmus although some specimens of it have marginal papillae. Three of the four remaining names are 
synonyms, Amphiodia antarctica (Ljungman, I867b) of A. chilensis (Müller \& Troschel, I842), according to Mortensen (I936), A. rhabdota H. L. Clark, I9I8 of Ophiophragmus pulcher H. L. Clark, I9I8, according to Thomas (I962) and A. rossica Djakonov, I935 of $A$. fissa (Lütken, I869), according to me (I965). Finally, Amphiodia cyclaspis (originally cyclospis), also of Djakonov, I935, was clearly based on a specimen with incompletely-regenerated disc, which accounts for the supposedly diagnostic characters of the diminutive separated radial shields and the mosaic of small plates on the upper side of the basal arm segments ; Djakonov compared it otherwise with the sympatric $A$. craterodmeta, with which I suggest it is synonymous. Djakonov (I954) gives a figure of the dorsal side but the ventral has never been illustrated.

\section{OPHIOCNIDA Lyman}

Ophiocnida Lyman, I865: I33 ; I882 : I52-I53 ; Verrill, I899b : 315-3I6 (sensu Lyman), p. 3 I 7 (restricted) ; H. L. Clark, I9I5 : 250; Thomas, I962: 683-684. Type-species :

Ophiolepis hispida Le Conte, r85I (designated by Verrill, I899b : 3I7).

Ophiocnidella Ljungman, I871 : 649. Type-species: Amphiura scabriuscula Lütken, I859.

Ophiocnida hispida, the type-species, has oral papillae of the Amphiodia (B)-type (fig. 7c). The same is not strictly true of one of the other species which is currently still included in Ophiocnida, having been referred to it by Lyman (1874), namely Ophiophragmus echinatus Ljungman, I867b. This species has Amphioplus (D)-type oral papillae (fig. $7 \mathrm{k}$ ), as least when mature, and accordingly with its spinose disc is now referred to the genus hitherto known as Amphiacantha Matsumoto, I9I7 for which a new name is proposed on p. 33 .

Another species is a doubtful member of the genus Ophiocnida, namely O. loveni (Ljungman, I867a), for further mention of which see p. 3r.

\section{AMPHIPHOLIS Ljungman}

Amphipholis Ljungman, I867a : I65; I867b : 3II-3I2 ; Verrill, I899a : 24 ; 1899b : 306, 3II3 I2 ; H. L. Clark, I915 : 240 ; Djakonov, I954 : 64 ; Fell, I962a : I5 ; Thomas, I962 : 657 ; I966 : 827-833. Type-species : Amphipholis januarii Ljungman, I867a.

[See below, p. 3I for synonyms.]

As with Amphiodia, the Amphiurid species with Amphipholis (C)-type jaw armament and unarmed discs exhibit a fairly narrow range of form in comparison with Amphiura with regard to disc scaling, though their tentacle scales may be reduced to one or (in one case) totally absent. Fell (I962a) was thus able to divide off only Monopholis with one tentacle scale and Nullopholis with none from Amphipholis restricted. As Thomas (I966) has pointed out, the second species which Fell refers to Nullopholis, Amphipholis pentacantha H. L. Clark, I9I5, has tentacle scales present on the basal segments (in fact there are twc on several pores of the very first segments though only one on the next two segments, the remaining pores having none, see fig. 6e, f). (Similarly A. murmanica Djakonov, I929 loses its single scale distally.) Thomas also notes that $A$. pentacantha is not at all closely related 
either to Amphipholis nudipora Koehler, I9I4 the type-species of Nullopholis, or to A. vitax (Koehler, I904), the type-species of Monopholis, being isolated from them both by its very coarse disc scaling and from nudipora also by its relatively numerous and elongated arm spines. Djakonov (I954) notes that A. murmanica is closely related to $A$. squamata except for having only a single tentacle scale, while the one remaining species referred to Monopholis by Fell, A. loripes Koehler, I922a (fig. 6a), is known only from a single discless specimen and appears to have some affinities with Amphiodia. Certainly the three species do not form a natural group and I can see no justification for separating them off from Amphipholis. Nor can I find other characters to support the absence of tentacle scales in A. nudipora to warrant its separation and I fully agree with the rejection of these two nominal genera. However, Thomas himself proceeds to divide up the species of Amphipholis on different criteria, most notably the shape of the oral plate in side view and the occurrence of perforations through the arm ossicles. The observation of both these characters requires dissection and special preparation ; also their use as taxonomic characters is of recent introduction, the study of oral plates being initiated by Murakami (I963) (discounting his preliminary paper of 1947 in Japanese) and of arm ossicles by Buchanan \& Woodley (I963). Although Murakami covered a fair number of Japanese species, these included only a few from each of the larger genera, four of Amphipholis for instance, while only two species of Amphiura, filiformis and chiajei have had their arm ossicles described with regard to this character, apart from Thomas's summarized remarks for his subdivisions of Amphipholis. The perforation of the arm ossicles appears to be correlated with the degree of extension of which the tube feet are capable and this appears to depend on the feeding habits of the animals. Evidently in Amphipholis januarii the distal (more immature) arm ossicles may be perforated but not the proximal ones; so there is also a chance that this is an ontogenetic rather than a functional modification. Much more work is clearly needed on the functional morphology of a wide range of species of Amphiurids before it can be determined to what extent the sharing of perforated ossicles is attributable to convergence of habit. Since Thomas is now engaged on such a study, it is obviously premature to take decisive action here with regard to his new taxa. More details are needed to render the preliminary distinction of these convincing.

The diagnoses Thomas gives for these three nominal genera can be summed up in the form of a table:

Oral papillae able to close slit

Tentacle scales

Arm spines

2nd spine modified

Successive dorsal arm plates contiguous

Arm ossicles perforated

Oral plates with strong abradial wings

Disc scales

Radial shields
Amphipholis

almost

2

4

$+$

$$
\begin{gathered}
\text { just } \\
\text { only distally }
\end{gathered}
$$

$\stackrel{+}{+}$

not stated but

joined for c. $2 / 3$
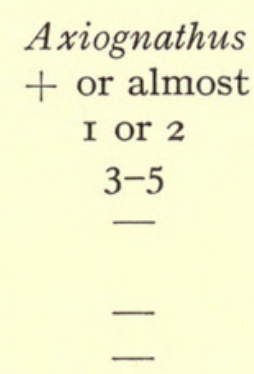

" large "

" joined their whole length" $+1-$ contiguous

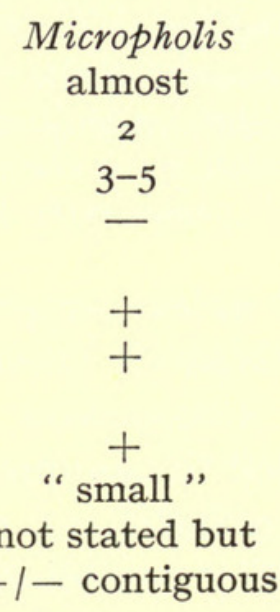

cropholis

most

3-5 
In the case of Amphipholis restricted, the diagnosis is derived from only a single species and in Axiognathus from four. Certainly most of the characters involved are only of specific weight, apart from the two already mentioned, the importance of which remains to be seen, while it is just possible that modification of the second arm spine will prove to allow a supra-specific grouping, though below the generic
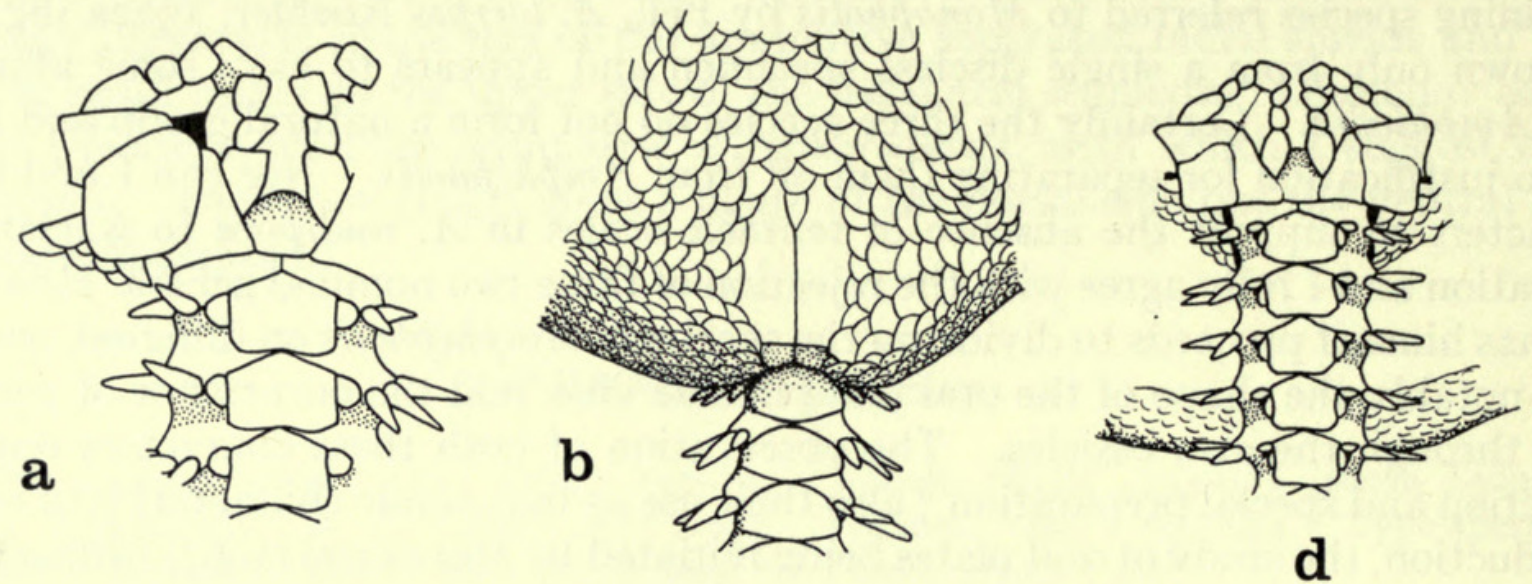

C
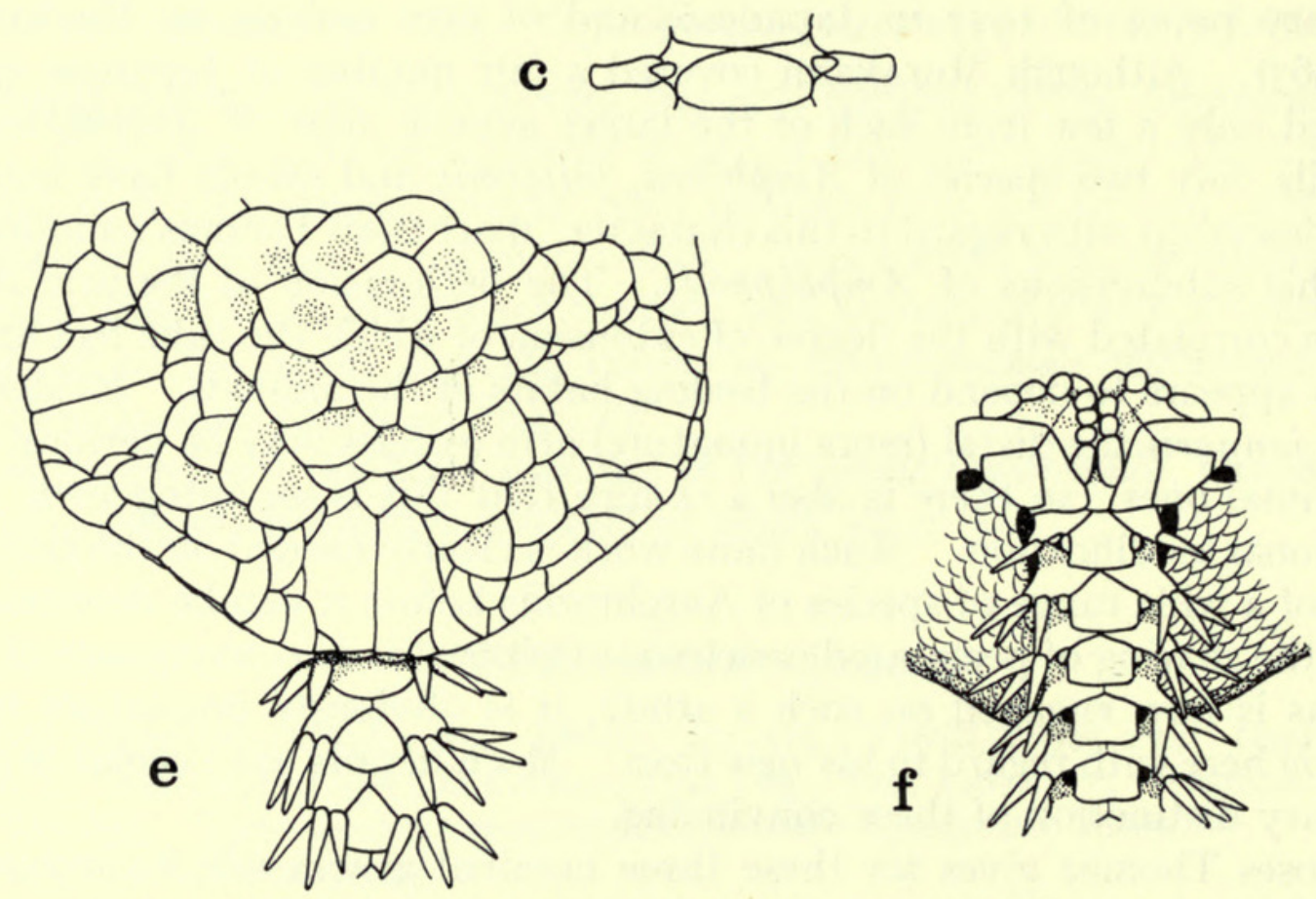

FIG 6. a. Amphipholis loripes Koehler, U.S.N.M. 4II90, holotype, " Albatross" st. 5375,

Philippine Is. (only a few disc scales remain attached to the oral shields but enough to show that the disc was not naked below) ; b-d. A. januarii Ljungman, M.C.Z. 4I40, holotype of $A$. pachybactra H.L.C., Buccoo Bay, Tobago, c shows the thirtieth arm segment from above (all the ventral interradii are ruptured, hence the gaps in d) ; e and $\mathrm{f}$. A. pentacantha H.L.C., M.C.Z. I437, holotype, off St. Lucia, West Indies.

level unless supported by other characters. Superficially the differences between Amphipholis januarii (fig. 6b-d) and A. squamata, the type-species of Amphipholis and Axiognathus respectively, are very slight and considerable evidence will be needed to convince me that they are generically distinct.

Inevitably my reluctance to accept this schism is increased by desire to retain the familiar combination Amphipholis squamata (Delle Chiaje, I829) for this the 
most nearly cosmopolitan echinoderm of all and one which must feature on a great number of fauna lists, so that a change of generic name would cause extensive confusion. However, after scrutinizing the literature I cannot find any explanation why the specific name squamata has been used since Igoo in face of the obvious priority of Ophiura elegans Leach, I8I5. Leach's short description and more particularly his notes that the disc scales are " of nearly one size and the margin has a distinct row of scales running round it ", together with the drab colour and the locality on the rocks in South Devon, convince me that his material was conspecific with $A$. squamata. If the latter name is to be retained, then some approach is needed to the International Commission on Zoological Nomenclature to request that the plenary powers be exerted to reject $O$. elegans Leach formally and validate $O$. squamata Delle Chiaje. Simultaneously I would have liked to be able to recommend that the usage of Amphipholis in Ljungman's preliminary paper (I867a) be suppressed in order to validate that in his main paper ( $1867 \mathrm{~b})$, where the first-named and best-known species included is A. elegans (Leach) with squamata given as a synonym. [A type-designation of $A$. squamata has already been given by Verrill (I899a : 24 and I899b : 306, but not p. 3II which names januarii).] However, it is difficult to justify squamata as type-species in face of Ljungman's treatment of the genus.

Accordingly I propose to suspend consideration of the adoption of Axiognathus and Micropholis pending publication of Thomas's monograph ; meanwhile I hope for some response by interested parties to my proposals for stabilizing the specific name squamata. At present therefore, Amphipholis is treated in the wide sense with only the following synonyms:

Nullopholis Fell, I962. Type-species : Amphipholis nudipora Koehler, I9I4.

Monopholis Fell, I962. Type-species : Amphiura vitax Koehler, I904.

In addition to the species listed by Fell, there are two others which have been referred to Amphipholis. One of these is A. tetracantha Matsumoto, I94I, from Japan and the other Amphiura murex Koehler, I908, from Brazil. The holotype of the latter is relatively small (d.d. only $2.5 \mathrm{~mm}$.) and has the under side of the disc covered with conical granules while the upper side has relatively large naked scales. This unusual combination is shared by Ophiocnida loveni (Ljungman, I967a), also known from Brazil, of which I believe $A$. murex is a synonym. I am uncertain whether $O$. loveni is congeneric with the type-species of Ophiocnida, O. hispida (Le Conte, I85I), the latter having the disc scales distinct on both sides and with small spinelets scattered all over. The affinities of O. loveni appear to be more with Amphichondrius granulosus Nielsen, I932 or Ophiophragmus filograneus (Lyman, I875), once also included in Ophiocnida. 

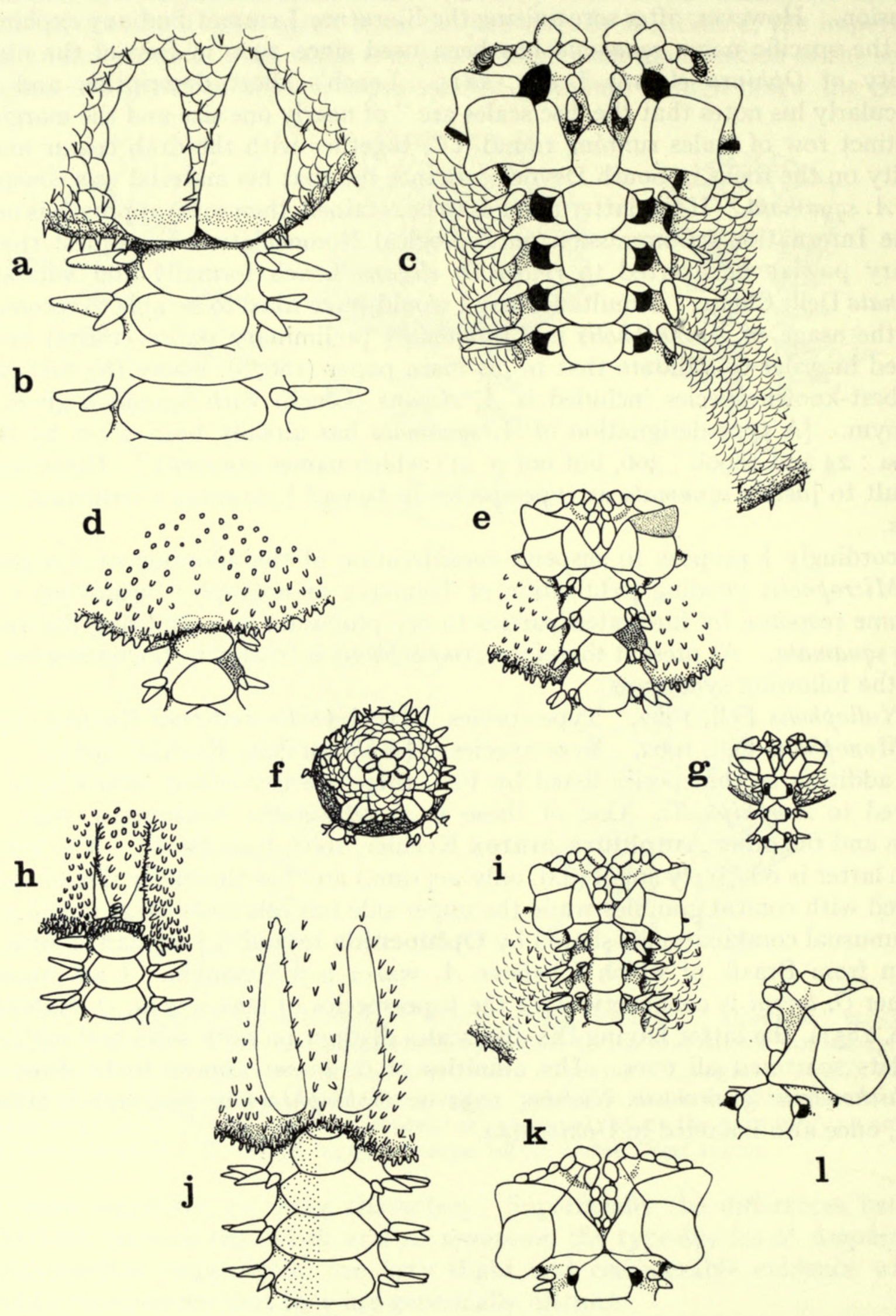


\section{OPHIOSTIGMA Lütken}

Ophiostigma Lütken, I856 : I3 ; I859b : 233 ; Lyman, I865 : I03 ; Ljungman, I867b : 3 I7 ; Lyman, I882 : I64-I65 ; H. L. Clark, I9I5 : 243 ; Fell, I960 : 22 ; Thomas, I962 : 689. Type-species : O. tenue Lütken, I856, by monotypy.

In I96o Fell referred Amphistigma H. L. Clark, I938, to the synonymy of Ophiostigma, being evidently misled by H. L. Clark's figure of the disc of $A$. minuta, the type-species, which is not very clear. Another figure of the holotype of $A$. minuta is given here (fig. $7 \mathrm{f}, \mathrm{g}$ ) which I hope shows up more conspicuously the marked difference in the disc in comparison with Ophiostigma, though certainly both have oral armament of the Amphipholis (C)-type. Ophiostigma tenue (fig. $7 \mathrm{~d}$, e) has papilliform spinelets scattered all over both sides of the disc, whereas in Amphistigma minuta there are only a few relatively very large papillae restricted to the margin of the disc while in the centre the five approximately radial scales of the rosette are extremely thickened and projecting but do not bear articulated papillae.

\section{Amphistigma minuta $\mathrm{H}$. L. Clark}

fig. $7 f, g$

Amphistigma minuta H. L. Clark, $193^{8}:$ 245-247, fig. I6.

\section{DOUGALOPLUS* nom. nov.}

Amphiacantha Matsumoto, I9I7 : I77-I79 ; Nielsen, I932 : 296 ; Djakonov, I954 : 57. Typespecies: Amphioplus acanthinus H. L. Clark, I9II. Non Amphiacantha Popofsky, I904, Protozoa.

Unfortunately the generic name Amphiacantha used by Matsumoto is preoccupied, as discovered recently by Miss M. Downey of the U.S. National Museum and communicated to me by Dr. D. L. Pawson, to both of whom I am indebted. The replacement name Dougaloplus is therefore proposed for the genus.

Apart from the type-species, the genus also includes Ophiostigma formosa Lütken, I872. Amphiura gastracantha and notacantha both of Lütken and Mortensen, I899, Ophiocnida libera Koehler, I907 and O. amphacantha McClendon, I909, all referred to Amphiacantha by Matsumoto, who also included a new nominal species Amphiacantha dividua and Ophiocnida sexradia Duncan, I887, which I consider are synonymous and referable to Ophiocomella (sexradia having been transferred in I963

* Dougal-a shaggy dog of television fame. Gender: masculine.

FIG. 7. a-c. Ophiocnida hispida (Le Conte), M.C.Z. I496, Hassler Expedition, Panama, b shows the twentieth free segment from above; d and e. Ophiostigma tenue Lütken, M.C.Z. 5712, "Velero" st. 870, Isabel Is., W Mexico (the texturing of the surface is indicated on a few plates); f and g. Amphistigma minuta H.L.C., M.C.Z. 4983, holotype, Lord Howe I. (the dorsal view slightly oblique); h-k. Dougaloplus echinatus (Ljungman), $\mathrm{h}$ and i. Stockholm Museum collection, holotype, N. Gaspar Strait, E of Sumatra, $\mathrm{j}$ and k. B. M. 98.6.30.I, Batavia (Jakarta) ; 1. Amphioplus (?) luctator Koehler, U.S.N.M., Kei Is. Expedition st. 77 .

C 
Clark in Parslow and Clark). Matsumoto also placed Amphilimna pentacantha H. L. Clark, I9II in Amphiacantha; this species has since been referred to the synonymy of Amphiacantha amphacantha by Nielsen, I932. Subsequent additions to the genus have been $A$. transacta Koehler, I930 and $A$. derjugini Djakonov, I949. Amphiacantha transacta appears to have multiple apical oral (or dental) papillae and the genital slits bordered with genital papillae unlike other Amphiurids ; it must therefore be a member of the Chilophiurida and should be referred to the Ophiocomidae or possibly Ophiochitonidae. Amphiacantha derjugini, however, is certainly congeneric with Dougaloplus amphacantha, resembling it in the spiniform two middle oral papillae but differing in the single tentacle scale.

One further species is now referred to the genus, namely Ophiocnida (originally Ophiophragmus) echinata (Ljungman, I867b), to which Lyman (I874) doubtfully referred a specimen from the Philippines although he thought it differed in two important respects from the holotype. There are two specimens in the British Museum collections from Batavia (Jakarta), Java which agree closely with Lyman's description and figures but again have the same two differences from Ljungman's description. To settle their identity, I requested Dr. P. A. Andersson of the Stockholm Museum to lend me the holotype of Ophiophragmus echinatus, which he very kindly did. A description of it is given below but the two supposed differences can be dealt with here. Firstly Ljungman describes the radial shields as almost concealed by the disc spines. This is true to some extent in the holotype, only the distal ends of the radial shields being naked and exposed but it looks to me as if the specimen may have been dried at some time (it is now in spirit) since the disc is rather shrunken and the scaling has distorted considerably, in most cases so as to form a fold coinciding with the radial shield and concealing it for most of its length. In one radius this does not apply but here the scaling around the shields appears to have been scraped free of spinelets so it is not absolutely certain that the naked condition of the shields is natural, though I believe it is. These two shields are very long and thin, equal in length to about half $\mathrm{r}$ of the disc. The second character concerns the number of oral papillae ; Ljungman describes only three whereas Lyman found four in his specimen with d.d. Io $\mathrm{mm}$. (at least $2 \mathrm{~mm}$. larger than the holotype), though in a small specimen, d.d. $4 \mathrm{~mm}$., Lyman notes that there are often only three. In the holotype the first impression is that there are only three papillae but on most of the adoral shields there is a small calcification on the edge distal to the third papilla. At best this " papilla " is inconspicuous and it may be quite lacking ; usually it is angled slightly down into the oral slit and partly concealed by the large third papilla so it is not difficult to see how Ljungman overlooked it.

Besides the two specimens from Batavia there are in the British Museum three from Macclesfield Bank, South China Sea and one from the Great Barrier Reef (recorded by H. L. Clark), all of them I believe conspecific with the holotype of echinatus. One Batavia specimen is discless but is similar in size to the other where d.d is $12.5 \mathrm{~mm}$. (fig. $7 \mathrm{j}, \mathrm{k}$ ). Both of them have four oral papillae in each series but the outermost one is distinctly the smallest and sometimes partly overlain by the third. Two of the Macclesfield Bank specimens are also discless, though their d.d. must have been about $7 \mathrm{~mm}$. ; their fourth papilla is developed in most series but 
often partly overlain. The same is true of the Barrier Reef specimen but this is dried and the fourth papilla has a much rougher texture than the other three. The third Macclesfield Bank specimen has d.d. only $4 \mathrm{~mm}$. and the fourth papilla is just distinguishable in a few series ; clearly its development is progressive with growth and seems to be retarded in comparison with most species of Amphioplus, though in I955 I noted something similar in Amphioplus congensis. All three intact specimens have long, narrow, separated and quite bare radial shields, as in Lyman's specimen. I think therefore that echinatus is better referred to Dougaloplus than left in Ophiocnida. Its affinities are probably with $D$. formosus from further north in the China Sea, which resembles it in jaw structure with the two innermost papillae widely spaced to the sides of the lowest tooth, the third papilla the largest and the fourth the smallest ; also both have very broadly contiguous adoral shields. D. formosus differs from echinatus in having the radial shields short, broad and contiguous.

\title{
Dougaloplus echinatus (Ljungman)
}

\author{
fig. $7 \mathrm{~h}-\mathrm{k}$, ? 1
}

Ophiophragmus echinatus Ljungman, I867b : 316.

?Ophiocnida echinata (O. longipeda MS) : Lyman, I874:230-23I, pl. 4, figs. 22, 23.

Ophiocnida echinata : Koehler, I898:68, pl. 5, fig. 47 ; I905: 32 ; H. L. Clark, I9I5 : 250 ; Koehler, I930 : II3.

?Amphioplus luctator Koehler, I922a : I78-179, pl. 68, figs. I-3 ; I930 : 106.

Description. I estimate that the holotype (fig. $7 \mathrm{~h}$, i) has the d.d. $8 \mathrm{~mm}$., although Ljungman puts the measurement at $7 \mathrm{~mm}$. The arms are all broken distally ; their length is $70+\mathrm{mm}$., probably c. IOO $\mathrm{mm}$. The disc is shrunken and partially detached from some of the arm bases. The scaling is obscured on the upper side by the numerous small, slightly tapering, spinelets, many of which have become displaced and directed almost horizontally, especially across the radial shields where the disc is distorted as described above. On the under side the spinelets are progressively fewer proximally and the scaling is distinct.

The oral shields are widest at about the middle of their length or just proximal to this, the proximal angle is acute and the distal lobe broadly rounded. The length just exceeds the breadth. The adoral shields are very broadly contiguous interradially but have no exposed part extending distal to the lateral angle of the oral shield. Radially they are separated by the very small first ventral arm plate. The innermost oral papilla of each series is offset to the side of the lowest tooth and is not strictly infradental. The second papilla is slightly smaller but the third much larger, though it cannot really be called operculiform as in Ophiostigma and Amphipholis. As described above the fourth papilla is rudimentary and sometimes appears to be absent ; usually it is partially concealed by the third.

The arms are distinctly convex above and below with the result that the dorsal arm plates appear almost carinate and the ventral arm plates have a broad flattened median area but incline inwards at the sides. The dorsal plates are broad fan-shaped with the widest part towards the distal end and the distal side becomes more or less 
flattened in the middle beyond the basal segments. The ventral arm plates are approximately quadrangular and about as wide as long, proximally slightly wider than long. The arm spines are slightly tapering and blunt-tipped ; they number four just beyond the disc but this soon falls to three.

The type-locality is $2^{\circ} 30^{\prime} \mathrm{S}: 107^{\circ} \mathrm{IO}^{\prime} \mathrm{E}$, Gaspar Strait (between Sumatra and the island of Billiton to the east), 33 metres.

Synonymy. I believe that Amphioplus luctator Koehler, I922a, (fig. 7l) known only from specimens from the Philippine area and Kei Islands all lacking the disc, will prove to be a synonym of $D$. echinatus. Although Koehler (I930) recorded both nominal species simultaneously from the Kei Islands, both the (presumably complete) specimens which he referred to Amphiacantha echinata were small and the distinctive disc would have served to identify them whereas the discless ones which he named luctator would all have been perforce identified from the mouth parts.

\section{AMPHIOPLUS Verrill}

Amphioplus Verrill, I899a : 25 ; I899b : 306, 314 ; H. L. Clark, I915 : 25I ; Matsumoto, I917 : I69-I70 ; Djakonov, I954: 59-60 ; Fell, I962a : 6, I6-17 ; Thomas, I962: 651. Typespecies : Amphiura tumida Lyman, 1878.

[See also p. 50 for synonym and p. 56 for diagnosis.]

The majority of species included in Amphioplus up to 1962 have two tentacle scales and fully-scaled discs, like the type-species, A. tumidus (Lyman, I878), so Fell's subdivision on the basis of these characters still leaves as many as 59 species in Amphioplus as restricted. The remainder Fell distributes between three new nominal genera, Silax, Unioplus and Ailsaria. (The last-named is misplaced in Fell's key as explained under the heading of Amphiodia.) Silax has the disc fullyscaled but no tentacle scales; Unioplus also has full scaling but one tentacle scale ; while Ailsaria has the disc at least partially naked below but two tentacle scales. As with Amphiodia and Amphipholis sensu extenso, the range of combinations of these two characters is much less than in the species of Amphiura sensu extenso. The number of species Fell refers to Silax, Unioplus and Ailsaria is respectively two, twelve and four.

The type-species of Silax is Amphioplus verrilli (Lyman, I879) from deep water (down to nearly 5,000 metres) in the West Indies. In the holotype of $A$. verrilli the lowest tooth on three of the jaws is distinctly tricuspid (fig. 8a) and the innermost oral papilla of each series cannot strictly be called infradental since it is offset to the side of the tooth ; however, on the two remaining jaws the lowest tooth is straightedged and there is a symmetrical, infradentally-placed pair of papillae at the apex of the jaw. The oral plates have a slight horizontal flange level with the base of the first oral tentacle scale and dorsal to the second oral tentacle, rendering the scale almost superficial in comparison with its position deeper in the oral slit in most species of Amphioplus including A.tumidus. Also, apart from the adapical papilla of each half-jaw, there are only two distal oral papillae (or scales of the second oral tentacle) making a total of three oral papillae, as in Amphichilus, not four as in 
Amphioplus sensu stricto, the fourth one mentioned by Lyman being the first oral tentacle scale. The oral formula is $\mathrm{m}, \mathrm{om}, \mathrm{m}+\mathrm{t}$ (or $\mathrm{m}, \mathrm{omn}, \mathrm{n}+\mathrm{t}$ ), though on the half-jaws which have the first oral tentacle scale most nearly superficial it could be written as $m,(m=t) m, m$.

This kind of jaw structure is an incipient modification from that of Amphioplus sensu stricto in the direction of Amphilepis, since Matsumoto's revision of I9I5 isolated in the family Amphilepididae, the relationship of which to the Amphiuridae is discussed further below (p. 70). An even more important modification in my view is that of the arms of Silax verrilli. Lyman described the ventral arm plates as swollen but I would call them keeled, though the apex of the keel is blunted. The consecutive dorsal arm plates are separated, even basally, but this condition is shared by a number of other deep-water amphiurids (as well as by Amphilepis).

The combination of the keeled arms with the oral structure and the complete absence of tentacle scales even basally in my opinion justifies a generic distinction of verrilli from Amphioplus tumidus; I therefore support Fell in this instance in recognizing Silax as a valid genus.

Fell (I962) tentatively referred a second species to Silax, namely Amphioplus trepidus (Koehler, I904). However, as he comments, this species is not at all Amphiurid-like, not only does the disc merge with the arms dorsally but the radial shields are small and very widely spaced, especially at their distal ends. I have examined the holotype and find that it has a group of tooth papillae at the apex of each jaw, numbering six or seven but with two of the more superficial ones arranged as a symmetrical pair, simulating the infradental pair of oral papillae of amphiurids ; usually there is also a single smaller median papilla superficial even to these two. In addition the dorsal-most arm spine is often enlarged on alternate sides of the arm and there are remnants of about eight irregularly-placed spines on the disc, one as much as $0.35 \mathrm{~mm}$. long, the d.d. being only $4 \mathrm{~mm}$. Despite the considerable depth (289 metres) I am certain that the species is referable to the family Ophiocomidae and probably to the genus Ophiomastix, which also has disc spines and enlarged uppermost arm spines.

There are, however, a number of other species which show some degree of affinity with Silax verrilli. These include the following:

Amphilepis patens Lyman, I879 W South America ; m,tt,om (fig. 8c)

Ophiomonas protecta (Koehler, I904) E Indies ; m,oo,m +t (fig. 8d)

Ophiomonas bathybia Djakonov, I952 W Pacific ; m,oo,m $+\mathrm{t}$

Amphioplus daleus (Lyman, I879) E Pacific-N and S Atlantic ; $\mathrm{m},(\mathrm{m}=\mathrm{t}) \mathrm{m}, \mathrm{n}$

(fig. 8I)

Amphioplus patulus (Lyman, I879) Southern Ocean ; $\mathrm{m},(\mathrm{m}=\mathrm{t}) \mathrm{mn}, \mathrm{n}$ (fig. 8j)

Amphioplus cernuus (Lyman, I879) N Pacific ; m, $(\mathrm{m}=\mathrm{t}) \mathrm{mn}, \mathrm{n}$

Amphiodia grata (Koehler, I904) E Indies ; $\mathrm{m},(\mathrm{m}=\mathrm{t}) \mathrm{m}, \mathrm{m}$ (fig. 8k)

Amphioplus falcatus Mortensen, I933a SE Africa ; $\mathrm{m},(\mathrm{m}=\mathrm{t}) \mathrm{m}, \mathrm{m}$

Amphioplus confinis (Koehler, I904) E Indies ; $\mathrm{m},(\mathrm{m}=\mathrm{t}) \mathrm{mn}, \mathrm{n}$

Amphiura koreae Duncan, I879 Japan ; m,om,m +t (fig. 8h)

Amphioplus gentilis (Koehler, I904) E Indies ; m,oM,m +t (fig. 8r)

Amphiodia servata (Koehler, I904) E Indies ; m,oM,m +t (fig. 8p) 

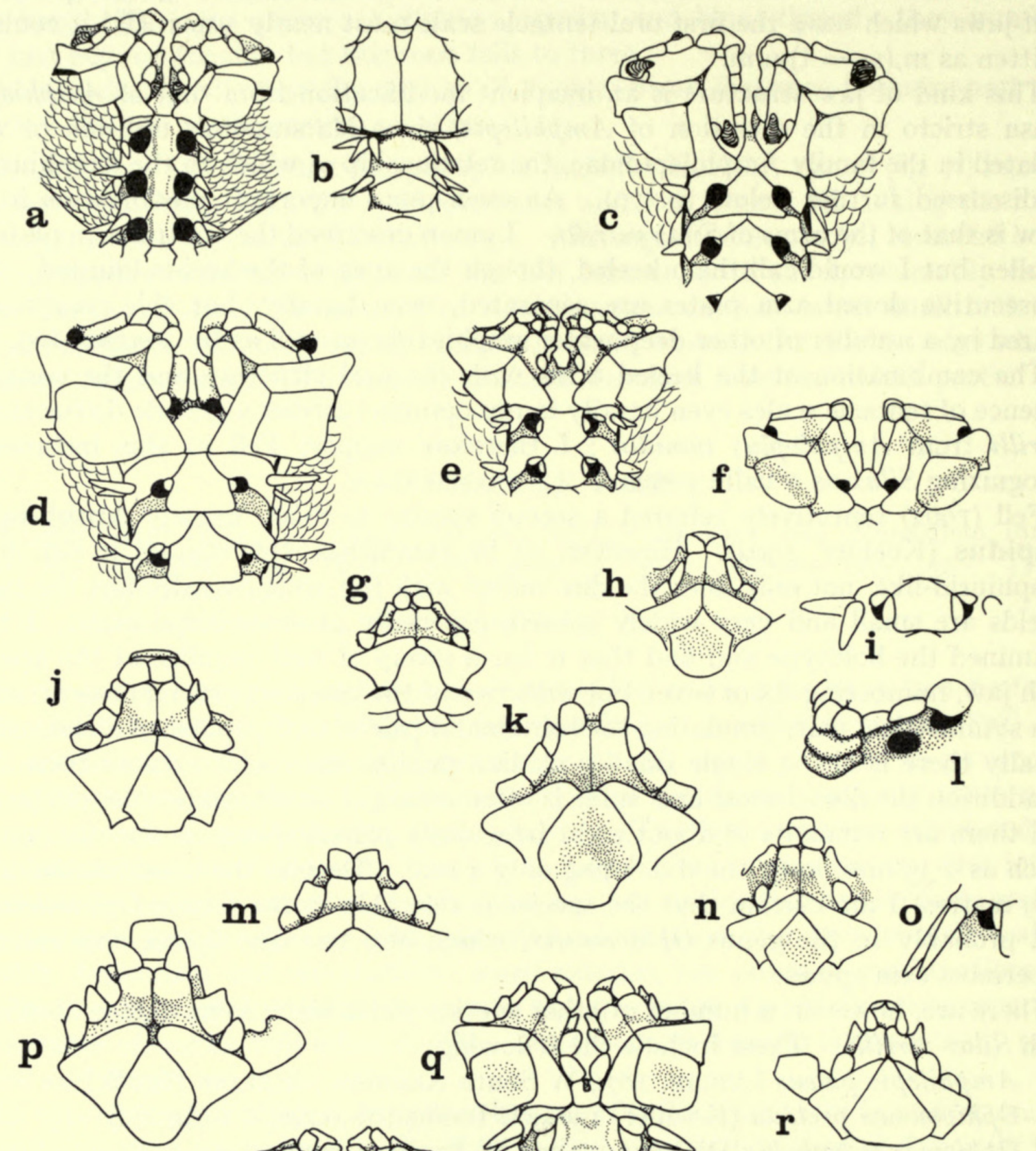

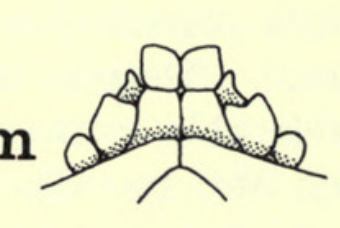

2

p
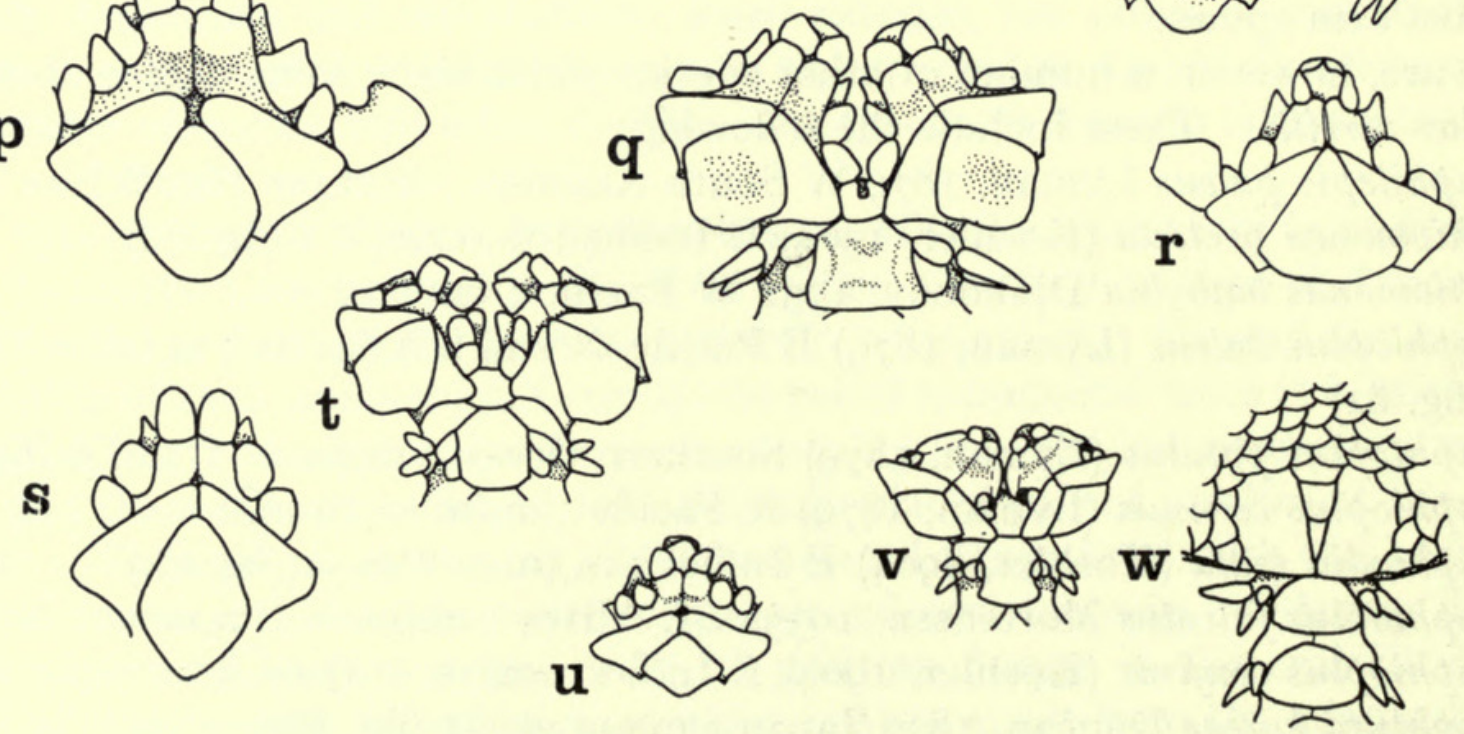
Amphioplus incisus (Lyman, I883) W Indies ; m,om,m +t (fig. 8q)

Amphiura concolor Lyman, I879 Japan ; m,om,m +t (fig. 8 g)

Amphiodia caulleryi (Koehler, I897) Indian Ocean ; m,on,nm $+\mathrm{t}$ ?

Amphiura diomediae Ltk. \& Mtsn., I899 Indo-Pacific ; m,on,nm +t (fig. 8n)

Amphiura lunaris Lyman, I878 W Indies ; m,oo,mm +t (fig. 8v)

Amphichilus cesareus (Koehler, I905) E Indies ; $\mathrm{m},(\mathrm{m}=\mathrm{t}$ ?)

Amphiodia reposita (Koehler, I905) E Indies; m,o $\overparen{\mathrm{N}, \mathrm{Nm}}+\mathrm{t}$ (fig. $8 \mathrm{~m}$ )

Amphioplus conditus (Koehler, I905) E Indies ; m,om,m +t (fig. 8s)

Amphiodia ochroleuca (Brock, I888) Indo-Pacific ; m,m,m $+\mathrm{t}$ (fig. 8t)

Amphichilus trichoides Matsumoto, IgI7 Japan; m,n,nm $+\mathrm{t}$

Amphiodia affinis (Studer, I885) Southern Ocean ; m,omm,o +t (fig. 5j)

Amphiura bidentata H. L. Clark, I938 Australia ; m,omm, +t (fig. 8u)

The generic names given in the list are those currently in use before Ig62 and mainly correspond to the ones given in H. L. Clark's catalogue (I9I5). The oral formula in some of the species is subject to variation but the version given is believed to be the most common one. The seven species below the dividing line are from shallow water, those above from deep ; only the southern Amphiodia affinis ranges from shallow depths to several hundred metres.

A tricuspid lowest tooth similar to that found in the holotype of $S$. verrilli, though a little smaller, occurs on two jaws of the holotype of Amphilepis patens (fig. 8c), the two innermost papillae again being offset and not truly infradental, though on

FIG. 8. a and b. Silax verrilli (Lyman), 82.I2.23.I7, holotype, "Challenger" st. 54, $\mathrm{N}$ of Bermuda ; c. Amphilepis patens Lyman, 82.I2.23.I4, holotype, "Challenger" st. 299, off Chile (the tip of one first oral tentacle just shows at top left) ; d. Ophiomonas protecta (Koehler), U.S.N.M. 4Ior3, " Albatross " st. 5359, Philippine Is. ; e. Amphioplus (Unioplus) sp. (Amphiura concolor according to Lyman), 82.12.23.455, "Challenger " st. I9I, Kei Is. ; f. Amphilepis norvegica (Ljungman), 98.5.3.688, Trondhjem Fjord ; g. Amphiura concolor Lyman, 82.12.23.107, holotype, "Challenger" st. I95, Banda Sea ; $\mathrm{h}$ and i. Amphiura koreae Duncan, 8o.I.3.4, holotype, Japan Sea (i shows the large tentacle scales on a proximal arm segment); j. Amphioplus (Unioplus) patulus (Lyman), 82.I2.23.369, holotype, "Challenger" st. I56, Southern Ocean, SW from Australia ; k. Amphioplus (Unioplus) gratus (Koehler), Amsterdam Museum, syntype, "Siboga " st. 2II, E Indies; 1. Amphioplus (Unioplus) daleus (Lyman), 82.I2.23.370, holotype, "Challenger" st. 325, SW Atlantic, oblique ventral view of superficial part of one side of a jaw ; m. Amphioplus (Unioplus) repositus (Koehler), Amsterdam Museum, syntype, "Siboga" st. 89, E Indies ; n and o. Amphiura diomediae Lütken and Mortensen, n. I948.5.26.56 (pt.), John Murray Expedition st. 54, S Arabian coast, o. I966.I.20.9, "Albatross" st. 5053, Suruga Gulf, Japan (tentacle scales for comparison with i); p. Amphioplus (Unioplus) servatus (Koehler), Amsterdam Museum, holotype, "Siboga " st. 262, (showing the single series of four oral papillae on the left) ; q. Amphioplus (Unioplus) incisus (Lyman), M.C.Z. I468, holotype, “ Blake ” st. I6I, off Guadeloupe, W Indies; r. Amphioplus (Unioplus) gentilis (Koehler), Amsterdam Museum, syntype, "Siboga " st. I78, E Indies (see also fig. IIf and g) ; s. Amphioplus (Unioplus) conditus (Koehler), Amsterdam Museum, holotype, "Siboga" st. 89, E Indies ; t. Amphioplus (Amphichilus) ochroleucus (Brock), M.C.Z. 4986, Broome, NW Australia ; u. Amphiura bidentata H.L.C., M.C.Z. 4947, holotype, Broome; v and w. A. lunaris Lyman, M.C.Z. I324, holotype, "Blake" st. 29, Gulf of Mexico. 
the three other jaws the teeth are all broadly rounded and the two papillae lie at least partially below the lowest one. As is usual in the genus Amphilepis, the apex of the pair of oral plates is less truncated than in most amphiurids, though less so in patens than in the type-species, Amphilepis norvegica (fig. 8f), and these two innermost papillae are relatively broad and short with their bases at an angle to each other, not in the same plane. Also the oral plates have a superficial flange bearing the first oral tentacle scale. Although in A. norvegica this oral tentacle scale is operculiform and extends right to the first ventral arm plate, in $A$. patens it is broken up into two, sometimes three, separate papillae while distally it curves outwards as a rim almost encircling the second oral tentacle, which is superficial in Amphilepis ; ventral to the second tentacle, on the edge of the adoral shield, this rim is again rather irregularly divided abradially, usually with a single papilla marked off from it, though Lütken \& Mortensen (I899) figure two papillae in this position in their " Albatross" specimen. Lyman failed to record the distal papillae of the holotype.

A very similar oral structure occurs in Ophiomonas bathybia with which Djakonov justifiably believes Amphilepis protecta to be congeneric. In Ophiomonas protecta (fig. 8d) the operculiform first oral tentacle scale is not quite superficial, hence the addition of $t$ at the end of the formula. A similar condition appears to occur in Amphilepis diastata Murakami, I942, which may have the second tentacle even more inset into the oral slit, judging from Murakami's pl. 4, fig. 34 (I963). In I965 I provisionally referred diastata to the synonymy of Amphiura koreae (that is sensu Matsumoto, which I now think may be better referred to diomediae, see pp. 4I-42). It should certainly be included in Amphiura, the jaw structure is quite unlike that of Amphilepis. Before discussing Amphiura koreae there are at least seven species in which the first oral tentacle scale is papilliform and almost superficial, coming more or less into series with the oral papillae ; these include Amphioplus daleus, patulus, cernuus, cesareus, confinis and falcatus, also Amphiodia grata, all of which have a basic oral formula of $3 \mathrm{~m}+\mathrm{t}$ like Silax verrilli. The first three also approximate to $S$. verrilli in reduction of the tentacle scales, though this was not remarked on by Lyman. In fact the largest of the three holotypes, that of Amphioplus patulus (d.d. I $4.5 \mathrm{~mm}$.) is the only one to have any tentacle scales beyond the eighth arm segment; they extend to about the twenty-fifth. The types of A. daleus and cernuus have d.d. respectively $9 \mathrm{~mm}$. and just under $6 \mathrm{~mm}$. ; the former has the single scales on only the first two segments (with one exception on the third). Some descriptive notes are given below (pp. 44, 45, 58-59 and 62-63) on type-material of the other four species.

A similar $3 \mathrm{~m}+\mathrm{t}$ formula occurs in all the other species in the list but in these the first oral tentacle scale is normally deeper in the oral slit and not in the same superficial plane as the oral papillae. Descriptive remarks for Amphioplus gentilis, Amphiodia ochroleuca, reposita and servata are given on pp. 46, 62 and 65-66 and they are also illustrated in fig. 8, as are Amphioplus incisus and conditus. It can be seen that all of them have a semblance of continuity in the series of oral papillae, the small diastema between the infradental one and the two distal papillae being partially filled by the oral tentacle scale above. This contrasts with species such as Amphiura lunaris (fig. $8 \mathrm{v}, \mathrm{w}$ ) and digitula, in which the two distal papillae are much more 
sharply dissociated from the infradental by the long diastema.

A common feature among the deep-water species in the list is irregularity in the symmetry of the infradental papillae. These may be unequal in size (e.g. in the holotype of Amphiura concolor, fig. $8 \mathrm{~g}$ ), or subdivided, usually with three papillae in place of the two (as in the specimen of Ophiomonas protecta illustrated here, fig. 8d). Matsumoto (I9I7) figured this latter condition in what he calls Amphiura koreae and it is also found in the holotype of Amphioplus patulus (though not in the paratype), causing Matsumoto to refer the latter species to Amphiactis which is incorrect, the teeth and the apices of the jaws being broad. The positions of the distal papillae and their relations with the oral tentacle scale are also subject to some variation. Again this has been noted particularly by Matsumoto in the species he calls Amphiura koreae, in which the inner of the two distal papillae may be based entirely on the oral plate rather than partially on the adoral shield and sometimes there may be an additional papilla making a total of four or conversely one of the two distal papillae may be lost. Having studied Duncan's holotype of Amphiura koreae (fig. 8h, i) I am not altogether convinced that Matsumoto was right in synonymizing with it Amphiura diomediae Lütken \& Mortensen (I899) (typelocality in the East Pacific) despite the considerable variation also reported by Lütken and Mortensen. Not only is the oral structure of the holotype of $A$. koreae inconsistent with its inclusion in Amphiura, the second oral papilla being entirely on the side of the oral plate, but also the oral plates themselves are relatively short, leaving only a very small diastema between the infradental and second papillae, the arm spines are tapering but slightly blunted at the tips and the two tentacle scales (fig. 8i) are distinctly larger than in any of the specimens which I have seen with oral structure like the holotype of diomediae (see Lütken and Mortensen's pl. I2 figs. I, 2), including two paratypes. It also seems to me that in "typical" diomediae not only are the arm spines sharper, the tentacle scales smaller and the oral diastemas longer, but also the disc is smoother with flatter scales showing little change of size at the marginal junction, while the other surface plates are also thinner. At least some of the differential characters shown by the holotype of $A$. koreae are shared by Lütken and Mortensen's unnamed variety of diomediae (I899, pl. I2, figs. 5-7), namely the shorter oral plates and the more marked size change between dorsal and ventral disc scales. Koehler's specimen (I922, pl. 67, fig. 9) from the Philippines shares at least the second of these characters besides having thicker, and incidently less imbricating, disc scales in the centre. The specimens from the Maldive area (John Murray Expedition station I43) recorded as diomediae by H. L. Clark in I939 also have thickish disc scales, coarser slightly blunted arm spines and the second oral papilla based entirely on the oral plate though the plate itself is relatively longer and the diastema larger than in the holotype of $A$. koreae. The other Murray Expedition specimens, from off the Arabian coast, are more like the holotype of diomediae with longer oral plates, sharper spines and smoother discs. I am inclined to think that there are two forms intergrading to some extent but it will need some much larger samples (particularly from Japan) than are available to me at present to investigate this. Unfortunately these two forms together bridge the borderline between Amphiura and Amphioplus, the holotypes of diomediae and koreae respectively agreeing in 
their oral structures with the accepted diagnoses of the two genera-Amphiura with a large diastema and one or sometimes two distal oral papillae besides the infradental one, as opposed to Amphioplus with a more or less continuous series of four or sometimes three papillae, in each case with the addition of the oral tentacle scale. This emphasizes the close relationship between the two genera. Since none of the other specimens seen by me or figured by others shows either such a small diastema or such large tentacle scales as the holotype of $A$. koreae, I propose to term all of them Amphiura diomediae. [As remarked opposite there is also a possibility that $A$. diomediae is conspecific with Amphiura caulleryi Koehler, I897.] The best generic position for specimens with the oral structure of the holotype of $A$. koreae is discussed further on pp. 43-44.

The great geographical range of Amphiura diomediae suggests that some of the other deep-sea nominal species in the list above may prove to be synonymous, for instance Amphioplus daleus, patulus and cernuus, despite the wide separation of their type-localities.

As I mentioned in I965, the "Challenger" specimens from station I9I (fig. 8e) named Amphiura concolor by Lyman are not conspecific with the holotype but are more closely related to Amphioplus confinis (Koehler, I904), differing in having much thinner scales on the disc though the mouth parts are rather similar ; two jaws out of five of the specimen figured have irregular and multiple papillae at the apex but the other three are undeniably amphiurid in form. A similar irregularity often occurs in Amphiodia affinis, not only in the apical papillae but also in the more distal ones. The usual arrangement of these is shown in fig. $5 \mathrm{j}$, with the two more distal papillae in series with, though slightly spaced from, the infradental and the third one not quite contacting the adoral shield. However, this is not always the case and there may be a fourth papilla present, also the apical arrangement varies widely, the lowest tooth is often distinctly conical, which provides some justification for Hertz's inclusion (I927) of the species in the genus Amphiactis, though the blunt apex of the jaw itself precludes this, while the infradental papillae vary in their spacing and size. An unusual feature is that the oral tentacle scale may be duplicated with two papillae arranged obliquely. [This contrasts with the duplication I have also seen in occasional specimens of species such as Amphiura diomediae in which the oral tentacle scale is considerably broadened horizontally and can be split into two parts, only the innermost being at all papilliform.] In fact Amphiodia affinis was included in Amphioplus by Koehler (I9I7) but transferred to Amphiodia by Mortensen (I936) followed by Madsen (I955). It is a very anomalous species with its very thick disc scales, convex disc, widely-separated radial shields and very short arms tapering abruptly at the tip to a large conical terminal plate and I can understand Studer's reference of a small specimen to the genus Ophioceramis (family Ophiuridae) ; only the jaw armament resembles that of amphiurids, especially those from deep water in which the apical structure is similarly somewhat variable. I suspect that a more detailed study of the species will lead to its inclusion in a genus distinct from Amphioplus but it certainly cannot be left in Amphiodia.

Notes on the type-material of Amphioplus confinis and some other interesting 'Siboga' species of Koehler are given on pp. $5^{8}$ to 66 at the end of the section on 
Amphioplus together with a description of a new genus and species based on a specimen in the Museum of Comparative Zoology, Harvard which Lütken \& Mortensen (I899) misidentified as Amphiura (i.e. Amphioplus) dalea.

There are two species in the list which are fairly remote from Silax verrilli and stand apart from the others by the symmetrical pairing of their two distal oral papillae and their isolation from the infradental one. Firstly Amphiura lunaris (fig. $8 \mathrm{v}, \mathrm{w}$ ), of which the holotype (d.d. only $3.5 \mathrm{~mm}$.) has two, sometimes one, distal oral papillae close together on the edge of the adoral shield and an almost superficial flange on each oral plate, the edge of which is indistinctly subdivided in rather the same way as that of Amphilepis patens (fig. 8c) ; however, the apex of the jaw is broadly truncated with wide rounded teeth and the infradental papillae are not at all divergent, unlike those of Amphilepis. The consecutive dorsal arm plates are not contiguous but this is common to a number of deep-water amphiurids. A better range of material is needed to show the true affinities of the species. Secondly Amphiura bidentata (fig. 8u), a shallow-water species, has a rather smaller diastema between the infradental and the two distal oral papillae, both of which are based on the more superficial part of the oral plate, not on the edge of the adoral. These two species are not closely related to each other but it seems best to leave both of them in Amphiura. The same may be true of Amphiura caulleryi (referred to Amphiodia by H. L. Clark in I9I5), judging from Koehler's figure which shows a large diastema between the infradental and the pair of distal papillae situated on the adoral " dans l'angle buccal " " recouvrent de chaque côté l'orifice du pore tentaculaire buccal " according to Koehler. In spite of the presence of the first oral tentacle scale on the side of each oral plate, Koehler (I930) follows H. L. Clark in including the species in Amphiodia. Until the type-material can be re-examined, the true position of the species cannot be determined though it probably belongs to Amphiura, possibly to Amphioplus, but certainly not to Amphiodia. Koehler's early figures were very diagrammatic and it may be noted that his illustration of Amphiura reposita (I905, pl. 4, fig. I3) similarly shows the inner of the two distal papillae as based entirely on the adoral shield whereas in fact it is more often entirely on the oral plate in the holotype and never more than partially in contact with the adoral (see my fig 8m). However, it should be noted that Koehler in I904 referred Amphiura caulleryi to the Amphioplus section and simultaneously identified a specimen as Amphiura diomediae, referring that species to the Amphiodia section. Were it not for this, I would have thought that caulleryi and diomediae could be synonymous, judging from Koehler's description of 1897 ; the type-locality of caulleryi is in the region of Ceylon and diomediae has been taken in the Maldive area nearby. A solution of the problem must await a re-examination of the holotype of $A$. caulleryi .

Although the diastema in the papilla series of the holotype of Amphiura concolor is hardly more conspicuous than that of species such as Amphioplus gentilis and incisus and the second papilla arises wholly from the oral plate, I am inclined to leave concolor in the genus Amphiura, unlike the second specimen referred to the species by Lyman (fig. 8e), which is certainly congeneric with Amphioplus falcatus. The problem is even more questionable when it comes to the holotype of Amphiura koreae. Strictly speaking, this specimen cannot be regarded as an Amphiura, the 
diastema being so small ; its affinities appear to be all with species such as Amphioplus daleus, as far as oral structure goes. However, in view of its other close relationship and even possible identity with Amphiura diomediae, it would be irresponsible to refer it to a different genus than Amphiura, at least until a more detailed study can be made of large samples from Japanese waters.

It remains to determine the best generic position for the rest of the species in the list above, excluding those just named as better retained in Amphiura and the three first species, Amphilepis patens, Ophiomonas bathybia and O. protecta at the top. Amphiodia can be ruled out to start with because of the presence of the first oral tentacle scale. This leaves Unioplus Fell, Amphichilus Matsumoto, Amphioplus or Amphiura.

The type-species of Unioplus is Amphioplus falcatus Mortensen, I933a, from moderately deep water (c. 400 metres) off SE Africa. It has the oral tentacle scale more or less superficial and in series with the true oral papillae, which number three more often than four. A paratype of $A$. falcatus in the British Museum collections shows the considerable variation described by Mortensen in the number and arrangement of the papillae and also has a third infradental papilla between the usual two on three of the five jaws. About half of the papilla series have four papillae plus the oral tentacle scale, the formula being $\mathrm{m},(\mathrm{m}=\mathrm{t}) \mathrm{m}, \mathrm{mm}$ but in the rest it is $\mathrm{m},(\mathrm{m}=\mathrm{t}) \mathrm{m}, \mathrm{m}$ with minor variations in the precise position of the distal papillae and the vertical alignment of the scale. The dorsal arm plates are barely contiguous but not so markedly separated as in the deep-water species such as $A$. daleus; also the single tentacle scale extends for almost the entire length of the arm and is not restricted to a few basal segments. The last character distinguishes falcatus from cernuus and patulus which Fell refers to Unioplus since both have been described as having a single tentacle scale. Amphioplus daleus he omitted since it had been referred by Matsumoto to Amphichilus, an interesting taxon intermediate between Amphiura and Amphioplus (at least as regards oral armament), which was unfortunately not taken into consideration in Fell's revision.

There is some affinity between these three nominal species of Lyman (daleus, cernuus and patulus) and $A$. falcatus but the same cannot be said of most of the other species which Fell has referred to Unioplus. At least four of them, Amphioplus strongyloplax (H. L. Clark, I9II), A. thrombodes (H. L. Clark, I9I8) A. philohelminthius Ziesenhenne, I940 and A. glaucus (Lyman, I879) differ from falcatus in having bare skin with only scattered scales over part or all of the ventral side of the disc (according to Fell's system thereby justifying further subdivision) and the first two, together with A. macraspis (H. L. Clark, I9II), also disagree with the diagnosis of Unioplus in having two tentacle scales on some of the proximal pores rather than one. They differ too in having the oral tentacle scale higher in the slit and usually four oral papillae (though in strongyloplax and macraspis the fourth or outermost rather than the second papilla may be lacking.) Of the other species referred to Unioplus, Amphioplus formatus (Koehler, I905) (fig. Ira, and see pp. 6I-62) is probably not an Amphiurid at all ; the holotype and only recorded specimen has very narrow elongated teeth and the two innermost papillae of each jaw are offset to the sides of the lowest tooth, though they each form a straight series of four with the other oral papillae, the distalmost of which is the broadest ; the formula is $n, n m m, M-t$. The 
oral shields are relatively very small and almost circular and the adorals are comparatively large and very broadly contiguous inwardly. Tentacle scales are lacking altogether on the first four to seven segments. The arms are only about three times the disc diameter and the arm spines are extremely long, even exceeding the width of the arm. The holotype of Amphioplus capax (Koehler, I905) has d.d. only I.5 $\mathrm{mm}$. and was very decalcified when I saw it recently ; most of its characters are juvenile ones but Koehler figures four oral papillae in a straight row and unusually elongated oral shields. The type of Amphioplus aciculatus Mortensen, I936 is also small, d.d. $2 \mathrm{~mm}$. ; its oral formula is $\mathrm{m}, \mathrm{om}, \mathrm{mm}+\mathrm{t}$ and the inner one of the two distal papillae is spiniform. The holotype of Amphioplus dispar (Koehler, I897) also has the second from outermost papilla spiniform but otherwise shows no particular resemblance to aciculatus.

With the possible exception of $A$. daleus and its two allies and $A$. falcatus, there appears to me to be no particular affinity between any of these species and I do not consider that Unioplus can be maintained on the basis of the single tentacle scale alone. However, it may be worth redefining in terms of the oral structure for some of the species in the list on pp. 37-39. Even so, the oral structure is liable to confusion with that of Amphichilus, which also has only three oral papillae, though in the typespecies, Amphichilus trichoides Matsumoto, I9I7, the tentacle scale is distinctly higher in the oral slit and the formula is better expressed as $m$,on,nm, $+t$ than as $\mathrm{m},(\mathrm{m}=\mathrm{t}) \overparen{n, n m}$, as in Amphioplus falcatus. The radial shields of Amphichilus trichoides are almost fully contiguous, unlike those of most of the other species under consideration ; Matsumoto included this in his generic diagnosis. He also referred Amphioplus daleus (Lyman, I879) as well as A. intermedius (Koehler, I905) to Amphichilus. I do not consider A.daleus is closely related to Amphichilus trichoides; apart from being a deep-sea species it has separated or barely contiguous radial shields, non-contiguous dorsal arm plates, no tentacle scales (except a single one on a few of the basal pores) and irregular apical oral papillae on some jaws. In the holotype of Amphioplus intermedius I found the second papilla to be perfectly in series with the other three, the four oral papillae closing the slit so well that it is impossible to tell without mutilation if the oral tentacle scale is also present behind the papillae ; the general appearance of the jaws agrees well with that of Amphioplus impressus (Ljungman, I867b), unlike Amphichilus trichoides.

Koehler (I930) has referred Amphioplus cesareus (Koehler, I905) to Amphichilus with some justification ; it has almost fully contiguous radial shields and comes from relatively shallow water, usually 5 -IO0 metres ; in one of the two syntypes in the Amsterdam Museum the second oral papilla is slightly inset in some series and with its conical rather than square shape is clearly homologous with the oral tentacle scale which is otherwise missing. However, after comparison of specimens named both Amphiura cesarea (or Amphichilus cesareus) and Amphioplus impressus by Koehler at different times (see pp. 63-64) with the same author's description and figures of the type-material of $A$. impressus, I have come to the conclusion that cesarea is a synonym of impressus. The normal position of the second oral papilla in the species is superficial (fig. 9m) and, like A. intermedius, I do not think that it can be referred to Amphichilus. These two species differ most obviously from one another in the much finer 
disc scaling of intermedius; together they form a link between Amphichilus and Amphioplus sensu stricto as well as between the latter and Amphipholis, from which only the presence of a fourth oral papilla distinguishes them, the outermost papilla approximating to an opercular form. However, I believe that Amphiodia ochroleuca (Brock, I888) (fig. 8t) can be referred to Amphichilus ; it is another shallowwater Indo-West Pacific species and cannot be left in Amphiodia since it has the first oral tentacle scale present ; this scale is distinctly higher than the oral papillae, of which the two outer ones are fairly broad and rectangular. Like A. trichoides the radial shields are contiguous, though in some specimens only for their distal halves.

In contrast, all the other species under consideration, like Amphioplus falcatus, have the radial shields only contiguous by their distal adradial corners or else separated altogether. Apart from the single antiboreal species Amphiodia affinis (Studer, I885), which ranges in depth from shallow-water to several hundred metres, and with the exception of Amphiodia reposita (Koehler, I905) and Amphioplus conditus (Koehler, I905), all these are from deep-water (400+ metres, many of them rooo + metres). [By coincidence, the type- and only recorded specimens of the two latter species were labelled as coming from "Siboga " station 89, the depth of which was only II metres ; it seems suspicious that they have not since been collected

FIG. 9. Amphioplus spp. (except t). a. A. tumidus (Lyman), M.C.Z. I476, holotype, "Blake" st. 47, Gulf of Mexico ; b. A. strongyloplax (H. L. Clark), U.S.N.M. 256r5, holotype, off Washington; c. A. cyrtacanthus H. L. Clark, M.C.Z. I489, holotype, Philippine Is.; d and e. A.coniortodes H.L.Clark, M.C.Z. 421 7, holotype, Key West, Florida, the disc shrunk away from the arm base ; $\mathrm{f}-\mathrm{i}$. A abditus (Verrill), showing the exceptional variation in the oral papillae and oral tentacle scale, f. B.M. 90.8.23.43, Martha's Vineyard (the oral shield shown is the madreporite), an oral tentacle scale occurs on one side in addition to the second oral papilla (the two oral tentacles are also shown on this side), g. U.S.N.M. I8007, holotype of $A$. macilentus (Verrill), a synonym, off New England, with five superficial papillae one side and four the other, h. M.C.Z. I456, Noank, Connecticut, with no second papilla but the oral tentacle scale more or less superficial, i. M.C.Z. 4842, Charleston, South Carolina, with superficial second papilla presumably representing the oral tentacle scale though rounded in shape and with an interstitial papilla between third and fourth on one side (and in five other series) ; j and k. A. stenaspis H. L. Clark, M.C.Z. 499o, holotype, near Darwin ; l and m. A impressus (Ljungman), U.S.N.M. 4I I 7I, "Albatross" st. 537I, Philippine Is. ; n. A. archeri A.M. Clark, B.M. I956.5.23.I, paratype, Ghana ; o. A. cinctus (Koehler), B.M. 1956.5.23.2I, off Accra, Ghana, the two middle papillae of the left-hand series reflexed; p and q. A. (Lymanella) hastatus (Ljungman), p. Amsterdam Museum, "Siboga " st. I67, W of New Guinea, " absolument conforme à l'exemplaire type de Ljungman" (Koehler), q. B.M. 1948.5.26.92, John Murray Expedition st. 89, northern Arabian Sea (d.d. only $3.5 \mathrm{~mm}$.), the three distal oral papillae removed on one side to show the rudimentary oral tentacle scale ; r. A. (Lymanella) megapomus H. L. Clark, U.S.N.M. 25633, holotype, "Albatross" st. 4964, Japan ; s. A. (Lymanella) laevis (Lyman), M.C.Z. 559o, syntype of A. praestans (Koehler), "Siboga " st. II, Java Sea ; t. Paracrocnida persica Mortensen, B.M. I964.7.I7.26, Eilat, Gulf of Akaba ; u. Amphioplus (Lymanella) depressus (Ljungman), Amsterdam Museum, "Siboga" st. 5I, Molo Strait, E Indies (named Amphiura relicta by Koehler, 1905), edge of disc from above ; v. A. (Lymanella) spinulosus (Koehler), Amsterdam Museum, paratype, "Siboga" st. 319 (not in published report but added MS to Amsterdam Museum copy), Java Sea, edge of disc from below ; w. A. (Lymanella) laevis (Lyman, M.C.Z., holotype, third dorsal arm plate (from drawing by Miss A. Schoener) ; x. $A$. (Lymanella) megapomus H. L. Clark, holotype (as above). 

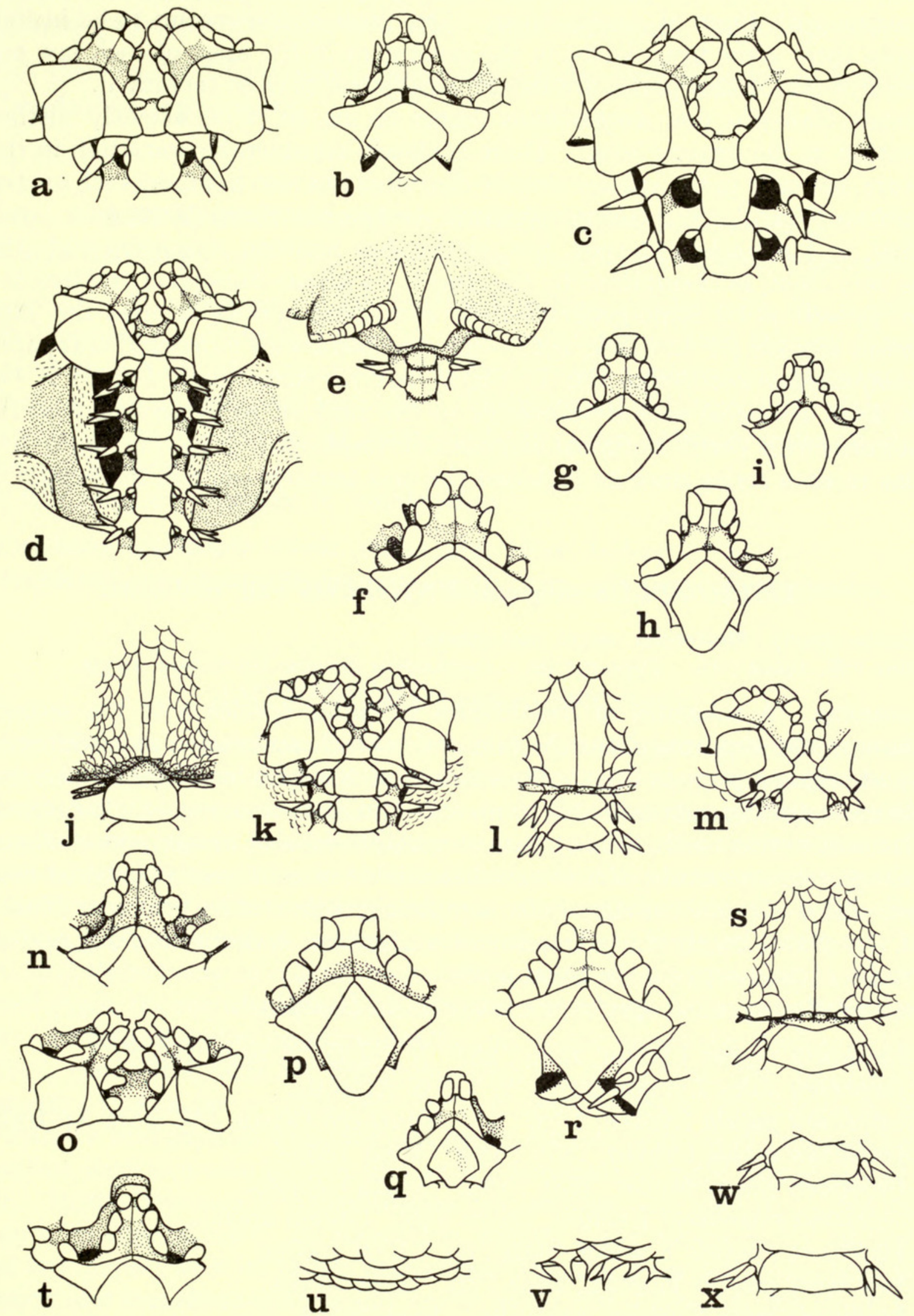
if this was true.] It is possible therefore to redefine Unioplus in terms of the $3 \mathrm{~m}+\mathrm{t}$ formula (often with $t=m$ ) coupled with the divergent or separated radial shields contrasting with those of Amphichilus. Also most of the species to be included in Unioplus show some irregularity in the armament of the apex of each jaw and the consecutive dorsal arm plates are barely contiguous or even separated.

Neither Unioplus nor Amphichilus seems to me to be sufficiently distinct for recognition at the generic level. There is clearly considerable variation in the oral structure, not only in the species already discussed but also in others such as Amphioplus abditus (Verrill, I87I) (see fig. $9 \mathrm{f}-\mathrm{i}$ ) and Amphioplus timsae Mortensen, I926. In addition, as I remarked in I965, the relationship between Amphiura and Amphioplus is very close, as exemplified by the Amphiura koreae-diomediae problem detailed above, as well as by some geographically coincident species such as the Japanese Amphiura digitula (H. L. Clark, I9II) - an Amphiura with two distal oral papillaeand Amphioplus ancistrotus (H. L. Clark, I9II). Accordingly I think it best to reduce both Unioplus and Amphichilus to the rank of subgenera of Amphioplus. This accords with Verrill's original diagnosis of Amphioplus as having four or five oral papillae in each series since he included the oral tentacle scale in his papilla count.

\section{AMPHIOPLUS subgenus UNIOPLUS Fell, re-defined}

Amphioplus (part) : Mortensen, 1933a, and others.

Unioplus Fell, r962a : r6. Type-species : Amphioplus falcatus Mortensen, I933a.

Diagnosis. A subgenus of Amphioplus including species with the second oral papilla normally suppressed but the first oral tentacle scale often more or less superficial and taking a place in the papilla series after the infradental papilla, so that the oral formula usually approximates to $\mathrm{m},(\mathrm{m}=\mathrm{t}) \mathrm{m}, \mathrm{m}$ or $\mathrm{m}, \mathrm{om}, \mathrm{m}+\mathrm{t}$; the infradental papillae and lowest tooth usually rather variable in size, shape and arrangement, sometimes asymmetrical ; the two radial shields of each pair either just touching by their distal adradial corners or else completely separated by the scales ; successive dorsal arm plates barely if at all contiguous ; tentacle scales numbering one or two, sometimes none except on the basal pores.

The following nominal species are referable to Unioplus ${ }^{1}$ :

Amphiura cernua Lyman, I879:28. N Pacific, E from Japan.

Amphiura dalea Lyman, I879:27. SW Atlantic.

Amphiura patula Lyman, I879:3I. Southern Ocean, SW from Australia.

Amphiura incisa Lyman, I883:250. West Indies.

Amphiura affinis Studer, I885 : I62. South Georgia.

? Amphiura caulleryi Koehler, I897 : 330. Ceylon area.

Amphiura confinis Koehler, I904: 89. East Indies.

Amphiura gentilis Koehler, I904 : 86. East Indies.

Amphiura grata Koehler, I904: 85. East Indies.

Amphiura servata Koehler, I904 : 84. East Indies.

1 In original combination, chronological order and with type-localities. 
Amphiura condita Koehler, I905: 46. East Indies.

Amphiura reposita Koehler, I905: 40. East Indies.

Amphiura falcatus Mortensen, I933a : 365. SE Africa. Type-species.

Of all these, only Amphioplus cernuus and patulus were included in Unioplus by Fell, besides the type-species.

\section{AMPHIOPLUS subgenus AMPHICHILUS Matsumoto}

Amphichilus Matsumoto, I9I7 : I75. Type-species : Amphichilus trichoides Matsumoto, I9I7.

Diagnosis. A subgenus of Amphioplus including species with the second oral papilla suppressed and the first oral tentacle scale inset, so that the oral formula is $\mathrm{m}, \mathrm{m}, \mathrm{m}+\mathrm{t}$ or $\mathrm{m}, \widetilde{\mathrm{n}, \mathrm{n} m}+\mathrm{t}$; armament of jaws normally symmetrical ; the two radial shields of each pair contiguous for at least the distal half of their length, often more ; dorsal arm plates contiguous, at least medially; two tentacle scales in the two species now included.

The following are referable to Amphichilus :

Amphiura ochroleuca Brock, I888: 484. East Indies.

Amphichilus trichoides Matsumoto, I9I7 : I75. Japan. Type-species.

\section{AMPHIOPLUS sensu extenso (cont.)}

As for Ailsaria, apart from the type-species, Amphioplus echinulatus Mortensen, I940, Fell refers to it Amphioplus archeri A. M. Clark, I955, A. coniortodes (H. L. Clark, I9I8) and $A$. personatus (Koehler, I905). Of these, Amphioplus archeri is not at all closely related to echinulatus ; its radial shields are short, wide and fully contiguous, rather than elongated and more than half separated proximally and the oral shields too are quite a different shape ; the oral formula (from Mortensen's figure) is $\mathrm{m}, \mathrm{on}, \mathrm{nm} m+\mathrm{t}$ in $A$. echinulatus but normally $\mathrm{m}, \mathrm{mm}, \mathrm{on}, \mathrm{n}-\mathrm{t}$ in $A$. archeri (figs. Ii, 9n), there being no oral tentacle scale on most jaws and a distal rather than proximal gap in the sequence of papillae; the arm structure is also very different in $A$. archeri. In Amphioplus coniortodes(fig. 9d, e) the dorsal disc scaling is fine and indistinct, the oral shields are triangular with no distal lobe, the oral formula is $\mathrm{m}, \mathrm{omm}, \mathrm{om}+\mathrm{t}$ or $\mathrm{m},(\mathrm{m}=\mathrm{t}) \mathrm{mm}, \mathrm{om}$, the oral tentacle scale being more or less in series with the oral papillae while the arm spines are simple at the tip, numbering only three rather than five with hooked tips, as in echinulatus, or eight proximally as in $A$. archeri. In the holotype of Amphioplus personatus, (see also pp. 64-65) the oral formula is $m, o m n, n n, n+t$, the distalmost papilla being based partly on the first ventral arm plate ; with its rather similar oral formula, divergent radial shields, five arm spines and spearhead-shaped oral shields with a distal lobe (though this is a little wider than it appears in Koehler's figure) A. personatus may prove to be closely related to $A$. echinulatus (both of them are from the Indo-West Pacific) but it does not agree with the two Atlantic species, archeri and coniortodes. Because of its oral 
structure, I think A. archeri is more closely related to Amphioplus cinctus (Koehler, I9I4) (fig. 9o) which has the disc fully scaled below, while Amphioplus echinulatus shows a parallel affinity for the fully-scaled A.timsae Mortensen, I926.

These observations lead me to the conclusion that the following is not a valid taxon of the genus-group and should be referred to the synonymy of Amphioplus Verrill, I899:

Ailsaria Fell, (type-species Amphioplus echimulatus Mortensen, I940).

As I noted in I965, among the many species of Amphioplus with two tentacle scales, a natural group exists which differs from the type-species, A. tumidus (Lyman, I878) (fig. 9a) in having the four oral papillae in a continuous row, their free edges forming a straight line so that they are capable of closing the oral slit almost completely, the third papilla being distinctly enlarged, often truncated conical in shape, while the oral tentacle scale is rudimentary and concealed behind the papillae, if present at all ; at the same time the radial shields are contiguous for more than half their length, there are only three arm spines and the two tentacle scales are large or very large, also there is often some specialization of the disc scales in the marginal region at the line of junction of the dorsal and ventral scales.

The most frequently recorded species of this group are probably Amphioplus depressus, integer and hastatus (fig. 9p, q), all described (as Amphipholis) by Ljungman, I867b, also Amphioplus laevis (Lyman, I874), relictus (Koehler, I898) and japonicus (Matsumoto, I9I5).

H. L. Clark (IgI8) first referred japonicus to the genus Amphioplus, protesting that it has no true articulated marginal papillae and four rather than three oral papillae, unlike Ophiophragmus wurdemanni Lyman, the West Indian type-species of Ophiophragmus, which up to that time had never been properly figured. However Matsumoto (I94I) persisted in including japonicus in Ophiophragmus, Koehler (I930) and Murakami (I943 and I944) following the same practice, though in I963 Murakami uses the generic name Amphioplus ; Matsumoto's grounds for this were that japonicus is distinguished from Amphioplus by the absence of the first oral tentacle scale. I have seen a number of specimens of japonicus but have not observed this scale in any of them; however, I have found it, at least in rudimentary form, on some oral plates of certain individuals of Amphioplus hastatus, A. laevis and particularly $A$. integer, all of which but especially the first are closely related to japonicus. The marginal "fence" on the disc of A. japonicus consists of the enlarged scales of the outermost dorsal row bordered by the up-turned scales of the uppermost ventral row which in young specimens Matsumoto found to be sufficiently prominent to form a "hem-like row of denticles" so that the disc edge is serrated. Comparable modifications of the marginal scales have also been recorded in A. furcatus (Mortensen, I933a), in $A$. hastatus by Mortensen, I940, in $A$. gibbosus (Ljungman, I867b) and in $A$. affinis (Duncan, I887) ; also in $A$. relictus (by Koehler in I922(a) though I believe that he confused relictus and japonicus in this work), while in A. spinulosus (Koehler, I904) (fig. 9v) even greater modification occurs. Not all individuals of japonicus show the marginal "fence" or flange and Mortensen (I940) notes that marginal thorns may be present or absent in hastatus in the Persian Gulf, so their occurrence is not diagnostic. 
In amphiurids such as Amphioplus with numerous oral papillae there is often considerable variation in the arrangement of the papillae and their relationship with the first oral tentacle scale. It should not be forgotten that the two distalmost oral papillae of Amphioplus are homologous with the scales of the second oral tentacle, as indeed Verrill (I899) termed than in his diagnosis of Amphioplus. It is then more understandable that the first oral tentacle scale can be transformed into an oral papilla by shifting to a superficial position, as already described in species such as $A$. falcatus or alternatively more or less suppressed at the expense of the oral papillae as in the group of species now under discussion.

In fact a straight row of four oral papillae with no visible oral tentacle scale is not restricted to the species of the hastatus-group, being shared notably by Amphioplus impressus (Ljungman, I867b) (fig. 9m), intermedius (Koehler, I905) and aurensis A. M. Clark, I955. These also have contiguous radial shields and only three arm spines but are distinguished from the hastatus-group by the smaller size of the two tentacle scales and the enlarged fourth rather than third oral papilla.

In A. stenaspis H. L. Clark, I938 (fig. 9j, k) and A. iuxtus Murakami, I943, also the oral papillae are in a straight row and at the same time the tentacle scales are very large, but both species have more than three arm spines proximally and their radial shields are separated or only contiguous for less than half their lengths, also in A. stenaspis at least the oral tentacle scale is present and visible above the oral papillae.

Amphioplus causatus and exsecratus (Koehler, I905), as well as A. cinctus (Koehler, I9I4) and ailsaclarki Cherbonnier, I957 (if the last two are distinct) resemble hastatus in the oral structure even to the extent of having the third oral papilla the largest ; they also have fairly large tentacle scales and, with the possible exception of exsecratus, the radial shields largely contiguous (though for only about half their length in causatus). However, causatus has four arm spines proximally and the others often have five ; even so it might be better to ally cinctus (and ailsaclarki) with the hastatus-group by setting aside the distinction of arm spine number ; although most specimens studied appear to have the oral papillae in a concave row, this is largely an illusion caused by the extension of the second oral tentacle and the erection of the third and fourth papillae to the vertical position.

There are of course several other species of Amphioplus with only three arm spines or with two more or less enlarged tentacle scales, sometimes both together.

Clearly none of these characters is restricted to the species of the hastatus-group, although they combine to distinguish it. Accordingly the limits are not sharply defined and I consider that the group merits only the rank of a subgenus.

\section{AMPHIOPLUS subgenus LYMANELLA nov.}

Type-SPECIEs. Amphipholis hastata Ljungman, I867b. [See Koehler, I927a, pl. 3 , figs. 2 and 3 for photographs of the holotype.]

Diagnosis. A subgenus of Amphioplus in which the four oral papillae are arranged in a continuous row with their free edges (when aligned horizontally) forming a 
straight line, so that they can almost completely close the oral slit, the third papilla being more or less distinctly enlarged so that the formula is $\mathrm{m}, \mathrm{mN}, \mathrm{Nm}+1-\mathrm{t} ; 1$ the radial shields are contiguous for over half their lengths; the two tentacle scales are large or very large, more or less completely covering the corresponding pores and the arm spines number not more than three. In some of the species the uppermost ventral row of disc scales (which usually comes just above the margin in preserved specimens) may project in a flange or else have small thorny prolongations of the scales ; rarely (A.spinulosus) the thorns are larger, rather like those of the subgenus Amphispina of Amphiodia but are still extensions of the scales and not articulated.

The following nominal species are referable to Lymanella ${ }^{2}$ :

Amphipholis hastata Ljungman, I867b : 313. Mozambique.

Amphipholis depressa Ljungman, I867b : 3I2. Java-Singapore.

Amphipholis integra Ljungman, I867b : 313. Port Natal.

Ophiophragmus gibbosus Ljungman, I867b : 3I6. Port Natal.

Amphipholis andreae Lütken, 1872: Io6. Java.

Amphiura laevis Lyman, I874 : 229. Philippine Is.

Amphiura congensis Studer, I882 : I9. Congo, West Africa.

Ophiophragmus affinis Duncan, I887: 89. Mergui Archipelago, Burma.

Amphiura relicta Koehler, I898: 69. Bay of Bengal.

Amphiura (Amphioplus) spinulosa Koehler, I904: 92. Lesser Sunda Is.

Amphiura (Amphioplus) praestans Koehler, I905: 52. Lesser Sunda Is.

Amphioplus megapomus H. L. Clark, IgII : I7o. Southern Japan.

Ophiophragmus japonicus Matsumoto, I9I5 : 70, with var. parvus Matsumoto, I94I : 334. Japan.

Amphioplus bocki Koehler, I927b : 6. Fiji.

Amphioplus potens Koehler, I930: 107. Kei Is.

Amphioplus furcatus Mortensen, I933a : 370. Natal.

Amphioplus caelatus Ely, I942 : 39. Hawaiian Is.

Amphioplus miyadii Murakami, I943: 227. Southern Japan.

Of these eighteen names, several have already been relegated to the synonymy of others and I think that when a proper appreciation is reached of the extent of variation, especially of the disc in relation to growth and regeneration, the total number of species recognized will be less than half that number.

Mortensen (I940) considers that $A$. furcatus is a synonym of $A$. hastatus, which he found in abundance in the Persian Gulf, although the type-material of furcatus appears to me to have relatively finer and more numerous disc scales than is usual in hastatus of the same size.

At the same time Mortensen notes that Amphioplus bocki could be a synonym of A. laevis. However, since Lyman published only very poor figures of the

1 In preserved specimens the third oral papilla particularly may be found projecting outwards so that the small, V-shaped gap between its tip and that of the fourth papilla, through which the second oral tentacle may be seen, is considerably widened. This is the case in the holotype of $A$. bocki Koehler, I927b for instance.

${ }_{2}$ With original combinations, in chronological order and with type-localities. 
holotype of $A$. laevis, this is uncertain. Unfortunately I omitted to study the holotype when visiting the Museum of Comparative Zoology, Harvard, but Miss Amy Schoener tells me that it is in poor condition with only a few damaged basal segments of the arms left attached to the disc. Her drawing of an arm base (fig. 9w) shows rather irregular dorsal arm plates with some suggestion of a median angle in their distal sides but with the broadest part of the plate towards the proximal end which is unusual. The specimen figures by Mortensen (I940) under the name of laevis has distinct median distal angles to the dorsal arm plates but the broadest part of each plate is near the distal end. This is just the shape figured by Koehler from a syntype of Amphioplus praestans and found also in another syntype in the Harvard Museum (fig. 9s), although some of the smaller " Siboga " specimens in the Amsterdam Museum have little sign of a median distal angle to these plates. In some ways it might be best to reject the name laevis on the grounds of the almost unrecognizable condition of the holotype but the name has been widely used in recent years for the species figured by Mortensen. Koehler (I905) referred two small "Siboga " specimens (d.d. c. $5 \mathrm{~mm}$.) to laevis at the same time that he described praestans and these two have particularly narrow radial shields, length : breadth $=3 \cdot 5-3.75:$ I $(4:$ I in the holotype according to Lyman), while their oral shields are relatively broad, though still longer than broad. Nevertheless I do not think that either is beyond the range of variation of a single species, nor is the slight difference in the shape of the dorsal arm plates compared with the holotype significant. There are specimens in the British Museum collections from the Red Sea, New Guinea and the Solomon Islands which agree with the type-material of praestans and at the same time with Lyman's description of laevis in having the disc flat and usually thin and more or less sharp at the edge, the scales and plates thin and the spines slender. The distinctive light line along the arms mentioned by Lyman is an illusion caused by the thinness and semitransparency of the arm plates, allowing the mid-line of the vertebrae to show through. Unfortunately most of the specimens studied have the arms more or less badly broken, except for some from the Solomon Islands in which the arm length is about ten times the d.d. This compares with a proportion of I3-I4 : I for the type-material of $A$. bocki. However, I am inclined to think that Mortensen may be right in referring bocki to the synonymy of laevis. Even so, it should be noted that Koehler describes the arm spines of bocki as blunt-tipped whereas in all the specimens I regard as referable to $A$. laevis the slender spines are more or less sharp.

Matsumoto (I94I) thinks that Amphioplus megapomus is allied to his variety parvus of japonicus but, as noted in I965. I doubt this since the discless holotype of megapomus (fig. 9x) is another specimen with a median distal angle on each dorsal arm plate, differing in this from japonicus. H. L. Clark in I9I5 recorded four smaller Japanese specimens as megapomus, noting that their radial shields are relatively short. However, he also notes that their arm plates show some differences from those of the types and it is possible that they were not conspecific in view of the number of other nominal species of Lymanella recorded from Japan. If the identification was correct and the radial shields are short in megapomus then it is very close to $A$. andreae, but if long then the affinity is with laevis again, or with Amphioplus miyadii, if that is itself distinct from laevis. 
H. L. Clark (I9I8) and Koehler (I922a) both note that Amphioplus affinis (Duncan) is a homonym of $A$. affinis (Studer, I885) (though Mortensen in I936 and Madsen in I955 put affinis Studer in Amphiodia) and that Duncan's material was probably conspecific with $A$. relictus. However, the Kagoshima specimens figured by Koehler in I922(a) (pl. 7I, figs. 7 and 8) named by him Amphioplus relictus appear to be conspecific with A. japonicus of which Kagoshima is the type-locality. Koehler's earlier specimens from the Indian Ocean which he named relictus at least may be distinguishable from japonicus by the longer distal lobes of their oral shields (though the shape of these is variable in many of the species of Lymanella) but his figures are so diagrammatic that this is not certain. In I930 he recorded Ophiophragmus japonicus from the Gulf of Siam and Amboina, thus extending the range well beyond Japan, though simultaneously he recorded other specimens from these same areas as Amphioplus relictus. H. L. Clark (I946) refers relictus to the synonymy of depressus, which seems to me well justified. I am even doubtful whether depressus and japonicus can be distinguished from hastatus. All of them have relatively broad radial shields, opaque scales and plates, no marked median distal angle to the dorsal arm plates and often more or less specialized marginal scales (fig. 9u). The distinction of Amphioplus hastatus from the others by its prominent primary rosette is not reliable because of the likelihood of loss and regeneration, in which case the rosette is probably not reformed. Mortensen (I940) records a number of discless specimens and assumes that the loss was incurred during capture since there is no sign of regeneration. However, I suggest that natural loss may occur during the breeding season when the disc is liable to be distended but this remains to be investigated. The considerable length of the distal lobe of the oral shields (fig. 9p) is also supposed to distinguish hastatus. Certainly all 2I Japanese specimens which I referred to japonicus in 1965 , have a very short distal lobe, more of a convex side, however, a very similar form of shield occurs in a specimen of hastatus (fig. 9q) from the northern Arabian Sea (John Murray Expedition) as well as in Koehler's I905 figure of hastatus. Unfortunately Koehler did not include Amphioplus depressus among those of Ljungman's types of which he gave photographs in 1927 (a), though in I930 he illustrates a specimen with d.d. $5 \mathrm{~mm}$. which he says is very like the holotype. The scales of this specimen are thick and stand out in relief and the central disc scales though large do not form a proper rosette ; it also has very long distal lobes to the oral shields, although Ljungman described those of the type as having " angulo externo parum producto". It does not seem markedly different from some of the specimens which I have seen attributed to hastatus.

Lyman (I882) referred two lots of "Challenger" specimens to A. depressus. The single discless specimen from Japan is almost certainly conspecific with $A$. megapomus since it has median distal angles to the dorsal arm plates. The other two are from Fiji, one having the disc intact and measuring $9.5 \mathrm{~mm}$. in diameter. The primary rosette is just distinct though the radial plates are very little larger than the scales around them; on a line between the radial shields across each interradius there are seven to nine scales. The radial shields are fairly wide and almost triangular in shape with length : breadth $2 \cdot 3:$ I and length : disc radius $I: 2 \cdot 7$. The uppermost row of ventral disc scales form a projecting flange. The dorsal arm plates are 
extremely wide (as might be expected at this large size) and the dorsal side of the arms is very convex, though when viewed immediately from above the distal edges of the plates appear straight. The oral shields are narrow spearhead-shaped with the distal lobe only a little shorter than the proximal angle and not very constricted. There is no sign of an oral tentacle scale in either specimen. Three other specimens in the British Museum collections can also be referred to $A$. depressus ; these are from Madras in 9 metres depth and all have d.d. c. $5 \mathrm{~mm}$. The primary rosette can just be distinguished in two of them and two have a slight marginal flange. The radial shields are relatively larger than in the Fiji specimen (in conjunction with the smaller total size), the ratio of length : disc radius being I : 2.5 in one specimen and I $: 2 \cdot 2$ in the other two. The dorsal arm plates are convex distally but this curve is truncated medially to some extent.

The largest Murray specimen of $A$. hastatus has d.d. $5 \mathrm{~mm}$. It also has relatively large radial shields with length : disc radius I : $2 \cdot \mathrm{I}$ and length : breadth $\mathrm{c}$. I.8 $: \mathrm{I}$. The primary rosette is quite distinct, there are about seven scales between the radial shields interradially and the disc has a sharp margin but no modification of the scales into a fringe of spiniform processes as Mortensen describes for some specimens from the Persian Gulf (I940). A rudimentary oral tentacle scale is present though normally concealed behind the oral papillae and the oral shields have only a short distal lobe. [A specimen from the Red Sea recorded as hastatus by Burfield (I924) with d.d. only $3.2 \mathrm{~mm}$. has relatively longer radial shields, length : breadth $2 \cdot 5^{-2 \cdot 8}$ : I and the scales are much smaller with II-I3 in a line between neighbouring radial shields interradially. Also the dorsal arm plates have a slight median distal angle. Accordingly I have re-identified Burfield's specimens as A. (Lymanella) laevis.]

Some of the other nominal species listed are also very closely related, for instance Amphioplus integer and caelatus, and need further investigation of their ranges of variation. Although it has often been noted that most of the species are liable to lose their discs very easily, little account has been taken of the consequences of regeneration on the characters shown by the disc, such as the distinctness of the primary rosette, the proportions of the radial shields, the size of the scales and the modification, if any, of the marginal scales. While regeneration is in process the newly formed radial shields undergo a marked change, starting as short wide separate plates but becoming longer and more contiguous as the disc grows to the original size. Mortensen (I933a) illustrates a regenerating specimen of $A$. integer showing an early stage in the regrowth of the radial shields and Koehler's figure 3, pl. I8 (I930) of the type and only specimen of Amphioplus potens, which is clearly in process of regeneration but at a rather later stage, shows the shields in contact but barely longer than wide and the whole disc still diminutive. I believe that potens will prove to be a synonym of either $A$. andreae (if its radial shields were originally short with a length : breadth ratio of c. $2: \mathrm{I}$ ) or A. laevis (if the ratio was about $3: \mathrm{I}$ ). There is of course some variation in the proportions of the fully-grown radial shields ; as noted in I965, those of 2I specimens of $A$. japonicus have the length : breadth ratio ranging from I.75 to $2.55:$ I, averaging $2 \cdot \mathrm{I}: \mathrm{I}$. In I5 specimens of $A$. integer (the only other sample of any size available) the variation is greater, from 2.3 to $3.7: \mathrm{I}$, averaging $2.8: \mathrm{I}$. 
It remains to give a diagnosis of the genus Amphioplus as reconstituted, as well as of the subgenus Amphioplus, excluding the species now referred to Unioplus, Amphichilus and Lymanella; also to construct a diagram illustrating the possible relationships between these taxa and some other amphiurids.

\section{Genus AMPHIOPLUS Verrill}

DiAgnosis. A genus of Amphiuridae with three or, more usually, four oral papillae forming a fairly continuous series on each half of the jaw, the consecutive ones either contiguous or else separated by relatively small spaces much less conspicuous than the large diastema of Amphiura which is often equal in length to the entire oral plate ; a first oral tentacle scale usually present on the side of the oral plate, sometimes suppressed (in which case the oral papillae do not number less than four, unlike Amphiodia), or displaced so as to come more or less into series with the superficial oral papillae (which then often number only three) ; disc scaling usually complete but sometimes reduced on the lower side leaving more or less extensive areas of naked skin, the scales not armed with spinelets though some of the marginal scales may have inconspicuous prolongations ; the two radial shields of each pair variously related, most often contiguous only by their distal adradial corners but sometimes almost completely contiguous or conversely completely separate ; tentacle scales usually numbering one or two, sometimes suppressed beyond the basal segments which have a single scale.

\section{AMPHIOPLUS subgenus AMPHIOPLUS Verrill}

TYPE-SPECIES. Amphiura tumida Lyman, I878.

Diagnosis. A subgenus of Amphioplus with the oral papillae numbering four and arranged in a concave, sometimes discontinuous, series not capable of closing the oral slit completely ; a first oral tentacle scale present, usually visible between and behind the first and second oral papillae so that the oral formula usually approximates to $\mathrm{m}, \mathrm{mn}, \mathrm{nm}+\mathrm{t}$; the radial shields usually only contiguous distally, sometimes more fully contiguous or completely separate ; one or two tentacle scales.

The following nominal species are referable to the subgenus Amphioplus :

abditus (Verrill, I87I)

aciculatus Mortensen, I936

acutus Mortensen, I936

ancistrotus (H. L. Clark, I9II)

asterictus $\mathrm{H}$. L. Clark, I9I5

basilicus (Koehler, I907)

conductus Koehler, I922

coniortodes H. L. Clark, IgI8

cuneatus (Lyman, I878)

cyrtacanthus H. L. Clark, I9I5

debilis (Koehler, I904) didymus H. L. Clark, I938 echinulatus Mortensen, I940 exsecratus (Koehler, I905) firmus (Koehler, I904) hexacanthus H. L. Clark, I9II legatus Koehler, I922 lobatus (Ljungman, I867) lucidus Koehler, I922 macraspis (H. L. Clark, IgII) magellanicus (Mortensen, I936) pectinatus Mortensen, I933 
personatus (Koehler, I905)

platyacanthus Murakami, I943

rhadinobrachius H. L. Clark, I9II

seminudus Mortensen, I940

stenaspis H. L. Clark, I938

stewartensis (Mortensen, I924) strongyloplax (H. L. Clark, I9II)

stratus Cherbonnier, I963

tesselatus (Koehler, I904)

thrombodes H. L. Clark, I9I8

timsae Mortensen, I926

tumidus (Lyman, I878)-Type-species

In addition there are a number of species incertae sedis, either because of insufficiently precise description of their jaw armament, or else showing some characters more or less intermediate between the subgenera as defined above. These are as follows :

ailsaclarki Cherbonnier, I957

archeri A. M. Clark, I955

aurensis A. M. Clark, I955

brachiostictus Tortonese, I948

capax (Koehler, I905)

causatus (Koehler, I905)

cinctus (Koehler, I9I4)

consors (Koehler, I907)

difficilis (Duncan, I887)

dispar (Koehler, I897)

famula (Koehler, I9Io)

glaucus (Lyman, I879)

impressus (Ljungman, I867)

\author{
intermedius (Koehler, I905) \\ iuxtus Murakami, I943 \\ longirima Fell, I952 \\ magnificus (Koehler, I907) \\ occidentalis Koehler, I9I4 \\ parviclypeus H. L. Clark, I9I5 \\ peregrinator (Koehler, I9I2) \\ philohelminthius Ziesenhenne, I940 \\ psilochora (H. L. Clark, I9II) \\ refectus (Koehler, I905) \\ signalis Koehler, I930 \\ textilis (Koehler, I907)
}

Of these last nominal species, A. archeri at least may warrant distinction in a special taxon, either a subgenus, or possibly even a genus, since it diverges from Amphioplus sensu stricto in the direction of Ophiophragmus, having some development of marginal papillae, though the true extent of these remains to be seen from better samples with original as well as regenerating discs. Only the presence of the fourth oral papilla, which in this case arises from the side of the first ventral arm plate, distinguishes it from Ophiophragmus, of which the oral structure is of the Amphiodia (B)-type. Also in A. archeri the oral tentacle scale, or at least an additional papilla probably corresponding to this, is only rarely present (fig. Ii), on one out of ten oral plates of the specimen figured.

Amphioplus psilochora is newly referred to the genus from Amphiodia and seems to occupy an isolated position. Its oral formula is $\mathrm{m}, \mathrm{mm}, \mathrm{o}+\mathrm{t}$, there being no fourth papilla at the distal end of the series, though the presence of the oral tentacle scale prevents its inclusion in Amphiodia ; in Amphichilus and Unioplus, also with only three papillae, it is the second one which is usually undeveloped. The affinities of psilochora may lie with A. strongyloplax, in which the fourth papilla can be reduced or lacking in some series or even entire specimens.

In addition to the species listed under the headings of the various subgenera of Amphioplus (pp. 48, 49, 52, 56-57) and those given as incertae sedis above, there are 
several other names which have been included in the genus which are now disposed of as follows :

agassizi Verrill, I899b, referable to Ophiochitonidae (fig. IIb).

cythera A. H. Clark, I949, referable to Amphiactis (fig. IId,e, see p. 74).

diacritus Murakami, I943, ? a synonym of $A$. ancistrotus (see A.M.C., I965). formatus (Koehler, I905), not an amphiurid (fig. IIa, see pp. 6I-62).

lorioli (Koehler, I897), referable to Amphiura, with synonym Amphiura ceramis

H. L. Clark, I939 (see pp. 22-23).

luctator Koehler, I922, ? a synonym of Dougaloplus echinatus (see p. 36). modestus (Koehler, I897), incomprehensibly referred from Ophiochiton (with which its affinities clearly lie) by H. L. Clark (I9I5). nereis (Lyman, I883), referable to Ophiochitonidae (fig. IIc).

papillatus (Lütken \& Mortensen, I899), referable to Ophiochitonidae. trepidus (Koehler, I904), referable to Ophiocomidae (see p. 37).

The presence of genital papillae in $A$. agassizi, nereis and papillata prohibits their inclusion in the Amphiuridae ; the narrow teeth with no infradental papillae exclude A. cythera and formatus; the diminutive widely-separated radial shields distinguish A. modestus and trepidus, while the latter also has a group of apical tooth papillae rather than an infradental pair of oral papillae.

My studies to date lead me to the conclusion that Amphioplus occupies a central position among amphiurids, having affinities with other taxa as indicated in the diagram on p. 60.

Some notes on type-material in the Amsterdam Museum of some relevant "Siboga " species of Koehler follow, arranged in alphabetical order of species.

\section{Amphioplus (Unioplus) conditus (Koehler)}

Amphiura (Amphioplus) condita Koehler, I905 : 46-47, pl. 5, figs. 9, Io.

Amphioplus conditus : H. L. Clark, I915 : 257.

Locality. " Siboga " st. 89 ; Pulu Kaniungan, East Indies, II metres ; Amsterdam Museum, the holotype.

Descriptive notes. D.d. is $4 \mathrm{~mm}$. The radial shields are c. $0.9 \times 0.3 \mathrm{~mm} .=$ $3:$ I. The dorsal arm plates are more fan-shaped than shown in Koehler's figure and barely contiguous, if at all. There are only three oral papillae, the supposed second papilla being distinctly higher than the two distal papillae, the inner one of which is the largest ; the formula is $\mathrm{m}, \mathrm{om}, \mathrm{m}+\mathrm{t}$.

\section{Amphioplus (Unioplus) confinis (Koehler)}


Locality. "Siboga" st. 2II, S of Celebes, II 58 metres; Amsterdam Museum, four syntypes. St. 22I, Flores Sea, 2798 metres ; two specimens. (The latter were not included in the "Siboga" report.)

Descriptive notes. D.d. is $3 \cdot 5^{-4} \cdot 0 \mathrm{~mm}$. The rosette is conspicuous ; the radial shields are long, divergent and completely separated, even distally. The disc scales are so thick as to produce an uneven profile. The dorsal arm plates are fan-shaped and not contiguous. The arm spines are conical and very acute, evenly tapering. The oral structure of the four syntypes shows some slight differences. One specimen has two jaws with the innermost oral papillae not infradental but offset to the sides of the lowest tooth, a third jaw has a close infradental pair, a fourth has three asymmetrical apical papillae and the fifth has three symmetrical papillae ; the first oral tentacle scale is superficial and in series with the oral papillae so that the formula is $\mathrm{m},(\mathrm{m}=\mathrm{t}) \mathrm{mn}, \mathrm{n}$; the adoral shields are widely contiguous and the oral shields are triangular with a slightly convex distal edge but the distal part distinctly hollowed. A second specimen has a close infradental pair of papillae on each jaw and the lowest tooth above may have a conical apex ; the oral tentacle scale is superficial for its whole length, even its base not being overlapped by the inner of the two distal papillae, while the outermost oral papilla barely makes contact with the adoral shield so that the formula is $\mathrm{m},(\mathrm{m}=\mathrm{t}) \mathrm{mm}$, ; the triangular oral shields have the distal side more convex but are less hollowed than in the first specimen. The third specimen has the infradental papillae more or less spaced on three jaws with a pointed tooth between, though the other teeth are broad as usual ; the oral tentacle scale is in continuous series with the oral papillae ; the inner of the two distal papillae is the largest one and the outer is small and seems to arise from the side of the first ventral arm plate rather than the edge of the adoral or the oral plate so that the formula is best expressed as $m,(m=t) m, m$. The fourth syntype (in fact only three specimens were mentioned in the report but there is no way of telling whether one was added) is very like the second one with the infradental papillae regularly paired but the oral tentacle scale is less superficial and is overlapped distally by the middle oral papilla ; the oral shields are very wide and short and triangular in shape, as well as markedly hollowed. The smaller of the two specimens from station $22 \mathrm{I}$ has three infradental papillae on one jaw ; the larger specimen is poorly preserved ventrally.

\section{Amphioplus (Amphioplus) exsecratus (Koehler)}

Amphiura (Amphioplus) exsecrata Koehler, I905:48-49, pl. 3, figs. 7, 8.

Amphioplus exsecratus : H. L. Clark, I915 : 254.

Locality. "Siboga" ; Amboina reefs ; Amsterdam Museum, the holotype.

Descriptive notes. The oral structure is very like that of Amphioplus (Lymanella) hastatus with the four papillae in a straight series closing the oral slit and the third one the largest and blunt-conical in shape. However, the oral tentacle scale is present although concealed behind the papillae so that the formula is $\mathrm{m}, \mathrm{m}$, $\mathrm{nm}+\mathrm{t}$. 

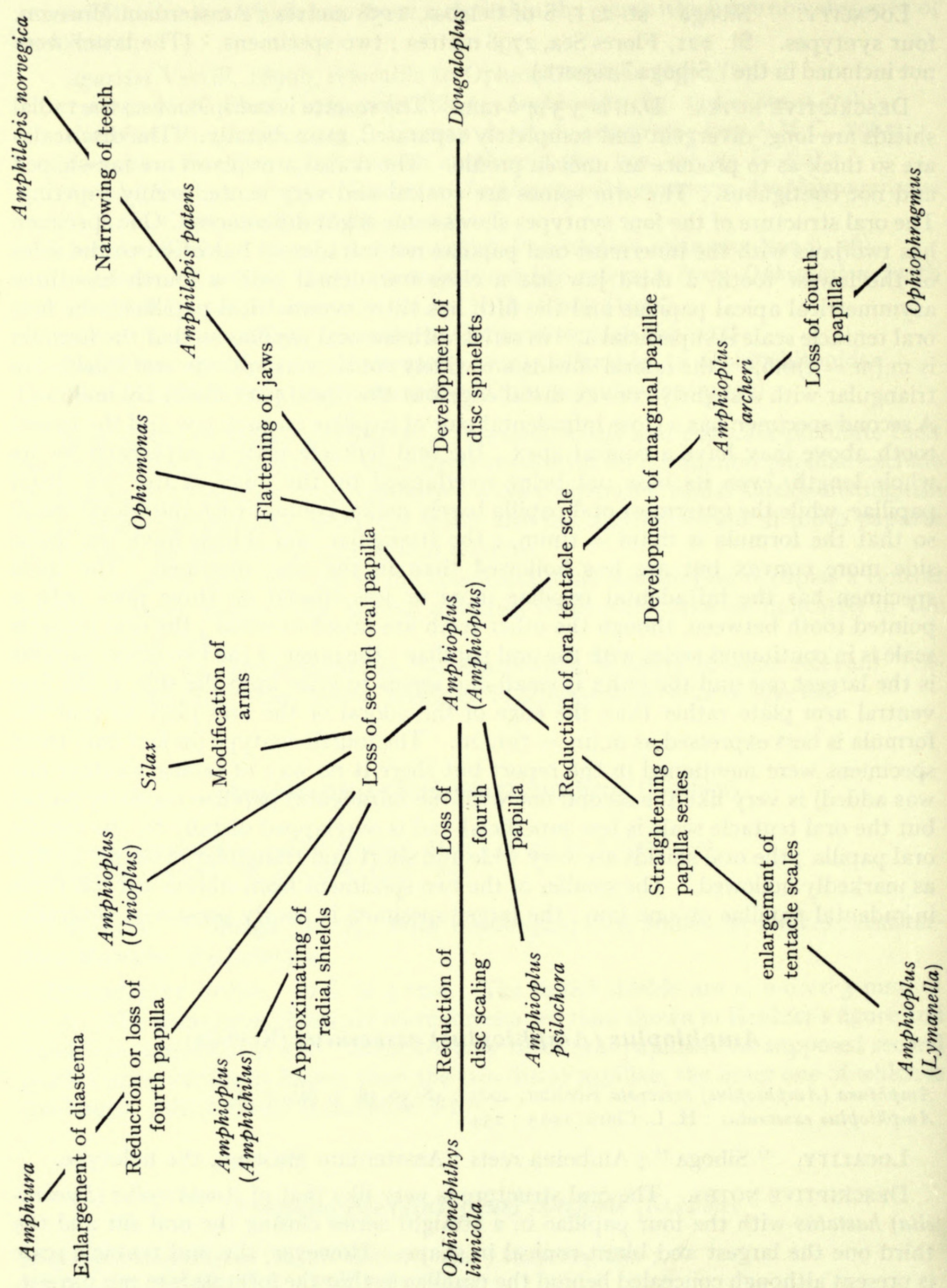
The oral shields are shaped like the sole of a shoe, being elongated with a wide distal " heel " and a very short and obtuse proximal angle or " toe". The two tentacle scales are very large, especially the ventral one. There are five arm spines proximally, the number falling to three. The upper surface is somewhat contorted ; the radial shields are probably narrow.

\section{Amphioplus (Amphioplus) firmus (Koehler)}

Amphiura (Amphioplus) firma Koehler, I904: 87-88, pl. I2, figs. 7, 8. Amphioplus firmus : H. L. Clark, I9I5 : 257.

Locality. "Siboga" st. I59, Molucca Is., 4II metres ; Amsterdam Museum, two syntypes.

DESCRIPTIVE NOTES. D.d. is $4.5 \mathrm{~mm}$. Both specimens have a very large central disc plate but no distinct primary radial scales though one appears to have distinctly enlarged primary interradials. In one the radial shields measure I.2:0.4-0.5 $\mathrm{mm}$. but in the other they are relatively a little broader ; the shields are completely separate, the scales between them not tapering outwardly ; interradially there are three to five scales between adjacent radial shields ; the dorsal arm plates are elliptical but slightly angled laterally ; two jaws have the pointed infradental papillae slightly separated and the tooth between them with a cusp ; the three distal oral papillae each side all arise from the side of the oral plate or else the narrow fourth one may abut on the first ventral arm plate so that the formula is $\mathrm{m},(\mathrm{o}) \mathrm{mmm}(\mathrm{o}), \mathrm{o}+\mathrm{t}$ or $\mathrm{m},(\mathrm{o}) \mathrm{mm}, \mathrm{m}$; the first ventral arm plate is large and its proximal angle is quite superficial; the tip of the first oral tentacle scale shows beyond the tip of the second oral papilla ; the third oral papilla is the largest. Both specimens have dark brown areas on the ventral side of the disc as if the scales are transparent.

\section{“ Amphioplus" formatus (Koehler)}

fig. IIa

Amphiura (Amphioplus) formata Koehler, I905 : 51-52, pl. 5, figs. II-I3, pl. I6, fig. 6.

Amphioplus formatus : H. L. Clark, I915 : 257.

Locality. "Siboga" st. 3Io or 3I2, N of Sumbawa, 73 or 274 metres ; Amsterdam Museum, the holotype.

Descriptive notes. D.d. is $12.5 \mathrm{~mm}$. (Koehler estimated it as $12 \mathrm{~mm}$.). The disc scaling is very fine, the rosette distinct but its plates very widely separated as in Koehler's figure ; there are some enlarged scales proximal to the radial shields, not shown by Koehler. The radial shields are contiguous for only about the distal fifth of their length ; their proportions are c. $2 \cdot 2: 0.8 \mathrm{~mm} .=2.75: \mathrm{I}$; the proximal arm spines are $I \cdot 0-I \cdot I 5 \mathrm{~mm}$. long compared with an arm breadth of $I \cdot 07 \mathrm{~mm}$. No oral tentacle scale could be found but behind the oral papillae there is a horizontal flange on the oral plate. 
The relatively short arms with length only about three times the d.d., the large size, the narrow teeth with the two innermost oral papillae offset, the diminutive oral shields and the relatively long arm spines leave little doubt that this specimen is not an amphiurid at all ; however, at present I am not prepared to hazard a guess as to its true taxonomic position.

\section{Amphioplus (Unioplus) gentilis (Koehler)}

figs. $8 \mathrm{r}, \mathrm{IIg}$

Amphiura (Amphioplus) gentilis Koehler : 1904: 86-87, pl. 16, figs. 8, 9. Amphioplus gentilis : H. L. Clark, 1915: 254 .

Locality. "Siboga" st. I78, Molucca Is., 835 metres; Amsterdam Museum, several syntypes.

DESCRIPTIVE Notes. All the specimens are about the same size with d.d. $2-3 \mathrm{~mm}$. The scales and plates are notably thickened and shiny, standing out in relief. In one specimen the radial shields are separated as shown in Koehler's figure but the six plates of the primary rosette may be closer than drawn, with only interstitial scales between their angles. The dorsal arm plates are all separate. The lowest tooth of this specimen has an abrupt median cusp on some jaws with the two innermost oral papillae offset rather than infradental ; their shape is conical. The two distal oral papillae each side are both partly or completely based on the edge of the adoral shield so that the formula is $\mathrm{m}, \mathrm{o}, \mathrm{mm}+\mathrm{t}$ or $\mathrm{m}$,on,nm $+\mathrm{t}$. The adoral shields are separated interradially in this specimen but in another they are broadly contiguous and the oral shields are much shorter. The latter also has the radial shields contiguous at their distal tips, the disc scales are flatter, also the outermost oral papilla is transparent or absent. Another has the oral shields intermediate between the two extremes. The infradental papillae may be almost contiguous and more rectangular in shape in some specimens, the first oral tentacle scale may be deeper in the oral slit and more rounded at the tip, the primary disc scales may be relatively larger and the radial shields contiguous distally for up to a quarter of their length. It is possible that not all these specimens are conspecific. Indeed a syntype in the collections of the Harvard Museum, no. M.C.Z. 350I (fig. IIf) has been labelled (probably by H. L. Clark) "Amphiactis prob. canescens" and I agree that it is an Amphiactis, the teeth are acute.

\section{Amphioplus (Unioplus) gratus (Koehler)}

fig. $8 \mathrm{k}$

Amphiura (Amphiodia) grata Koehler, I904: 85-86, pl. 18, fig. 6, pl. 19, fig. 7 . Amphiodia grata : H. L. Clark, I915 : 249.

Locality. "Siboga"” st. 2II, S of Celebes, II 58 metres ; Amsterdam Museum, two syntypes.

Descriptive notes. The larger one has d.d. io $\mathrm{mm}$. (Koehler gives $9 \mathrm{~mm}$.). 
The radial shields are $2 \cdot 0 \times \mathrm{I} \cdot 0 \mathrm{~mm}$. and rather more angular than shown in Koehler's figure. There is a large central disc plate but the five widely spaced primary radials are barely larger than the other scales. The oral shields are rounded spearheadshaped and hollowed in the middle ; the adorals are very convex. There are three oral papillae with which the oral tentacle scale is more or less in series, being superficial, so that the formula is $\mathrm{m},(\mathrm{m}=\mathrm{t}) \mathrm{m}, \mathrm{m}$. The outermost oral papilla is the widest and rectangular in shape. The dorsal arm plates have a slight median distal angle. The smaller syntype has d.d. $8 \mathrm{~mm}$. It has the oral tentacle scale superficial on only three half-jaws so that the usual formula is $\mathrm{m}, \mathrm{om}, \mathrm{m}+\mathrm{t}$.

\section{Amphioplus impressus (Ljungman)}

$$
\text { fig. } 91, \mathrm{~m}
$$

Amphipholis impressa Ljungman, I867b : 3I4.

Amphiura (Amphioplus) cesarea Koehler, I905: 44-45, pl. 5, figs. I, 2.

Amphioplus cesareus : H. L. Clark, I9I $5: 257$.

Amphioplus impressus : H. L. Clark, I9I5 : 258 ; Koehler, I922 : I74-I76, pl. 64, figs. 3, 4 ; I927a : 16-19, pl. 2, fig. Io, pl. 3, fig. I.

Amphichilus cesareus : Koehler, I930 : II9.

Localities. "Siboga" st. 294 ; off Timor, 73 metres ; Amsterdam Museum, two syntypes of Amphiura cesarea. Mortensen, I922; Kei Is., 20 metres; B.M. I949.8.I5.I6, one specimen. "Albatross" st. 537I ; Philippine Is., I52 metres ; U.S.N.M. 4II7I, one specimen.

Descriptive notes. The larger of the syntypes of Amphiura cesarea has d.d. $6.5-7.5 \mathrm{~mm}$., the disc being distorted; its radial shields are c. I. $55 \times 0.5 \mathrm{~mm} .=$ $2 \cdot 3$ : I and contiguous for about three-quarters of their length. The smaller specimen has d.d. $5.5 \mathrm{~mm}$. and its radial shields are also $\mathrm{I} \cdot \mathrm{I} 5 \mathrm{~mm}$. long but slightly narrower with the ratio $2.5 \mathrm{I}$. The rosette is distinct in both, with one row of scales between the primary plates. The disc scales are all thin and flat so that the disc appears fairly smooth ; there are six or seven scales between the radial shields across the interradii in the larger specimen but only three to five in the smaller. The dorsal arm plates of the smaller specimen particularly show the median distal angle which is rather exaggerated in Koehler's figure. In the larger one the oral slits are completely closed by the straight rows of four papillae but the second papilla is always small and conical and more often than not lies slightly above the level of the other papillae and clearly represents the oral tentacle scale ; the formula is therefore $\mathrm{m},(\mathrm{m}=\mathrm{t}) \mathrm{mN}, \mathrm{N}$, the distalmost papilla being very broad and almost opercular, with only its distal end contacting the adoral shield. Koehler's figure shows the oral shields as too pear-shaped; they are relatively small and rhombic with the distal lobe only a little more blunt than the proximal. The arm spines are unusually diminutive on the first three segments. The tentacle scales are of moderate to small size. In the smaller specimen the second oral papilla is almost perfectly in series with the other three.

Remarks. The Kei Islands specimen was identified as Amphichilus cesareus by 
Koehler (I930), whereas the "Albatross" specimens in the Smithsonian Institution he determined as Amphioplus impressus (I922) ; in the meantime (I927a) he redescribed and figured the two syntypes of $A$. impressus. Comparison of all these reveals no significant difference between the two nominal species, as far as I can see. The disc scaling appears to stand out a little more in relief in Ljungman's types than in those of cesarea but this could easily be due to the shading effect of angled lighting for the photographs. The border of narrow rectangular scales around the disc shown in Koehler's pl. 3, fig. I (I927a) of one syntype of impressus and in his drawing of one of cesarea (I905, pl. 5, fig. I) is an unusual and distinctive feature. Another significant resemblance is the form of the first ventral arm plate ; in nearly all amphiurids this inclines more or less gradually up into the oral slit, especially at its proximal end. In the types of both impressus and cesareus and the other specimens seen by me its superficial part is horizontal, ending proximally in an abrupt angle from which it passes vertically into the oral slit. I am convinced therefore that only a single species exists and that Amphiura cesarea is a synonym of Amphioplus impressus.

As for the precise position of the species within Amphioplus, without a larger sample I find this hard to determine. Apart from the one syntype of $A$. cesarea none of the specimens I have seen have the second oral papilla inset and it is difficult to ally them with Amphichilus trichoides, although the second papilla must represent the first oral tentacle scale. For the present at least I propose to leave the species in Amphioplus sensu stricto.

\section{Amphioplus (?Amphioplus) intermedius (Koehler)}

Amphiura (Amphioplus) intermedia Koehler, I905 : 42, pl. 4, figs. I4, I5.

Amphioplus intermedius : H. L. Clark, I915 : 258.

Locality. "Siboga" st. 77, Borneo Bank, 59 metres; Amsterdam Museum, the holotype.

Descriptive notes. D.d. is $4 \mathrm{~mm}$. The radial shields are much more fully contiguous than is suggested by Koehler's figure, only the proximal tips being separated by a narrow V-shaped scale; their measurements are $\mathrm{I} \cdot 0 \times 0.25 \mathrm{~mm}$. The fourth and outermost oral papilla is twice as wide as the third, while the second papilla is conical but perfectly in series with the other three. Together they form a straight series completely closing the oral slit so that it is impossible to see if there is an additional oral tentacle scale present above the series.

\section{Amphioplus (Amphioplus) personatus (Koehler)}

Amphiura (Amphioplus) personata Koehler, I905: 47-48, pl. 5, figs. 7,8 . Amphioplus personatus : H. L. Clark, I9I5 : $25^{8}$.

Locality. "Siboga" st. 50, E of Flores, 40 metres; Amsterdam Museum, the holotype. 
Descriptive notes. D.d. is $6 \mathrm{~mm}$. The radial shields are $\mathrm{r} \cdot 6 \times 0.4 \mathrm{~mm}$. The distal lobe of the oral shields is wider than is shown in Koehler's figure. The infradental papillae are huge, while the fourth and outermost papilla is very small and inconspicuous, apparently partly joined to the first ventral arm plate. The oral formula can be expressed as $M$,omn,nn,n $+t$, since the inconspicuous oral tentacle scale is placed well above the first and second papillae between which there is a space. The adoral shields almost meet radially as well as meeting interradially.

\section{Amphioplus (?Amphioplus) refectus (Koehler)}

Amphiura (Amphioplus) refecta Koehler, I905: 52-53, pl. 6, figs. 3, 4 .

Amphioplus refectus : H. L. Clark, I9I5: 258.

Locality. "Siboga" st. I93, Molucca Is., 22 metres; Amsterdam Museum, the holotype.

Descriptive notes. The holotype is somewhat decalcified. The edge of the disc is armed with a series of acute or slightly thorny spinelets. The radial shields are divergent for the proximal half to two-thirds of their length. The condition of the specimen makes it difficult to tell if the oral tentacle scale is present; the oral formula is otherwise $\mathrm{m}, \mathrm{m}$, nm (or $\mathrm{m}, \mathrm{mm}, \mathrm{m}$ ). The tentacle scales are moderate in size.

\section{Amphioplus (Unioplus) repositus (Koehler)}

fig. $8 \mathrm{~m}$

Amphiura (Amphiodia) reposita Koehler, I905 : 40-4I, pl. 4, figs. I2, I3.

Amphiodia reposita: H. L. Clark, I9I $5: 250$.

Locality. "Siboga" st. 89, II metres ; Amsterdam Museum, three syntypes.

DESCRIPTIVE NOTES. All three have d.d. c. $6.5 \mathrm{~mm}$. In one specimen the second oral papilla is the largest and may have a double peak ; it arises mainly from the side of the oral plate so that the formula is $\mathrm{m}$, on, nm $+\mathrm{t}$ (fig. $8 \mathrm{~m}$ ). However, in another specimen the second papilla arises from the edge of the adoral shield so that the formula is $\mathrm{m}, \mathrm{o}, \mathrm{mm}+\mathrm{t}$, more like the condition shown in Koehler's figure. The radial shields are almost contiguous at their distal ends ; their adradial sides are straight and each measures c. $\mathrm{I} \cdot 3 \times 0.43 \mathrm{~mm}$. The ventral disc scaling is very obscure.

\section{Amphioplus (Unioplus) servatus (Koehler)}

fig. $8 \mathrm{p}$

Amphiura (Amphiodia) servata Koehler, 1904: 84-85, pl. 15, figs. 6-8.

Amphiodia servata : H. L. Clark, I915:250.

Locality. "Siboga" st. 262, W of Aru Is., 560 metres ; Amsterdam Museum, the holotype. 
DESCRIPTIVE notes. D.d. is $5 \mathrm{~mm}$. The radial shields are c. $\mathrm{I} \cdot 25 \times 0.43 \mathrm{~mm}$. and are neither so long nor so much separated as Koehler's figure shows. Nine of the series of oral papillae consist of three, with a formula of $\mathrm{m}, \mathrm{om}, \mathrm{m}+\mathrm{t}$ but on the tenth there is an additional papilla in the space between the first two and the formula is $\mathrm{m}, \mathrm{mm}, \mathrm{m}+\mathrm{t}$. The first ventral arm plate has a markedly concave inner side.

\section{Amphioplus (Lymanella) spinulosus (Koehler)}

fig. $9 \mathrm{v}$

Amphiura (Amphioplus) spinulosus Koehler, 1904:92-93, pl. I7, figs. 7, 8.

Amphioplus spinulosus : H. L. Clark, I9I5: 258.

Locality. "Siboga " st. 306, off Flores, 247 metres ; Amsterdam Museum, the holotype. St. 3I9 (omitted from report but added MS in Amsterdam Museum copy) ; Amsterdam Museum, one paratype.

Descriptive nOtes. The holotype has d.d. $5 \mathrm{~mm}$. The primary rosette is distinct and there is a V-shaped scale between the proximal ends of each pair of radial shields. The scales of the uppermost ventral row, which lie around the dorsal disc margin as preserved, have their edges prolonged into usually single spine-like processes. The paratype has d.d. $4 \mathrm{~mm}$. The radial shields are oval, $0.8 \times 0.46$ $\mathrm{mm}$., and hardly separated even at their proximal ends. There are six or seven scales between the adjacent radial shields interradially. The primary rosette is not distinct. The series of marginal spinose processes (fig. 9v) is better preserved than in the holotype and is situated towards the ventral side of the margin. Some of the processes have a forked tip. The arms are distinctly rounded carinate above and the dorsal arm plates have the distal edge curved with a suggestion of a median angle. The arm spines are very acute. The tentacle scales are fairly large. The series of four oral papillae forms a straight row ; the third papilla is massive, truncated conical, while the others are rounded. They completely close the oral slits so that the occurrence of the oral tentacle scale cannot be ascertained. The oral shields are rather small and sunken in the middle, with a long distal lobe ; the adorals are very widely contiguous interradially.

\section{Amphioplus capax (Koehler, I905) and debilis (I904)}

Unfortunately the type-material of both species is in poor condition orally, the holotype of capax being somewhat decalcified while the syntypes of debilis are either obscured with mud or else not conspecific with the specimen described and figured, having contiguous radial shields or only three oral papillae. 
TRIODIA gen. nov.

\section{TYPe-SPEcIEs. Triodia abdita ${ }^{1}$ nov.}

Diagnosis. A genus of Amphiuridae with three oral papillae, the second one running the length of the short oral plate and the third bordering the adoral shield ; with no oral tentacle scale developed, the oral formula is $\mathrm{m}, \mathrm{m}, \mathrm{m}-\mathrm{t}$; a triangular supplementary adoral shield (possibly to be interpreted as one of a pair of supplementary oral shields) is present between each adoral and the genital slit ; the disc scales are unarmed ; the dorsal arm plates are not contiguous, even basally; the ventral arm plates are somewhat swollen; single crescentiform tentacle scales are present on a varying number of proximal arm segments, each scale bordering the lateral edge of the ventral arm plate and curving round on to the proximal part of the following lateral arm plate, the remaining tentacle pores lack scales.

\section{Triodia abdita sp. nov.}

fig. IO

Amphiura dalea (part) : Lütken \& Mortensen, I899: I54-I55, pl. I2, fig. II only. [Non $A$. dalea Lyman, $\mathrm{r} 879: 27$.

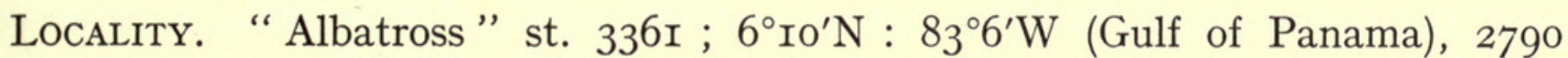
metres ; Museum of Comparative Zoology, Harvard, no. I488, one specimen.

DESCRIPTION. D.d. is I4 mm. ; all the arms are broken within three joints of the base but there are some associated arm fragments, at least one of which belongs to this species.

The disc is covered with fine, well-defined scales, slightly larger and smoother around the radial shields and on the lower side towards the oral shields. The six plates of the primary rosette are enlarged but widely separated. In preservation the disc has tended to shrink into a crease in each interradius. In length the radial shields are just over a third of the disc radius, with length : breadth just under $3:$ I. The two shields of each pair are contiguous for about a quarter of their length distally, otherwise being separated by about four enlarged scales.

The oral papillae number three in each series. The infradental pairs of papillae are compact; on one jaw three papillae take the place of two. The two other papillae each side also form contiguous series. The oral plates are unusually short and the second papilla is broad and occupies the whole length of the superficial edge of the oral plate. In shape it has some resemblance to an oral tentacle scale but it is completely superficial and perfectly in series with the two other papillae. The third and outermost papilla is equally broad but is based entirely on the edge of the

1 The generic name is derived from the triangular tentacle scales, the series of three oral papillae and the triads of plates formed by the oral shields and adjoining supplementary adoral shields. The specific name signifies " hidden", the holotype having for so long been submerged under another name in the collections of the Harvard museum. Gender: feminine. 
adoral shield ; in one out of the ten series, this papilla is split into two. The second oral tentacle is visible behind the third papilla but there is no sign of a first oral tentacle scale on the vertical face of the oral plate. The oral formula can therefore be expressed as $\mathrm{m}, \mathrm{m}, \mathrm{m}-\mathrm{t}$. The oral shields are almost heptagonal, the distal part having three straight sides separated by distinct angles, while the four more proximal sides tend to merge into one another ; the length is greater than the breadth. The adoral shields just meet interradially ; distally they are very broad, separating the oral shield widely from the first lateral arm plate, also they are divided by an oblique suture forming a supplementary adoral shield adjacent to the genital slit.

The dorsal arm plates are very broad and short, the basal ones more than 2.5 times as broad as long and elliptical in shape; those on a detached arm fragment have become more pentagonal with the distal side flattened. All the plates are distinctly separated, the lateral arm plates meeting midradially for over a quarter of the segment length proximally. The ventral arm plates are relatively narrow, mostly
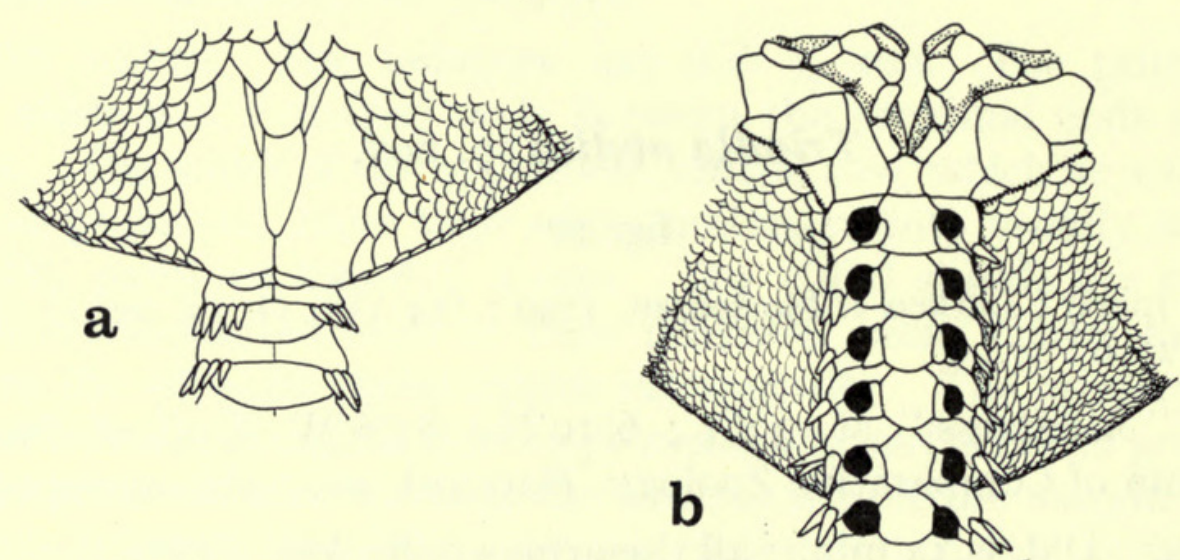

FIG. Io. Triodia abdita gen. \& sp. nov., holotype, M.C.Z. I488, “ Albatross" st. 336r, Gulf of Panama, a. dorsal and b. ventral views of part of disc and an arm base.

slightly longer than broad. Their shape changes from rectangular on the first two segments to hexagonal by tapering of the proximal and distal ends. The large lateral arm plates bear eight or nine short tapering spines on the first free segments ; judging from the arm fragments the number rapidly falls to three. Even the longest spines are distinctly shorter than the segment. The middle spines are somewhat flattened.

On about the first five segments a crescent-shaped tentacle scale corresponds to each pore, running along the side edge of the ventral arm plate and curving around distally on the proximal side of the following lateral arm plate. The extent of the segments with scaled pores is clearly variable since one arm fragment has them at its proximal end although the number of arm spines has dropped to as little as four. On the other arm segments the large pores are naked.

Remarks. This specimen was labelled Amphioplus dalea when I saw it in I953, with a double query of the name added by H. L. Clark. Although in many ways it is similar to the other specimens which Lütken and Mortensen named Amphiura dalea, notably in the disc scaling, radial shields, the absence of tentacle scales from 
most arm pores (though this seems not unusual in deep-water amphiurids) and the non-contiguous dorsal arm plates (again a feature of many deep-water species), the coincidence of the modified oral structure, including the papillae and the adoral shields, and the unusual shape of the tentacle scales make it necessary to distinguish the specimen.

Of the other "Albatross" specimens, most have the oral formula approximating to $\mathrm{m},(\mathrm{m}=\mathrm{t}) \mathrm{m}, \mathrm{m}$. Three of the four from station 4670 have no tentacle scales at all and the fourth only has three or four proximal segments with single shorter scales restricted to the sides of the ventral arm plates. Those from station 4493 have more triangular oral shields, much wider distally ; also they have only three or four arm spines, even at d.d. c. I4 $\mathrm{mm}$. Their identification is probably correct.

\section{[AMPHILEPIDIDAE]}

Amphilepididae Matsumoto, I9I5 : 66 ; I9I7 : I44-I46 ; Fell, I960 : 23 ; Spencer \& Wright, I966 : Uroo.

Amphilepididae : Koehler, I922 : 202 ; Mortensen, I927 : 222 ; I933b : 372.

Amphilepidées : Koehler, I930 : I32.

When established by Matsumoto this family included Amphilepis Ljungman, I867b with the second oral tentacle pore opening outside the mouth, also Amphiactis Matsumoto, I9I5 (non Verrill, I867) and Ophiochytra Lyman, I880 with this pore concealed inside the slit. ${ }^{1}$ Most of Matsumoto's diagnosis appears to have been derived from Amphiactis umbonata, probably the only species personally studied by him. The main point of resemblance between Amphilepis and Amphiactis appears to be in the oral structure as seen in internal (dorsal) view, shown by a comparison of fig. Ic or Lyman's pl. XL, fig. I $^{2}$ and Matsumoto's pl. III, fig. 7 ; these show that both have unusually reduced lateral wings to the oral frames. Regardless of this, H. L. Clark (I9I8), Mortensen (I927) and A. H. Clark, (I949) remove Amphiactis from the Amphilepididae and ally it with Ophiactis, while Fell (I960), followed by Spencer \& Wright (I966), even adopt H. L. Clark's short-lived idea of Amphiactis as a synonym of Ophiactis, expressed in I9I5 before due consideration. Only Koehler (I922 and I930) seems to have retained the genus in the family Amphilepididae, mistakenly in my view since the arm structure particularly is very similar to that of Ophiactis, though I am sure the differing jaw structure warrants a generic distinction.

The removal of Amphiactis drastically undermines the validity of the Amphilepididae by implying that the reduction of the lateral wings of the oral frame is a

1 In fact Matsumoto was mistaken about this character as far as the type-species of Ophiochytra, O. epigrus Lyman, $\mathbf{1 8 8 0}$, is concerned, the second oral pore being superficial in the holotype and only recorded specimen. Ophiochytra is not closely related to either Amphilepis or Amphiactis and I do not know why Lyman in his "Challenger" report placed it between Ophiostigma and Ophiocentrus (both Amphiurids according to Ljungman ( $1867 \mathrm{~b})$ and subsequent authors). With its short arms covered largely by the lateral arm plates, few peglike arm spines, very firm convex disc and strong oral skeleton and diminutive radial shields, I consider that it is a member of the Ophiurinae.

"It should be noted that Mortensen (1933b) has re-identified Lyman's "Challenger" specimens as Amphilepis ingolfiana, though this is very closely related to the type-species, A. norvegica. 
character of lesser taxonomic weight, probably of generic value only, though Matsumoto's figures show marked variation from one species to another even within the same genus.

The affinities of Amphilepis are clearly with the Amphiuridae, as mentioned above (p. 37) under the heading of Amphioplus. It is quite easy to derive the jaw form of Amphilepis norvegica from that of Amphioplus via Ophiomonas (formerly Amphilepis ) protecta and Amphilepis patens by progressive flattening of the jaws, bringing the second oral tentacle pore into a superficial position while the apex of the jaw and the teeth themselves become narrower, the two infradental papillae becoming slightly offset laterally with their bases inclined with respect to one another and at the same time come into series with the now superficial extended and subdivided first oral tentacle scales which have come to assume the function of the more or less reduced (ultimately absent) distal oral papillae (or second oral tentacle scales). I find Lyman's description of the oral structure of Amphilepis as stouter than that of most amphiurids very surprising. On the contrary it appears to me to be much more delicate, though this is especially noticeable in lateral view of the jaws (fig. Ia, d), which Lyman did not illustrate. [It should be noted that Murakami's remarks about the jaw structure of the Amphilepididae (I963), being based on Amphilepis diastata, are also misleading since the species is more closely related to Amphiura diomediae than to Amphilepis norvegica; see p. 40.]

In view of the series of species bridging the gap between Amphioplus and Amphilepis, as far as jaw structure goes, I find it difficult to maintain the latter as representative of a distinct family. Accordingly I propose to reduce the rank of the Amphilepididae to that of a subfamily of the Amphiuridae.

\section{AMPHILEPIS Ljungman}

Amphilepis Ljungman, I867b : 322 ; Lyman, I882 : I49 ; H. L. Clark, I915 : 244. Typespecies : Amphiura norvegica Ljungman, I864.

FIg. II. a. "Amphioplus" formatus (Koehler), Amsterdam Museum, holotype, " Siboga " st. 3Io or 312, off Sumbawa, E Indies, showing narrow teeth and very long arm spines ; b. "Amphioplus" agassizii Verrill, M.C.Z. I26r, holotype, off St. Lucia, W Indies ; c. "Amphioplus" nereis (Lyman), M.C.Z. I260, holotype, off Montserrat, W Indies (b and $\mathrm{c}$ showing chilophiurid-type distal oral tentacle scale and genital papillae); d and e. Amphiactis cythera (A. H. Clark), U.S.N.M. E.69r6, syntype, Hawaiian Is., e. the second free arm segment showing serrated arm spines; f. Amphiactis sp. ?canescens (Lyman), M.C.Z. 3501, syntype of Amphioplus gentilis (Koehler) but not conspecific with most other types, "Siboga" st. I78, N. of Ceram, E Indies ; g. Amphioplus (Unioplus) gentilis (Koehler), Copenhagen Museum, Kei Is. Expedition st. 23 (see also fig. 8r) ; $\mathrm{h}$ and i. "Amphiactis" astarte A. H. Clark, U.S.N.M. E.702I, holotype, Hawaiian Is. ; showing chilophiurid-type distal oral tentacle scale ; the oval at the interradial apex of the adoral shields is an erect papilla, there is also a small nodule at the distal abradial corner of each shield not mentioned by A.H.C. ; j and k. Amphiactis lycidas A. H. Clark, U.S.N.M. E.70I9, holotype, Hawaiian Is., the disc rather distorted. 

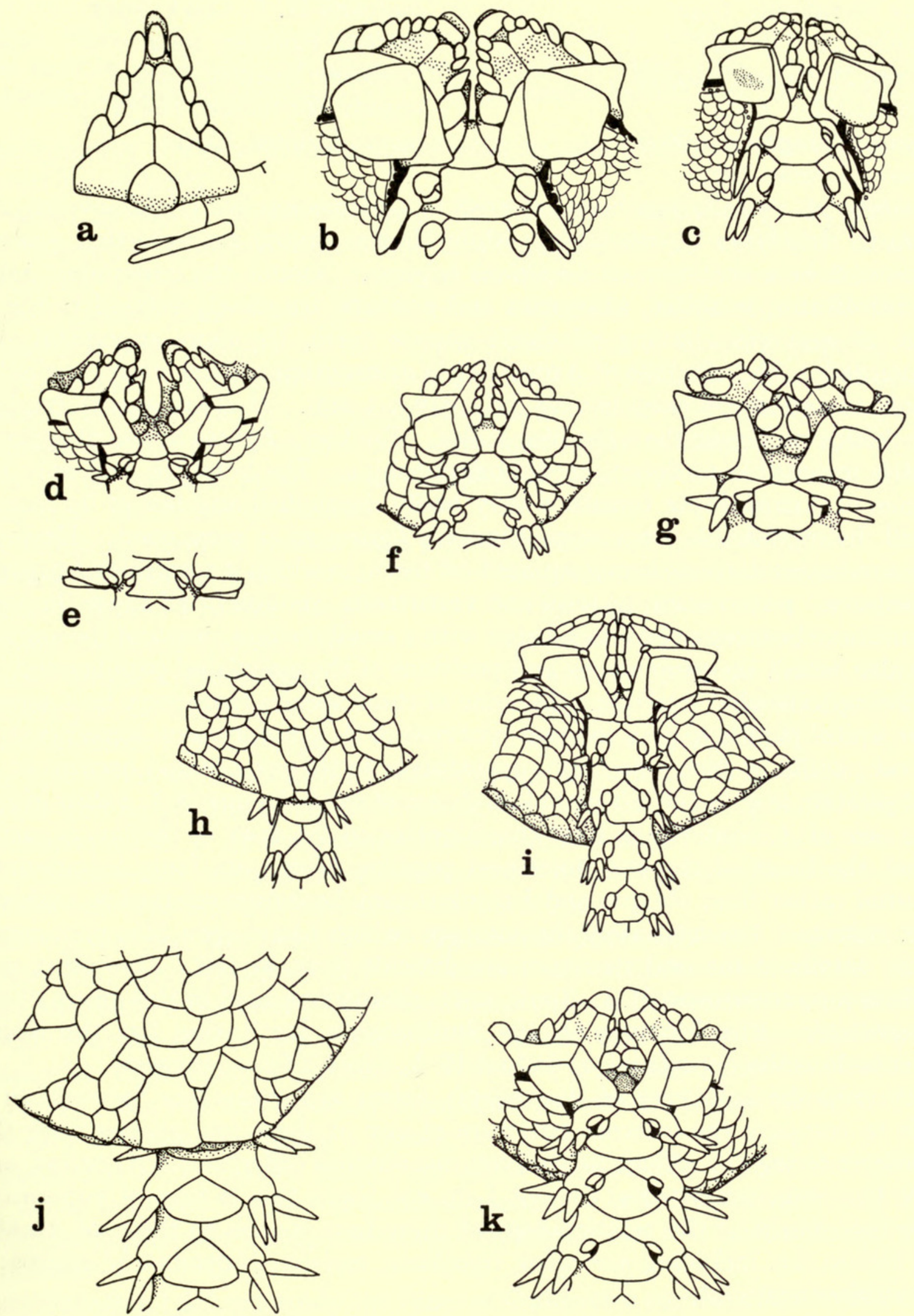
Thirteen species have been referred to Amphilepis, namely : antarctica Koehler, I907

diastata Murakami, I942

gymnopora Hertz, I927

ingolfiana Mortensen, I933b

mobilis Koehler, I904

norvegica (Ljungman, I864)

papyracea Lyman, I 879

Of these, A. protecta has been referred to Ophiomonas by Djakonov (I952) and diastata to Amphiura by me (I965), while Madsen (I967) suspects that gymnopora will prove to be a synonym of Amphiura belgicae. Among the remainder, Amphilepis infolfiana, mobilis, platytata and scutata are closely related to the typespecies, $A$. norvegica, having relatively narrow teeth, the more superficial ones at least pointed. The affinities of Amphilepis antarctica are uncertain, the holotype and only recorded specimen having d.d. only $2.5 \mathrm{~mm}$. It is unusual in having the radial shields no bigger than the disc scales. Koehler's figures are so diagrammatic that it is impossible to determine its relationships. The holotype and only known specimen of Amphilepis tenuis is very badly decalcified and few of its characters are still distinguishable ; nor were Lyman's figures of it very good. However, it appears to have relatively broad squared-off teeth, in which it resembles Amphilepis gymnopora, ${ }^{1}$ papyracea, patens and remittens, though in all these the ventralmost one may be more or less rounded or with a small median cusp and the apex of the jaw is also broad, the proportions and positions of the associated papillae and lowest tooth being somewhat variable. In some of these species there may be a superficial median apical papilla (e.g. in the two syntypes of $A$.gymnopora on some jaws) or the first oral papilla of each side may approximate to its partner and occupy an infradental position (e.g. in the left hand jaw shown of the holotype of $A$. patens in fig. 8c). In the case of $A$. remittens at least this blunting of the apex of the jaw is carried so far that the bases of the two innermost papillae, which are truly infradental, are tangential rather than oblique and I think it may be better referred to Ophiomonas like $A$. protecta. Unfortunately the holotype, which I have seen, is in poor condition and the details of the oral structure are difficult to make out. One other species, Amphiura pycnostoma H. L. Clark, I9II, should be added to this group of species of Amphilepis. The holotype in the Smithsonian Institution has the elongated oral tentacle scales superficial, as indeed H. L. Clark's figure suggests.

With only the holotypes of Amphilepis patens and papyracea to work on I am unable to compare the internal structure of any of these four species with that of Amphilepis norvegica. There is however, one obvious difference in A. patens, namely that it has long genital slits, though I do not think this is true of papyracea. A proper assessment of the relationships of these four species to those of Amphilepis sensu stricto (i.e. including norvegica, infolfiana, mobilis, platytata and scutata) must await further material.

1 Hertz describes the teeth of A. gymnopora as pointed but this is not supported by her photograph, which shows the apex of the jaw as relatively broad and blunt; possibly the most superficial tooth is pointed. 


\section{Family OPHIAGTIDAE}

\section{HIST AMPICA ${ }^{1}$ nom. nov.}

Amphiactis Matsumoto, I9I5 : 66-67; I9I7 : I46-I47 ; H. L. Clark, I9I8 : 294 (discussed under heading of Ophiactis) ; Koehler, I922 : 204 ; A. H. Clark, I949 : 29. Type-species : Amphiactis umbonata Matsumoto, I9I5. Non Amphiactis Verrill, I869, Coelenterata.

Unfortunately the generic name Amphiactis as used by Matsumoto is preoccupied and must be replaced.

As noted in the discussion above of Matsumoto's family Amphilepididae, Fell (I960) followed H. L. Clark's short-lived idea (I9I5, revoked in I9I8) that Amphiactis is a synonym of Ophiactis. I consider that, on the contrary, it is more widely markedoff from Ophiactis than Amphioplus is from Amphiura, indeed almost as remote as Amphilepis is from Amphiura ; not only are there four or five oral papillae in each series rather than one or sometimes two, as found in Ophiactis, but also the teeth of Amphiactis are narrowed in a comparable fashion to those of Amphilepis, with which Matsumoto related it. I regard this as a convergent modification, not a sign of affinity. The internal structure of Amphiactis and Ophiactis is very different, judging from Matsumoto's studies.

The following nominal species have been referred to Amphiactis :

Amphiura canescens Lyman, I879

Ophiactis dissidens Koehler, I904

Amphiura duplicata Lyman, I875

Ophiactis parata Koehler, I904

Amphiura partita Koehler, I897

Amphiura patula Lyman, I879
Amphiactis umbonata Matsumoto, I9I5

type-species

Ophiactis pectorale Lyman, I880

Ophiocnida picteti de Loriol, I893

Amphiactis astarte A. H. Clark, I949

Amphiactis lycidas A. H. Clark, I949.

The first seven were included by Matsumoto, followed by H. L. Clark who added pectoralis and picteti (the latter conditionally) and the last two by A. H. Clark.

As mentioned on p. 4I Amphiura patula Lyman is an Amphioplus, the apex of the jaw being broad, the additional median third infradental papilla being a peculiarity of the holotype and not shared by the paratype.

I have examined the holotype of Ophiactis pectorale and find that its jaw structure and interradially-folded disc accord not with the Ophiactidae but with certain members of the family Ophiacanthidae ; also it possesses the very distinctive diminutive hooks on the upper parts of the lateral arm plates characteristic of the ophiacanthid Ophiodictys uncinatus Koehler, I922, though these were not noticed by Lyman. The two are certainly conspecific so pectorale is now referred to Ophiodictys with uncinatus becoming a synonym.

I think that H. L. Clark's misgivings about Ophiocnida picteti were justified ; since it has only two distal oral papillae each side, broad teeth with only a single infradental papilla and the disc with scattered spinelets, it is undoubtedly referable to Ophiactis.

Unfortunately I did not study the types of Ophiactis parata and dissidens when visiting Amsterdam. Koehler's figures are not sufficiently precise to fix the

\footnotetext{
1 Histampica, an anagram of Amphiactis. Gender: feminine.
} 
relationships of the species with any certainty. The three tentacle scales on the proximal arm segments of $O$. dissidens and the rugose arm spines are features otherwise unknown in the Ophiactidae but which do occur in the Ophiacanthidae, to which the species must be referred; it has some affinity with Ophiophrura H. L. Clark, I9II, except that the radial shields are distinct. Ophiactis parata, while not sharing these two characters, has an even closer resemblance to another ophiacanthid, namely Ophiocopa singularis Koehler, I922, particularly the very short fullycontiguous radial shields with granular armament along their distal edges, unlike any ophiactid. I suspect that a comparison of specimens will prove the two to be conspecific, certainly they are congeneric.

Ophiactis partita, described earlier by Koehler, is evidently an Amphiactis in Matsumoto's sense, having been referred to the synonymy of Amphiactis duplicata by Koehler (I922).

I have seen the holotypes of both Amphiactis lycidas (fig. IIj, k) and astarte (fig. IIh, i) in the Smithsonian Institution. A. lycidas superficially recalls some ophiacanthids, especially in the proximal constriction of each arm segment, however, there seems no good reason for removing it from Amphiactis. Amphiactis astarte on the other hand resembles some of the Ophiolepidinae, notably Ophiozonella. Matsumoto has pointed out that Amphiactis umbonata, the type-species, has some resemblance in the disc scaling to Ophiozona (from which he split off Ophiozonella). However, in $A$. astarte an additional feature is that there is a fifth oral papilla at the distal end of the series (not mentioned by A. H. Clark) which is inclined up into the oral slit, a characteristic of the order Chilophiurida, which agrees with inclusion of the species in the Ophiolepidinae not the Ophiactidae, the latter being a family of the Gnathophiurida. I think that astarte should be referred to Ophiozonella.

Finally, the holotype of Amphioplus cythera A. H. Clark, I949 (fig. IId, e) is in my opinion congeneric with Amphiactis umbonata. It has rounded or tapering teeth, narrower than is usual in Amphioplus and there are no infradental papillae; the structure of the arms is very like that of ophiactids.

The following species can therefore be included in Histampica: $\mathrm{H}$. canescens (Lyman), cythera (A. H. Clark), duplicata (Lyman), lycidas (A. H. Clark) and umbonata (Matsumoto).

SUMMARIES OF PROPOSED TAXONOMIC CHANGES

I. Changes in Rank, New Taxa and Synonyms

A. GENUS-GROUP TAXA

Amphinephthys Fell a synonym of Amphiura Forbes

page

Icalia Fell a synonym of Amphiura Forbes .

Pandelia Fell a synonym of Amphiura Forbes

Hemilepis Ljungman a synonym of Amphiura Forbes

Nullamphiura Fell a synonym of Amphiura Forbes

Monamphiura Fell a synonym of Amphiura Forbes

Ophiopeltis Düben \& Koren reduced to a subgenus of Amphiura Forbes . 
Fellaria subgen. nov. of Amphiura for type Ophionephthys octacantha H. L. Clark I8

Ophionema Lütken reduced to a subgenus of Amphiura Forbes $\quad . \quad$. $\quad$. $\quad$ I9

Ophionephthys Lütken restricted to the type-species . . . . . . 20

Gymnadia Fell a synonym of Amphiodia Verrill . . . . . . . . . 25

Diamphiodia Fell a synonym of Amphiodia Verrill . . . . . . . $\quad 25$

Amphiodia (Amphispina) validated by type-designation . . . . . $\quad 25$

Nullopholis Fell a synonym of Amphipholis Ljungman . . . . . . . 3 31

Monopholis Fell a synonym of Amphipholis Ljungman . . . . . . . $\quad 3$ I

Amphistigma H. L. Clark a valid genus distinct from Ophiostigma . . $\quad$. 33

Amphiacantha Matsumoto pre-occupied, replaced by

Dougaloplus nom. nov. . . . . . . . . . . . . 33

Amphichilus Matsumoto reduced to subgenus of Amphioplus Verrill . $\quad$. $\quad 48$

Unioplus Fell reduced to a subgenus of Amphioplus Verrill . . . . . $\quad$. 48

Ailsaria Fell a synonym of Amphioplus Verrill . . . . . . . . . 50

Lymanella subgen. nov. of Amphioplus for type A. hastatus Ljungman . $\quad$. $\quad 5^{\mathrm{I}}$

Triodia gen. nov. for type $T$. abdita sp. nov. $. \quad . \quad . \quad . \quad$. $\quad . \quad 67$

Amphiactis Matsumoto preoccupied, replaced by

Histampica nom. nov. . . . . . . . . . . . . . . . . $\quad$. 73

B. SPECIES-GROUP TAXA page

Ophionephthys octacantha H. L. Clark designated type-species of Amphiura subgen. Fellaria nov. . . . . . . . . . . . . . .

Ophionephthys decacantha H. L. Clark a synonym of A. (Fellaria) octacantha (H. L. Clark)

Amphiura norae Benham and abernethyi Fell both synonyms of $A$. correcta Koehler

Amphiura ceramis H. L. Clark a synonym of $A$. lorioli (Koehler) ${ }^{-} \cdot{ }^{\prime}$

Amphiodia cyclaspis Djakonov a synonym of $A$. craterodmeta $\mathrm{H}$. L. Clark $\quad . \quad 28$

Amphipholis murex (Koehler) a synonym of Ophiocnida loveni (Ljungman) . $\quad 3 \mathrm{I}$

Amphiacantha dividua Matsumoto a synonym of Ophiocomella sexradia (Duncan) 33

Amphioplus luctator Koehler ?a synonym of Dougaloplus echinatus (Ljungman) . $\quad 36$

Amphichilus cesareus (Koehler) a synonym of Amphioplus impressus (Ljungman) 45

Amphioplus praestans (Koehler) a synonym of $A$. (Lymanella) laevis (Lyman) . $\quad 53$

Amphioplus bocki Koehler ? a synonym of A. (Lymanella) laevis (Lyman) . 53

Amphioplus megapomus H. L. Clark a synonym of either A. (Lymanella) laevis (Lyman) or of $A$. (L.) andreae (Lütken) . . . . . . . . . . 53

Amphioplus miyadii Murakami ? a synonym of $A$. (Lymanella) laevis (Lyman) . $\quad 53$

Amphioplus potens Koehler a synonym of either A. (Lymanella) laevis (Lyman) or of $A$. (L.) andreae (Lütken)

Ophiodictys uncinatus Koehler (Ophiacanthidae) a synonym of $O$. pectoralis (Lyman), referred from Ophiactis

Ophiactis parata Koehler ? a synonym of Ophiocopa singularis Koehler (Ophiacanthidae)

(1)

(1)

5

3

TRANSFERS OF SPECIES TO DIFFERENT GENERA (OR FAMILIES)1

Pre-1962 combination Genus according Genus according to Fell to A.M.C.

\begin{tabular}{lll}
\hline Ophionephthys africana Balinsky & Ophiopeltis & Amphiura (Fellaria) \\
Ophionephthys heptacantha Mtsn. & Ophiopeltis & Amphiura (Fellaria) \\
Ophionephthys iranica Mtsn. & Ophiopeltis & Amphiura (Ophiopeltis)
\end{tabular}

1 Not exhaustive for Fell's larger subdivisions. 
TRANSFERS OF SPECIES (cont.)

Pre-1962 combination
Genus according to Fell
Genus according to A.M.C.
Ophionephthys magellanica Mtsn.

Ophionephthys octacantha H.L.C.

Ophionephthys phalerata Lyman

Ophionephthys stewartensis Mtsn.

Ophionephthys tenuis H.L.C.

Ophionema hexactis Mtsn.

Amphiura aestuarii Matsumoto

Amphiura alba Mtsn. \& other spp. ref. to

Amphiura crossota Murakami \& other spp.

ref. to

Amphiura ecnomiotata H.L.C.

Amphiura fragilis Verrill \& other spp. ref. to Amphiura hinemoae Mtsn. \& other spp. ref. to Amphiura psilopora H.L.C. \& other spp. ref. to

Amphiura pycnostoma H.L.C.

Amphiura semiermis Lyman \& other spp. ref. to

Amphiura sinicola Matsumoto

Amphiura vadicola Matsumoto

Amphipholis loripes Koehler

Amphipholis murmanica Djakonov

Amphipholis nudipora A.M.C.

Amphipholis pentacantha H.L.C.

Amphipholis vitax Koehler

Amphistigma minuta H.L.C.

Amphiodia affinis (Studer)

Amphiodia assimilis (Ltk. \& Mtsn.)

Amphiodia caulleryi (Koehler)

Amphiodia fuscoalba (Brock)

Amphiodia grata (Koehler)

Amphiodia ochroleuca (Brock)

Amphiodia olivacea (Brock)

Amphiodia platyspina Nielsen

Amphiodia psilochora H.L.C.

Amphiodia reposita (Koehler)

Amphiodia servata (Koehler)

Amphiodia tabogae Nielsen

Amphiodia urtica (Lyman)

Amphiodia violacea (Lütken) \& other spp. ref. to

Ophiocnida echinata (Ljungman)

Ophiocnida picteti de Loriol

Ctenamphiura sinensis A.H.C.

Amphiacantha acanthina (H.L.C.)

Amphiacantha amphacantha (McCl.)
Ophionephthys

Ophiopeltis

Ophionema

Ophionephthys

ophionema

Ophiopeltis

Monamphiura

Amphinephthys

Ophiopeltis

Icalia

Pandelia

Nullamphiura

Monamphiura

Hemilepis

Ophiopeltis

Monopholis

Monopholis

Nullopholis

Nullopholis

Monopholis

Ophiostigma

Amphiodia

Diamphiodia

Diamphiodia

Diamphiodia

Diamphiodia

Amphiodia

Gymnodia

Gymnodia

Diamphiodia

Diamphiodia

Gymnodia

Ophiophragmus

Diamphiodia

Diamphiodia

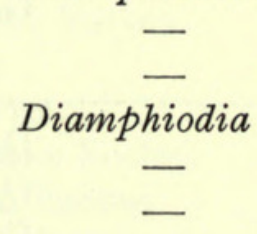

Amphioplus (Amphioplus) ${ }^{1}$

Amphiura (Fellaria)

Amphiura (Ophiopeltis)

Amphioplus (Amphioplus)

Amphiura (Ophiopeltis)

Amphiura (Ophiopeltis)

Amphiura (Ophiopeltis)

Amphiura (Amphiura)

Amphiura (Amphiura)

Amphiura (Fellaria)

Amphiura (Amphiura)

Amphiura (Amphiura)

Amphiura (Amphiura) Amphilepis

Amphiura (Amphiura)

Amphiura (Fellaria)

Amphiura (Fellaria)

Amphipholis or Amphiodia Amphipholis

Amphipholis

Amphipholis

Amphipholis

Amphistigma

Amphioplus

Amphiura (Amphiura)

? Amphiura or Amphioplus (Amphichilus)

Acrocnida

Amphioplus (Unioplus)

Amphioplus (Amphichilus)

Ophiophragmus

Amphiodia

Amphioplus

Amphioplus (Unioplus)

Amphioplus (Unioplus)

Amphiodia

Amphiodia

Amphiodia

Dougaloplus

Ophiactis

Paracrocnida

Dougaloplus

Dougaloplus

${ }^{1}$ Referred to Amphioplus by Castillo (1968). 
TRANSFERS OF SPECIES (cont.)

Pre-I962 combination

Genus according to Fell
Genus according

to A.M.C.
Amphiacantha formosa (Ltk.)

Amphiacantha gastracantha (Ltk. \& Mtsn.)

Amphiacantha libera (Koehler)

Amphiacantha notacantha (Ltk. \& Mtsn.)

Amphiacantha transacta Koehler

Amphichilus daleus (Lyman)

Amphichilus intermedius (Koehler)

Amphichilus trichoides Matsumoto

Amphioplus aciculatus Mtsn.

Amphioplus agassizi Verrill

Amphioplus andreae (Lütken)

Amphioplus brachiostictus Tort.

Amphioplus caelatus Ely

Amphioplus capax Koehler

Amphioplus cernuus (Lyman)

Amphioplus conditus (Koehler)

Amphioplus confinis (Koehler)

Amphioplus congensis (Studer)

Amphioplus coniortodes H.L.C.

Amphioplus cyrtacanthus H.L.C.

Amphioplus cythera A.H.C.

Amphioplus depressus (Ljungman)

Amphioplus dispar (Koehler)

Amphioplus echinulatus Mtsn.

Amphioplus falcatus Mtsn.

Amphioplus formatus (Koehler)

Amphioplus gentilis (Koehler)

Amphioplus gibbosus (Ljungman)

Amphioplus glaucus (Lyman)

Amphioplus hastatus (Ljungman)

Amphioplus incisus (Lyman)

Amphioplus integer (Ljungman)

Amphioplus japonicus (Mats.)

Amphioplus laevis (Lyman)

Amphioplus lorioli(Koehler)

Amphioplus lucidus Koehler

Amphioplus macraspis H.L.C.

Amphioplus modestus (Koehler)

Amphioplus nereis (Lyman)

Amphioplus patulus (Lyman)

Amphioplus personatus (Koehler)

Amphioplus philohelminthius Zies.

Amphioplus seminudus Mtsn.

Amphioplus spinulosus (Koehler)

Amphioplus strongyloplax (H.L.C.)

Amphioplus thrombodes (H.L.C.)

Amphioplus trepidus (Koehler)

Amphilepis diastata Murakami

Amphilepis remittens Koehler

\begin{tabular}{|c|c|}
\hline - & Dougaloplus \\
\hline - & Dougaloplus \\
\hline 一 & Dougaloplus \\
\hline- & Dougaloplus \\
\hline 一 & order Chilophiurida \\
\hline 一 & Amphioplus (Unioplus) \\
\hline 一 & Amphioplus \\
\hline - & Amphioplus (Amphichilus) \\
\hline Unioplus & Amphioplus (Amphioplus) \\
\hline Amphioplus & family Ophiochitonidae \\
\hline Amphioplus & Amphioplus (Lymanella) \\
\hline Amphiodia & Amphioplus \\
\hline Amphioplus & Amphioplus (Lymanella) \\
\hline Unioplus & Amphioplus \\
\hline Unioplus & Amphioplus (Unioplus) \\
\hline Amphioplus & Amphioplus (Unioplus) \\
\hline Amphioplus & Amphioplus (Unioplus) \\
\hline Amphioplus & Amphioplus (Lymanella) \\
\hline Ailsaria & Amphioplus (Amphioplus) \\
\hline Ophionephthys & Amphioplus (Amphioplus) \\
\hline Amphioplus & Histampica \\
\hline Amphioplus & Amphioplus (Lymanella) \\
\hline Unioplus & Amphioplus \\
\hline Ailsaria & Amphioplus (Amphioplus) \\
\hline Unioplus & Amphioplus (Unioplus) \\
\hline Unioplus & ? not amphiurid \\
\hline Amphioplus & Amphioplus (Unioplus) \\
\hline - & Amphioplus (Lymanella) \\
\hline Unioplus & Amphioplus \\
\hline Amphioplus & Amphioplus (Lymanella) \\
\hline Amphioplus & Amphioplus (Unioplus) \\
\hline Amphioplus & Amphioplus (Lymanella) \\
\hline Amphioplus & Amphioplus (Lymanella) \\
\hline Amphioplus & Amphioplus (Lymanella) \\
\hline Amphioplus & Amphiura \\
\hline Ophionephthys & Amphioplus \\
\hline Unioplus & Amphioplus (Amphioplus) \\
\hline 一 & Ophiochiton \\
\hline Amphioplus & Ophiochitonidae \\
\hline Unioplus & Amphioplus (Unioplus) \\
\hline Ailsaria & Amphioplus (Amphioplus) \\
\hline Unioplus & Amphioplus \\
\hline Ophionephthys & Amphioplus (Amphioplus) \\
\hline - & Amphioplus (Lymanella) \\
\hline Unioplus & Amphioplus (Amphioplus) \\
\hline Unioplus & Amphioplus (Amphioplus) \\
\hline ? Silax & Ophiocomidae \\
\hline - & Amphiura \\
\hline - & ? Ophiomon \\
\hline
\end{tabular}


TRANSFERS OF SPECIES (cont.)

Pre-I962 combination

Genus according to Fell

Genus according to A.M.C.

$\begin{array}{cc}- & \text { Ophiozonella (Ophiuridae) } \\ - & \text { Histampica } \\ - & \text { Ophiacanthidae } \\ - & \text { Histampica } \\ - & \text { Histampica } \\ - & \text { Ophiodictys (Ophiacanthidae) } \\ - & \text { Histampica } \\ & \text { Ophiuridae }\end{array}$

Amphiactis astarte A.H.C. Amphiactis canescens (Lyman) Amphiactis dissidens (Koehler) Amphiactis duplicata (Lyman) Amphiactis lycidas A.H.C. Amphiactis pectorale (Lyman) Amphiactis umbonata Matsumoto Ophiochytra epigrus Lyman

\section{REFERENCES}

Balinsky, J. B. I957. The Ophiuroidea of Inhaca Island. Ann. Natal Mus. 14: I-33, 7 figs., 4 pls.

Benham, W. B. I909. Scientific results of the New Zealand Government Trawling Expedition, I907. Rec. Canterbury Mus. 1(2) : I-34, pls. 7-I I.

Brock, J. I888. Die Ophiuridenfauna des indischen Archipels. Z. wiss. Zool. $47: 465-539$.

Buchanan, J. B. \& Woodley, J. D. 1963. Extension and retraction of the tube-feet of Ophiuroids. Nature, Lond. 197 : 6I6-6I 7, 2 figs.

BURFIELD, S. T. I924. A new species and a new variety of ophiuroid with notes on a collection of Ophiuroidea from the Sudanese Red Sea. Ann. Mag. nat. Hist. (9)13: 144-154, 2 figs.

Castillo Alarcon, J. I968. Ophiuroideos colectados por la XIX Expedicion Antartica Chilena. Publnes Inst. antart. Chile No. 13 : I-34, 6 pls.

Chang, F.-Y. 1948. Echinoderms of Tsingtao. Contr. Inst. Zool. Acad. Peiping 4 : 33-104, 24 figs., II pls.

Cherbonnier, G. I957. Ophiures rares ou nouvelles des côtes de Sierra-Leone. Bull. Mus. Hist. nat. Paris 29 : 163-I 7I, 3 figs.

Clark, A. H. I949. Ophiuroidea of the Hawaiian Islands. Bull. Bernice P. Bishop Mus. No. 195 : I-I33, 22 figs.

Clark, A. M. 1955. Echinodermata of the Gold Coast. Jl West Afr. Sci. Ass. 1(2) : 16-56, 23 figs., pl. 2.

I965. Japanese and other ophiuroids from the collections of the Münich Museum. Bull. Br. Mus. nat. Hist. Zool. 13(2) : I-7I, 6 figs., I pl.

- I966. Port Phillip Survey, I957-63. Echinodermata. Mem. natn. Mus. Vict. 27 : 289-355, 4 pls.

I967. Echinoderms from the Red Sea, part 2. (Crinoids, Ophiuroids, Echinoids and more Asteroids). Bull. Sea Fish. Res. Sta. Haifa $41: 26-58,5$ figs.

Clark, H. L. I9I I. North Pacific Ophiurans in the collection of the United States National Museum. Bull. U.S. natn. Mus. 75 : I-302, I44 figs.

1915. Catalogue of recent Ophiurans. Mem. Mus. comp. Zool. Harv. 25(4) : 165-376, 20 pls.

I9I7. Reports on the scientific results of the expedition to the tropical Pacific — the U.S. Fish Commission Steamer "Albatross", I899-1900. XVIII. Reports on the scientific results of the expedition to the eastern tropical Pacific — , by the U.S. Fish Commission steamer "Albatross", 1904-1905. XXX. Ophiuroidea. Bull. Mus. comp. Zool. Havv. $61: 429-453,5$ pls.

I918. Brittle-stars new and old. Bull. Mus. comp. Zool. Havv. 62 : 265-338, 8 pls.

1938. Echinoderms from Australia. Mem. Mus. comp. Zool. Havv. 55 : viii + 596, 63 figs., 28 pls. 
Clark, H. L. I939. Ophiuroidea. Scient. Rep. John Murray Exped. 4 : 29-136, 62 figs. - 1946. The Echinoderm fauna of Australia. Publs Carnegie Instn No. 566 : 1-567.

Djakonov, A. M. I954. [Ophiuroidea of the Soviet Union.] Opred. Faune SSSR 55 : I-I36, 47 figs., I pl. [In Russian ; translation, I967 ; Israel Program for Scientific Translations, I23 pp.]

Düben, M. W. von \& Koren, J. I845. Arch. skand. Beitr. Naturgesch. Part $1: 436-440$.

- I846. Ofversigt af Skandinaviens Echinodermer. K. svenska VetenskAkad. Handl. 1844 : 229-328, pls. 6-II.

Duncan, P. M. I879. On some Ophiuroidea from the Korean Seas. J. Linn. Soc., Zool. 14 : 445-482, pls. 9-II.

r887. On the Ophiuridae of the Mergui Archipelago, collected for the Trustees of the Indian Museum by Dr. John Anderson. J. Linn. Soc., Zool. 21 : 85-106, figs. 28-40, pls. 8, 9 and II.

Ely, C. A. 1942. Shallow-water Asteroidea and Ophiuroidea of Hawaii. Bull. Bernice P. Bishop Mus. No. 176 : I-63, I 8 figs., I3 pls.

FELL, H. B. I95I. Some off-shore and deep-sea ophiuroids from New Zealand waters. Zool. Publs Vict. Univ. Wellington No. 13 : I-4, 4 figs.

1958. Deep-sea Echinoderms of New Zealand. Zool. Publs Vict. Univ. Wellington No. 24 : I-40, 5 pls.

1960. Synoptic keys to the genera of Ophiuroidea. Zool. Publs Vict. Univ. Wellington No. 26 : I-44, 6 figs.

1962a. A revision of the major genera of amphiurid Ophiuroidea. Trans. R. Soc. N.Z., Zool. 2 : I-26, I pl.

1962b. A revised classification of the Australian Amphiuridae (Ophiuroidea). Proc. Linn. Soc. N.S.W. 87 : 79-83.

Forbes, E. I843. On the Radiata of the eastern Mediterranean. Pt. I. Ophiuridae. Trans. Linn. Soc. Lond. 19 : I43-I53, pls. I3, I4.

Koemler, R. I897. Echinodermes recueillis par l'Investigator dans l'Ocean Indien. I. Les Ophiures de Mer Profonde. Ann. Sci. Nat. (8)4 : 277-372.

1899. An account of the deep-sea Ophiuroidea collected by the Royal Indian Marine Survey Ship Investigator. Echinoderma of the Indian Museum. viii $+76+$ ii pp., I4 pls. Calcutta.

I904. Ophiures de l'Expedition du Siboga. I. Ophiures de mer profonde. Siboga Exped. 45a : I-I67, 36 pls.

I905. Ophiures de l'Expedition du Siboga. 2. Ophiures littorales. Siboga Exped. 45b : I-I 42, I 8 pls.

1907. Révision de la collection des Ophiures du Museum d'Histoire naturelle de Paris. Bull. scient. Fr. Belg. 41 : 279-35I, 5 pls.

- I9I4. Asteroidea, Ophiuroidea et Echinoidea. In Michaelsen \& Hartmeyer. Beiträge zur Kenntnis der Meeresfauna Westafrikas. 2 : 129-303, pls. 4-15. Hamburg.

I9I7. Echinodermes (Asteries, Ophiures et Echinides) recueillis par M. Rallier du Baty, aux Iles de Kerguelen, en I9I3-I4. Annls Inst. oceanogr. Monaco 7(8) : I-82, Io pls.

1922a. Ophiurans of the Philippine Seas and adjacent waters. Bull. U.S. natn. Mus. 100(3) : I-486, I03 pls.

1922b. Ophiuroidea. Scient. Rep. Austral. Ant. Exped. C8(2) : 1-98, pls. 76-9o.

r927a. Révision de quelques ophiures de Ljungman, appartenant au Musée d'Histoire Naturelle de Stockholm. Ark. Zool. 19A(2) : I-29, 4 pls.

I927b. Ophiures recueillis aux iles Gilbert, Marshall et Fiji. Göteborgs K. Vetensk. o. VitterhSamh. Handl. 33(3) : I-I3, I pl.

I930. Papers from Dr. Th. Mortensen's Pacific Expedition, I9I4-I6. LIV. Ophiures recueillis par le Docteur Th. Mortensen dans l'Archipel Malais. Vidensk. Meddr dansk. naturh. Foren. 89 : I-295, 20 pls.

LEACH, W. E. I8I5. Zoological Miscellany. 2 : I-I54, I20 pls.

LJungman, A. I867a. Om några nya arter af Ophiurider. Öfvers. K. VetenskAkad. Förh. Stockh. 1866 : I63-166. 
LJungman, A. I867b. Ophiuroidea viventia huc usque cognita enumerat. Öfvers. $K$. VetenskAkad. Förh. Stockh. 1866 : 303-336.

I87ז. Förteckning öfver uti Vestindien af Dr. A. Goës samt under Korvetten Josefinas Expedition i Atlantiska Oceanen samlade Ophiurider. Öfvers. K. VetenskAkad. Förh. Stockh. 1871 : 6I5-658.

LÜTKEN, C. F. 1856. Bidrag til kundskab om Slangestjernerne. II. Oversigt over de vestindiske Ophiurer. Vidensk. Meddr dansk. naturh. Foren. 1856 : I-I9.

I859a and b. Additamenta ad Historiam Ophiuridarum. I and 2. Beskrivelser af ny eller hidtil kun ufuldstaendigt hjendte Arter af Slangestjerner. $K$. dansk. Vidensk. Selsk. Skr. 5(5) : I-74, 2 pls. ; I 79-27I, 5 pls.

— r869. Additamenta ad Historiam Ophiuridarum. 3. Beskrivende og kritiske Bidrag til Kundskab om Slangestjernerne. K. dansk. Vidensk. Selsk. Skr. 5(8) : 24-Io9, 3 figs.

LÜtKen, C. F. \& Mortensen, T. I899. Reports on an exploration off the west coasts of Mexico, Central and South America, and off the Galapagos Islands. XXV. The Ophiuridae. Mem. Mus. comp. Zool. Harv. 23(2) : 97-208, 23 pls.

Lyman, T. I865. Ophiuridae and Astrophytidae. Illust. Cat. Mus. comp. Zool. Harv. No. 1 : I-200, I9 figs., 2 pls.

I869. Preliminary report on the Ophiuridae and Astrophytidae dredged in deep water between Cuba and Florida reef. Bull. Mus. comp. Zool. Havv. 1 : 309-354.

I874. Ophiuridae and Astrophytidae new and old. Bull. Mus. comp. Zool. Harv. 3 : 22I-272, 7 pls.

I879. Ophiuridae and Astrophytidae of the "Challenger" Expedition. II. Bull. Mus. comp. Zool. Harv. 6(2) : 17-83, 8 pls.

- 1880. A structural feature hitherto unknown among Echinodermata found in deep-sea Ophiurans. Anniv. Mem. Boston Soc. nat. Hist. : I-I2, 2 pls.

I882. Ophiuroidea. Rep. scient. Res. Challenger, Zool. 5 : I-386, 46 pls.

I883. Reports on the results of dredging, _- in the Caribbean Sea (1878-79) and on the east coast of the United States, during the summer of 1880 , by the U.S. Coast Survey steamer "Blake". XX. Report on the Ophiuroidea. Bull. Mus. comp. Zool. Harv. 10: $227-287,8$ pls.

McClendon, J. F. I909. The Ophiurans of the San Diego region. Univ. Calif. Publs Zool. 6(3) : 33-64, 6 pls.

MADSEN, F. J. I955. Echinoderms other than Holothurians collected in Sub-Antarctic and Antarctic seas, mainly by the Norvegia Expeditions, 1928-30. Scient. Res. Norweg. Antarct. Exped. No. 37 : I-I7, 2 figs.

- 1967. Ophiuroidea.Rep.B.A.N.Z.Antarctic Res. Exped., I929-3I. B9 : 123-145, 8 figs., I pl.

Matsumoto, H. I9I5. A new classification of Ophiuroidea : with descriptions of new genera and species. Proc. Acad. nat. Sci. Philad. $67: 43-92$.

- 1917. A monograph of Japanese Ophiuroidea, arranged according to a new classification. J. Coll. Sci. Tokyo 38(2) : I-408, roo figs., 7 pls.

- I94I. Report of the biological survey of Mutsu Bay and vicinities. Sci. Rep. Tohuku Univ. (4) 16 : 33I-344, Io figs., pls. 2I-23.

May, R. M. I924. The Ophiurans of Monterey Bay. Proc. Calif. Acad. Sci. (4)13:26I-303, I 7 figs.

Mortensen, T. I924. Echinoderms of New Zealand and the Auckland-Campbell Islands. II. Ophiuroidea. Vidensk. Meddr dansk. naturh. Foren. 77 : 91-I77, 36 figs., 2 pls. 1927. Handbook of the Echinoderms of the British Isles. ix +47 I pp., 269 figs. London.

- 1933a. Echinoderms of South Africa (Asteroidea and Ophiuroidea). Vidensk. Meddr dansk. naturh. Foren. 93 : 21 5-400, 9I figs., I2 pls.

- 1933b. Ophiuroidea. Dan. Ingolf-Exped. 4(8) : I-I2I, 52 figs., 3 pls.

- I933c. Biological observations on Ophiurids with descriptions of two new genera and four new species. Vidensk. Meddr dansk. naturh. Foren. 93 : I-I2I, 7 figs., I pl. 
Mortensen, T. I936. Echinoidea and Ophiuroidea. “ Discovery" Rep. 12 : I99-348, 53 figs., 9 pls.

1940. Echinoderms from the Iranian Gulf. Dan. scient. Invest. Ivan. Part 2 : 55-I I2, 24 figs., 2 pls.

1952. Reports of the Lund University Chile Expedition, I948-49. 3. Echinoidea and Ophiuroidea. Acta Univ. Lund N.F. (2)47(8) : I-22, 3 figs., I pl.

Murakami, S. I942. Ophiurans of Izu, Japan. J. Dep. Agric. Kyushu Univ. $7:$ I-36, I2 figs.

I943. Reports on the Ophiurans of Palao, Caroline Islands. Reports on the Ophiurans of Yaeyama, Ryukyu. Ophiurans from some Gulfs and Bays of Nippon. J. Dep. Agric. Kyushu Univ. 7 : I59-204, I 7 figs. ; 205-222, 2 figs. ; 223-234, 2 figs.

- I944. Report on the Ophiurans from off Ogasawara Islands and from off the Yaeyama group, Nippon. Note on the Ophiurans of Amakusa, Kyūsyū. J. Dep. Agric. Kyushu Univ. 7 : 235-257, I4 figs. ; 259-280, 5 figs., I pl.

1963. The dental and oral plates of Ophiuroidea. Trans. R. Soc. N.Z., Zool. 4 : I-48, I fig., 7 pls.

Nielsen, E. I932. Ophiurans from the Gulf of Panama, California and the Strait of Georgia. Vidensk. Meddr dansk. naturh. Foren. $91: 24 \mathrm{I}-346,42$ figs.

Parslow, R. E. \& Clark, A. M. I963. Ophiuroidea of the Lesser Antilles. Stud. Fauna Curacao $15: 24-50,4$ figs.

SARS, G. O. I87I. Nye Echinodermer fra den norske Kyst. Forh. VidenskSelsk. Krist. 1871 : I-3I.

SARS, M. I861. Oversigt af norges Echinodermer. I60 pp., I6 pls. Christiania.

Spencer, W. K. \& Wright, C. W. I966. Asterozoans. In Moore, R. C. Treatise on Invertebrate Paleontology. Part U. Echinodermata 3, vol. 1: 4-I07, 89 figs. (Geological Society of America Inc. ; University of Kansas Press.)

Studer, T. I885. Die Seesterne Süd-Georgiens nach der Ausbeute der deutschen Polarstation in 1882 und 1883 . Jahrb. Hamb. Wiss. Anst. 11 : I43-166, 2 pls.

Tномаs, L. P. I962. The shallow water amphiurid brittle stars (Echinodermata, Ophiuroidea) of Florida. Bull. mar. Sci. Gulf Caribb. 12 : 623-694, 23 figs.

— 1963. A redescription of the amphiurid brittle star Ophiocnida cubana A. H. Clark, I9I7. Proc. biol. Soc. Wash. 76 : 217-222, 3 figs.

— 1964. Amphiodia atra (Stimpson) and Ophionema intricata Lütken, additions to the shallow water amphiurid brittlestar fauna of Florida (Echinodermata: Ophiuroidea). Bull. mar. Sci. Gulf Caribb. 14 : I58-167, 3 figs.

— 1966. A revision of the tropical American species of Amphipholis (Echinodermata: Ophiuroidea). Bull. mar. Sci. Gulf Caribb. $16: 827-833$.

VERrill, A. E. I899a. Report on the Ophiuroidea collected by the Bahama Expedition from the University of Iowa in $\mathrm{r} 893$. Bull. Univ. Iowa 5(I) : I-86, 8 pls.

I899b. North American Ophiuroidea. I. Revision of certain families and genera of West Indian Ophiurans. 2. A faunal catalogue of the known species of West Indian Ophiurans. Trans. Conn. Acad. Arts Sci. $10: 301-386,2$ pls.

Ziesenhenne, F. C. I937. Echinoderms from the west coast of Lower California, the Gulf of California and Clarion Island. Zoologica, N.Y. 22 : 209-239, 2 figs.

Ailsa M. Clark, M.A.

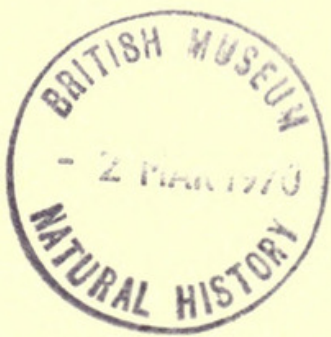

LONDON, S.W. 7 


\section{$2 \mathrm{BHL}$ Biodiversity Heritage Library}

Clark, Ailsa McGown. 1970. "Notes on the family Amphiuridae (Ophiuroidea)." Bulletin of the British Museum (Natural History) Zoology 19, 1-81. https://doi.org/10.5962/bhl.part.24085.

View This Item Online: https://www.biodiversitylibrary.org/item/19529

DOI: https://doi.org/10.5962/bhl.part.24085

Permalink: https://www.biodiversitylibrary.org/partpdf/24085

\section{Holding Institution}

Natural History Museum Library, London

\section{Sponsored by}

Natural History Museum Library, London

\section{Copyright \& Reuse}

Copyright Status: In copyright. Digitized with the permission of the rights holder.

Rights Holder: The Trustees of the Natural History Museum, London

License: http://creativecommons.org/licenses/by-nc-sa/4.0/

Rights: http://biodiversitylibrary.org/permissions

This document was created from content at the Biodiversity Heritage Library, the world's largest open access digital library for biodiversity literature and archives. Visit BHL at https://www.biodiversitylibrary.org. 